\title{
Simulation of a vertical ground-coupled heat pump system with optimal ground loop design
}

\author{
Krishna C. Adivi \\ West Virginia University
}

Follow this and additional works at: https://researchrepository.wvu.edu/etd

\section{Recommended Citation}

Adivi, Krishna C., "Simulation of a vertical ground-coupled heat pump system with optimal ground loop design" (2003). Graduate Theses, Dissertations, and Problem Reports. 1340.

https://researchrepository.wvu.edu/etd/1340

This Thesis is protected by copyright and/or related rights. It has been brought to you by the The Research Repository @ WVU with permission from the rights-holder(s). You are free to use this Thesis in any way that is permitted by the copyright and related rights legislation that applies to your use. For other uses you must obtain permission from the rights-holder(s) directly, unless additional rights are indicated by a Creative Commons license in the record and/ or on the work itself. This Thesis has been accepted for inclusion in WVU Graduate Theses, Dissertations, and Problem Reports collection by an authorized administrator of The Research Repository @ WVU. For more information, please contact researchrepository@mail.wvu.edu. 


\title{
SIMULATION OF A VERTICAL GROUND-COUPLED HEAT PUMP SYSTEM
} WITH OPTIMAL GROUND LOOP DESIGN

\author{
Krishna C. Adivi
}

Thesis submitted to the College of Engineering and Mineral Resources at West

Virginia University in partial fulfillment of the requirements for the degree of

\author{
Master of Science \\ In \\ Mechanical Engineering
}

Dr. Kenneth H. Means, Ph.D., Chair

Dr. Gary J. Morris, Ph.D.

Dr. Scott Wayne, Ph.D.

Department of Mechanical and Aerospace Engineering

\author{
Morgantown, West Virginia
}

2003

Keywords: Heat Pump, Bin Method, Optimization and Circulator Pump Energy Copyright 2003 Krishna C. Adivi 


\section{ABSTRACT \\ Simulation of a Vertical Ground-Coupled Heat Pump with Optimal Ground Loop Design \\ Krishna C. Adivi}

As the natural resources for conventional energy will steadily diminish in the future, it becomes necessary to search for alternate sources of energy. One of those sources includes the geothermal energy, which is defined as the thermal energy found in the earth's crust. Ground coupled heat pumps (GCHP) consist of a water-to-air or water-to-water heat pump, a circulator pump, a buried pipe grid and an interconnecting header. Heat is extracted from or rejected to the ground through this buried pipe grid that circulates a heat transfer fluid such as water or a water/antifreeze solution. Energy is spent to run the heat transfer fluid through this ground loop known as circulator pump energy. It plays an important role in the design of a GCHP. Ground coupled systems for residential applications typically require circulator pumps to operate the ground loop. Therefore selecting the right pump and ground loop piping is critical in this design. Care should be taken not to oversize or undersize the equipment that would result in increased installation and operating costs.

The design of GCHP systems includes many factors to be considered such as soil, undisturbed ground temperature, Fourier number and so on. Bin method analysis was done to estimate the operational times of the heat pump, which are used in determining the bore lengths required for the ground loop. A computer program was developed in this thesis that takes the location, design loads and a few other factors as input, calculates the optimum length of the ground loop and optimizes the pump energy for various pipe sizes. The software tool is user friendly and is useful in the selection of vertical GCHP systems for almost anywhere in the United States. Simple features are included for easy navigation to view the output and it is absolutely upgradeable. 


\section{ACKNOWLEDGEMENT}

I would like to thank my parents Mr. A.V.G. Krishnaiah, Mrs. Suguna Rani and brothers Vardhan, Prashant for the love and motivation they have provided throughout my career. I would like to thank God for giving me the self-confidence and persistence to make this thesis a reality.

I would like to extend my sincere gratitude and appreciation to my advisor, Dr. Kenneth $\mathrm{H}$. Means, for his patience, continuous support, leadership and guidance. I consider myself very fortunate to have had the opportunity to work with a teacher and friend like Dr. Means.

I am also thankful to Dr. Gary J. Morris for guiding me as an academic advisor while acting as the Graduate program director for the MAE department. Dr. Morris has been motivating me throughout my length of study at WVU and I am undoubtedly indebted to him. I am also grateful to have Dr. Scott Wayne to be a member of my committee and for helping me very much.

Last, but not the least, I would like to thank my friends Santosh, Suresh, Vinay, Kaparthi, Sreeman, Pasumarty, Vijay, Partha, Rekh, guys of Baldwin and NJ for their support. 


\section{TABLE OF CONTENTS}

$\begin{array}{lll}\text { ABSTRACT } & \text { ii }\end{array}$

ACKNOWLEDGEMENT $\quad$ iii

TABLE OF CONTENTS iv

LIST OF FIGURES V vi

LIST OF TABLES viii

LIST OF EQUATIONS IX

$\begin{array}{ll}\text { CHAPTER 1: INTRODUCTION } & 1\end{array}$

CHAPTER 2: LITERATURE REVIEW

2.1 OVERVIEW OF PAST RESEARCH

2.2 THEORITICAL ASPECTS AND MODELS 6

$\begin{array}{ll}2.3 \text { COMPUTER SIMULATIONS } & 7\end{array}$

$\begin{array}{ll}\text { 2.3.1 RESIDENTIAL APPLICATIONS } & 8\end{array}$

$\begin{array}{ll}\text { 2.3.2 COMMERCIAL APPLICATIONS } & 11\end{array}$

CHAPTER 3: PROBLEM STATEMENT 14

$\begin{array}{ll}\text { CHAPTER 4: MODEL DEVELOPMENT } & 15\end{array}$

$\begin{array}{ll}\text { 4.1 CLIMATE } & 15\end{array}$

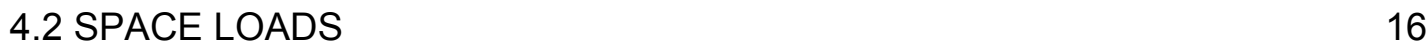

$\begin{array}{ll}\text { 4.3 HEAT PUMP - ELEMENTS } & 18\end{array}$

$\begin{array}{ll}\text { 4.3.1 OPERATION OF HEAT PUMP } & 19\end{array}$

4.4 GROUND COUPLED HEAT PUMP - DESIGN 20

$\begin{array}{ll}\text { 4.4.1 SOIL } & 21\end{array}$

4.4.2 UNDISTURBED GROUND TEMPERATURE 23

4.4.3 THERMAL RESISTANCE OF GROUND 24 
$\begin{array}{ll}\text { 4.4.3.1 FOURIER NUMBER } & 25\end{array}$

4.4.4 BORE LENGTH CALCULATION 28

4.4.4.1 EFFICIENCY OF A HEAT PUMP 31

4.4.5 ENTERING WATER TEMPERATURE 32

4.4.6 HEAT PUMP CAPCITIES 34

$\begin{array}{ll}\text { 4.4.7 ENERGY ESTIMATION } & 37\end{array}$

4.4.7.1 SIMPLIFIED BIN METHOD 38

$\begin{array}{ll}\text { 4.4.8 OPTIMIZATION } & 43\end{array}$

4.4.9 PUMP ENERGY 46

CHAPTER 5: PROGRAMMING - JAVA 50

$\begin{array}{ll}5.10 R I G I N & 50\end{array}$

5.2 OBJECT ORIENTED PROGRAMMING 51

5.3 HOW JAVA WORKS

5.4 RUNNING THE SOFTWARE 56

CHAPTER 6: RESULTS 58

$\begin{array}{ll}\text { 6.1 VERIFICATION } & 68\end{array}$

CHAPTER 7: CONCLUSIONS AND FUTURE WORK 70

$\begin{array}{ll}\text { 7.1 CONCLUSIONS } & 70\end{array}$

$\begin{array}{ll}\text { 7.2 FUTURE WORK } & 71\end{array}$

$\begin{array}{ll}\text { REFERENCES } & 72\end{array}$

$\begin{array}{ll}\text { APPENDIX } & 76\end{array}$ 


\section{LIST OF FIGURES}

FIGURE 1-1 Vertical GCHP ground loop arrangement 3

FIGURE 2-1 Diagram of pipe sizing software tool "GHP Piping Design" 8

FIGURE 2-2 Earth coupling analysis (ECA) interface to get bore lengths 9

FIGURE 2-3 Graphical user interface of ECA pressure loss calculator 10

FIGURE 2-4 "GeoCalc" program GUI to calculate head loss 11

FIGURE 2-5 Main screen of the program "GCHP Calc" 12

FIGURE 2-6 GUI to change ground properties of "GCHP Calc" program 13

$\begin{array}{lll}\text { FIGURE 2-7 } & \text { Results of "GCHP Calc" program } & 13\end{array}$

FIGURE 4-1 Cooling mode operation of a basic heat pump 19

FIGURE 4-2 Correlation between Fourier number and G - Factor 27

FIGURE 4-3 Capacities of a Three Ton heat pump unit 35

FIGURE 4-4 COP \& EER of a Three Ton heat pump unit 36

FIGURE 4-5 Bin method calculation procedure 40

FIGURE 4-6 Flow diagram of the optimization tool 44

FIGURE 5-1 Standard Execution of a Java program inside a computer 55

FIGURE 5-2 Instructions on installing Java plug-in 57

FIGURE 6-1 Main Page showing the user input 59

FIGURE 6-2 Graphical user interface of the results page 60

FIGURE 6-3 Head Loss calculation in the piping loop 62

FIGURE 6-4 Screen capture of the ground loop arrangement 63

FIGURE 6-5 GUI showing the specifications 65

FIGURE 6-6 Energy estimation for the heating season 66 
FIGURE 6-7 Energy estimation for the cooling season

FIGURE 6-8 Variation of pump energy with pipe size \& loop arrangement 68 


\section{LIST OF TABLES}

TABLE 4-1

TABLE 4-2

TABLE 4-3

TABLE 4-4

TABLE 4-5

TABLE 4-6

TABLE 4-7

TABLE 4-8

TABLE 4-9

TABLE 4-10

TABLE 6-1
Thermal properties of various soils

23

Approximate ground water temperatures in the U.S.A.

24

Pipe size and outside diameter in inches.

25

Recommended Lengths of Bore Per Ton for GCHPs.

30

Correction Factors for different values of $\mathrm{k}_{\mathrm{g}}$

31

Capacity \& Efficiency of a 3Ton heat pump vs. EWT

34

Mean percentages of sunshine hours in USA

42

Recommended GCHP piping arrangement and pumps

45

Equivalent pipe thermal resistance and outside diameters

47

Equivalent length of pipe for fittings and valves in feet

48

Comparison of results

65 


\section{LIST OF EQUATIONS}

TABLE 1-1 Equation to size ground heat exchangers 6

TABLE 4-1 Equation to calculate Fourier Number 25

$\begin{array}{lll}\text { TABLE 4-2 } & \text { Equation to calculate G-Factor }\end{array}$

TABLE 4-3 Equation to obtain thermal resistance of the ground 28

TABLE 4-4 Equation to estimate length of bore in cooling 28

TABLE 4-5 Equation to calculate length of bore in heating 29

TABLE 4-6 Equation to obtain Corrected bore length 30

TABLE 4-7 Equation to obtain power input for cooling 32

TABLE 4-8 Equation to estimate power input for heating 32

TABLE 4-9 Estimate entering water temperature for cooling 33

TABLE 4-10 Estimate entering water temperature for heating 33

TABLE 4-11 Equation to calculate efficiency of circulator pump 49

TABLE 4-12 Estimate water horse power of circulator pump 49

TABLE 4-13 Estimate brake horse power of circulator pump 49 


\section{Chapter 1: Introduction}

Our planet's surface constitutes only twenty nine percent of land and its population plays a more important role as years pass by. Some day there may be a lot of energy efficient skyscrapers around the world for the human beings to live in. This situation is a possibility in the near future taking into account the earth's land area and the rate at which the population is growing. But even today, the construction of energy efficient buildings is a difficult task. Earth is hot on the inside, which in turn is a viable source of thermal energy. This source of energy has led to the invention of heat pumps as an alternative to the conventional heating and air-conditioning systems for residential and commercial applications.

A heat pump is a mechanical device that delivers heat from one thermal reservoir to another [2]. One end of the thermal reservoir would be the building to be cooled or heated and the other would be the environment (source/sink) based on the seasonal variations. There are three types of sources/sinks for a heat pump namely outdoor air, surface water and the ground. The air and surface water heat pump utilize the outdoor air and water respectively as the primary medium for transferring heat. Likewise, the ground source heat pump (GSHP) uses the ground as the main source/sink. 
These systems often require supplemental heat to the building during winter especially in the northern regions. Their capacity depends on the variation of outdoor air or surface water temperature. Since the deep earth temperature remains constant all year long, the GSHP can operate more efficiently. This attributes to improved performance and high efficiency values of GSHP compared to an air source heat pump (ASHP). Although many GSHP systems are installed every year worldwide, this technology is relatively new and has become popular in the late 1980s. The lack of reliable design models and higher installation costs may limit the choice of these systems.

Heat is extracted from or rejected to the ground by means of buried pipes, through which a heat transfer fluid circulates such as water or a water/antifreeze solution. Heat transfer fluid such as water or an antifreeze solution flows only in the ground loop and refrigerants such as Freon etc. are used in the heat pump that includes the compressor, a reversing value and two heat exchangers. These buried pipes are known as ground loop heat exchangers, and are placed in either vertical boreholes or horizontal trenches [6]. The borehole size varies from four to six inches in diameter and the buried pipe diameters vary from three quarter of an inch to two inches. For example in cooling mode, the ground acts as a heat sink and the building to be cooled becomes the heat source and vice-versa. The arrangement of the ground loop in horizontal trenches occupies more space when compared to that in vertical boreholes. A schematic of heat pumps installed in vertical boreholes would look like the Figure 1-1 

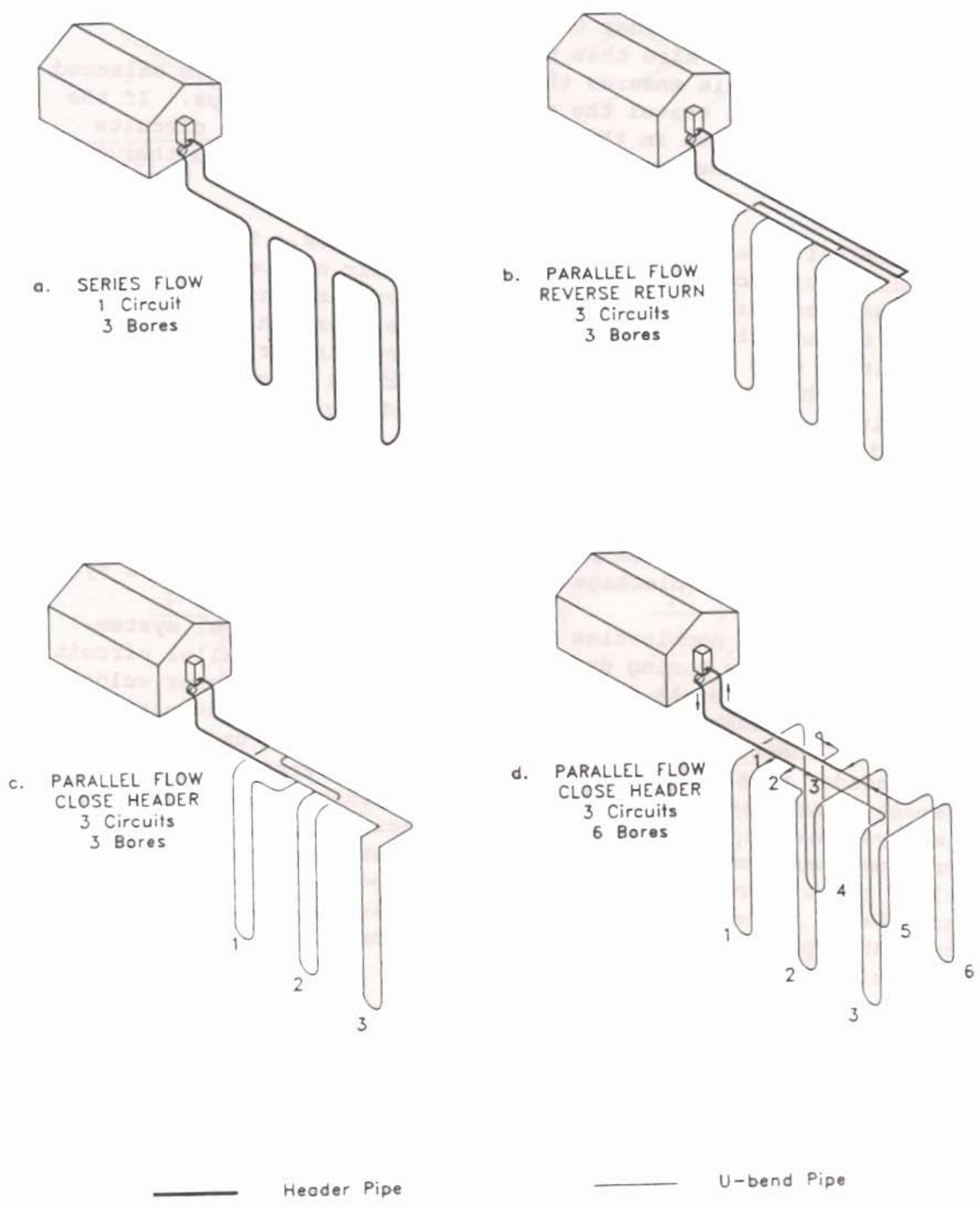

Figure 1-1: Vertical GCHP ground loop arrangement [2]. 
In general, ground source heat pumps can be divided into two categories namely open and closed loop systems. A closed loop ground source heat pump is also known as a ground coupled heat pump (GCHP) system, because it is a closed network of heat exchangers interconnected between the building to be cooled or heated and the ground. The surface water heat pumps (SWHPs) use the surface water as the main source/sink for heat transfer process and are sometimes included in the GSHPs because of the similarities in applications and installation methods [4]. The open loop systems are usually termed as ground water heat pumps (GWHP).

Pump energy plays an important role in the design of a heat pump. The scope of this thesis is contained to vertical, closed loop, ground coupled heat pumps. Ground coupled systems for residential applications require circulator pumps to operate the ground loop. If proper care is not taken to select the right pump and ground loop piping, this can lead to increased installation and operating costs. The goal of this thesis is to create a design tool for the optimum selection of GSHP at the residential level for anywhere in the United States. The tool developed by the author studies a variety of combinations for the ground loop. It also gives the head loss taking all the fittings into account, optimizes the pump energy by optimizing the pipe sizes and the typical arrangement of the ground loop. 


\section{Chapter 2: Literature Review}

As the natural resources for conventional energy will steadily diminish in the future, it becomes necessary to search for alternate sources of energy. One of those sources includes the geothermal energy, which is defined as the thermal energy found in the earth's crust ${ }^{[4]}$. As discussed in the previous chapter, the ground source heat pump is an application to provide heating and air-conditioning by means of this thermal energy. This topic of research deals with the study of vertical GCHP system, which is a subset of the GCHP systems depending on the alignment of the ground loop in either vertical boreholes or horizontal trenches. If properly installed, the heat pump unit can provide high levels of comfort and efficiency. Most of the common drawbacks involved in improper installations would be undersized piping, huge pump over sizing and so on.

\subsection{Overview of Past Research}

The design of heat pump systems poses a challenge in maximizing the efficiency and minimizing the cost, while keeping the energy consumption rates at optimum levels. This can be accomplished in many ways, the most popular being computer simulations. First of all, this review comprises theoretical aspects and then deals with various types of simulation models studied in the past. 


\subsection{Theoretical Aspects and Models}

The design of heat pumps is based upon the solution for the equation for heat transfer from a cylinder buried in the earth developed by Carslaw and Jaeger in 1947. Then an appropriate method of sizing ground heat exchangers was suggested by Ingersoll and Zobel in 1954 that uses the steady state equation 1-1 [4]:

$$
\mathrm{q}=\frac{L\left(\mathrm{t}_{\mathrm{g}}-\mathrm{t}_{\mathrm{w}}\right)}{R}
$$

where $\mathrm{q}=$ heat transfer rate, $\mathrm{Btu} / \mathrm{h}$.

$$
\begin{aligned}
& \mathrm{L}=\text { required bore length, } \mathrm{ft} . \\
& \mathrm{t}_{\mathrm{g}}=\text { undisturbed ground temperature, }{ }^{\circ} \mathrm{F} . \\
& \mathrm{t}_{\mathrm{w}}=\text { liquid temperature, }{ }^{\circ} \mathrm{F} . \\
& \mathrm{R}=\text { effective thermal resistance of the ground, h-ft- }{ }^{\circ} \mathrm{F} / \mathrm{Btu}[4] .
\end{aligned}
$$

The heat pumps were in operation from the 1960s based on the concept of sizing ground heat exchangers mentioned above, but they became popular in the 1980s. In 1987, a book by Hannifan M.J and Joseph King titled "Geothermal Heat Pump Options Manual" [5] was released in the market. It deals with ground loop sizing and installation procedures of geothermal heat pump (GTHP) systems. The ground loop sizing section of this manual covers the selection of circulator pumps for residential applications based on the flow rate 
with units in gallons per minute (gpm) and head loss of the ground loop with units in feet per 100 feet of water ( $\mathrm{ft} . / 100 \mathrm{ft}$. of $\mathrm{H}_{2} 0$ ), which is a part of this thesis in calculating the energy required to circulate fluid in the ground loop.

\subsection{Computer Simulations}

Computer simulations not only resolve a problem efficiently, but also are capable of providing results with less effort and labor. An experimental study was conducted by Bingul Hasan [17] that deals with the development of a computer-modeling tool to assess the performance of horizontal earth coupled heat pumps (ECHP). It aims to calculate the heating and cooling loads and life cycle cost versus alterations in coil lengths of ECHPs in their life span.

A general-purpose software program [3] developed by Joe Hoggle, University of Alabama known as "GHP Piping Design" is useful in estimating the head loss in a circuit. The user has the right to include as many fittings depending on the nature of the application. The type of fluid selected can be either water or an anti-freeze solution provided at the start of the program and helps to select the right pump based on the head loss and the flow rate values. Screen capture of the tool "GHP Piping Design" is shown in Figure 2-1. 


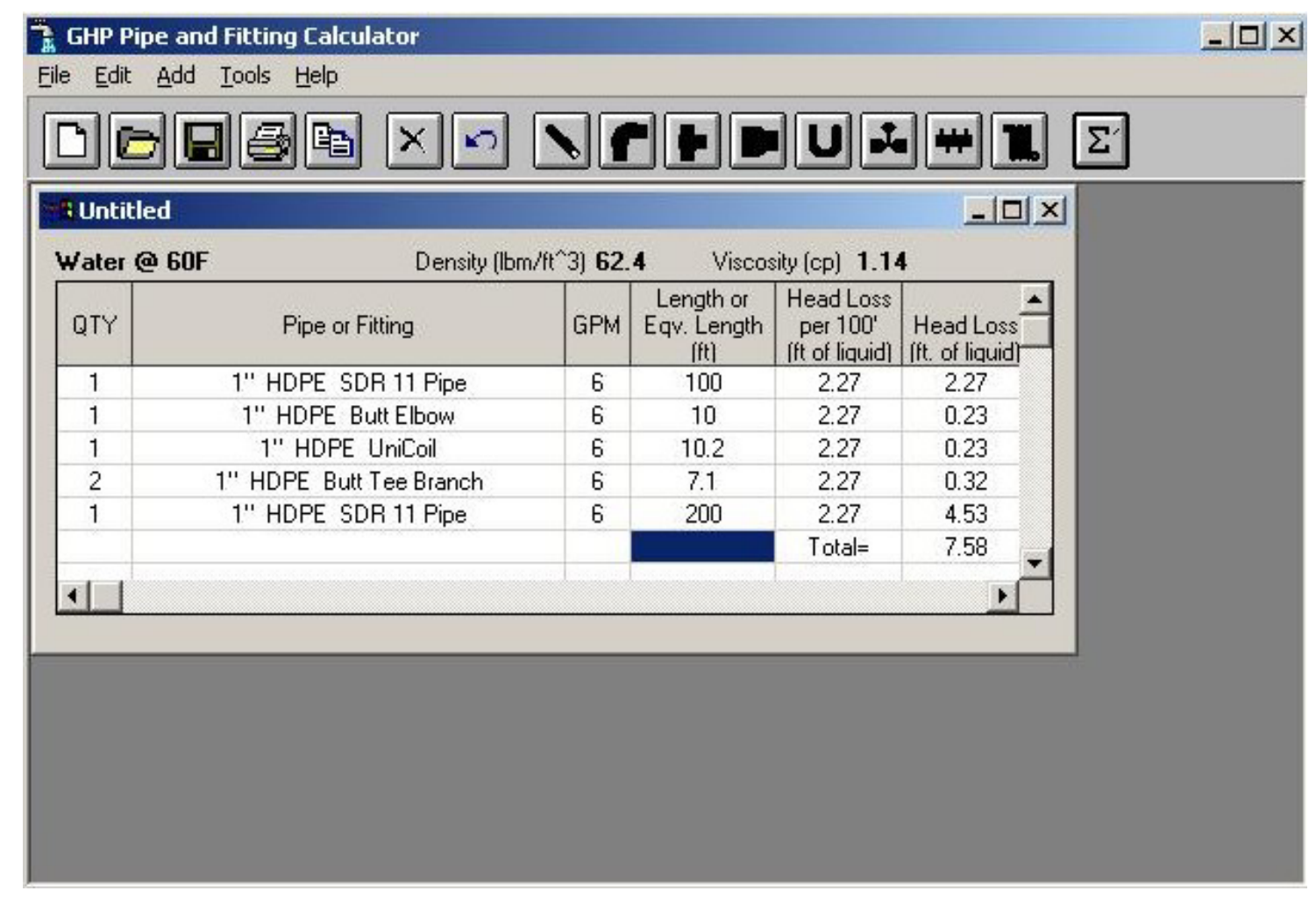

Figure 2-1: Diagram of pipe sizing software tool "GHP Piping Design" [3].

\subsubsection{Residential Applications}

A number of computer models have been developed so far on ground source heat pumps and to study their performance. They can be further divided based on the nature of their application, namely for residential or commercial purposes. A simulation program known as the Earth Coupled Analysis (ECA) was developed by Elite Software group to study ground source heat pumps for residential applications [8]. The user has the option of selecting the heat pump, flow rate, pipe type such as polyethylene, polybutylene, polyvinyl chloride (PVC), copper etc. and the entering water temperatures. Based on these values, the bore lengths in heating and cooling a building are obtained. ECA is 
capable of analyzing both vertical and horizontal ground loop systems [8]. Figure 2-2 shows the picture of an ECA application window or user interface able to perform these tasks depending on the user input.

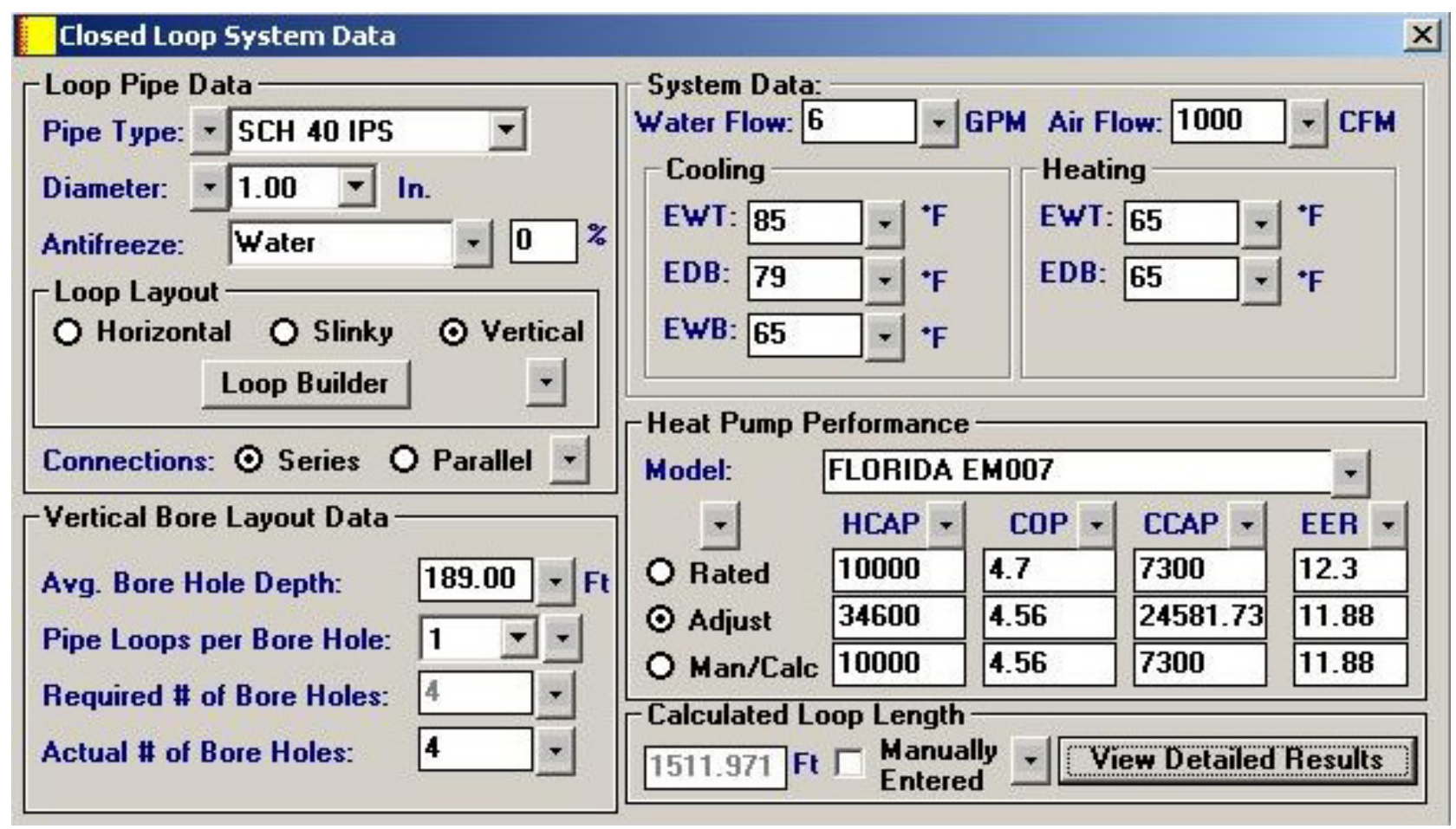

Figure 2-2 Earth Coupling Analysis (ECA) graphical user interface (GUI) to calculate bore lengths [8].

ECA software purely works on a windows platform that is good enough to execute pressure drop calculations and cost analysis. The equivalent lengths of all the fittings included in the ground loop are calculated upon the quantity of those specified by the user. ECA software tool includes most of the pipe materials, fitting data, series or parallel flow and heat pump capacity values. Figure 2-3 gives a brief idea of how the pressure loss calculations can be made. 

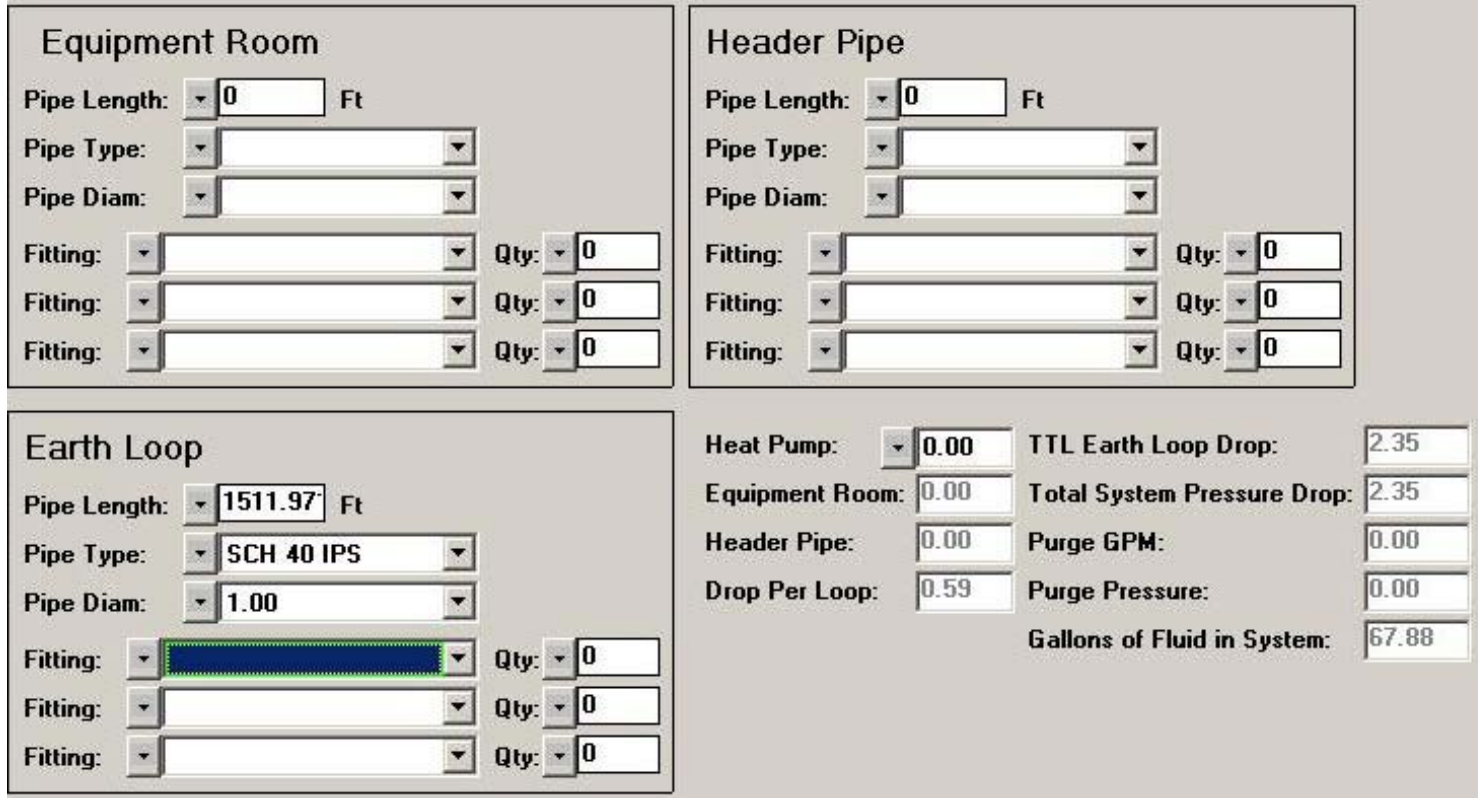

Figure 2-3: Graphical user interface of ECA pressure loss calculator [8].

Thermo works group [9] developed a software program called GeoCalc, which is useful in sizing geothermal systems. It is based on Windows operating system and assists in determining the heat loss on buildings, annual operating costs and pump requirements. The user has the flexibility to input specific parameters according to geographic locations, climatic conditions, different types of piping material and specific building types. Sizing of the ground loop can be achieved by selecting the appropriate pipe type, pipe diameter and the number of fittings included [9]. The user interface to do these calculations is shown in Figure 2-4. 


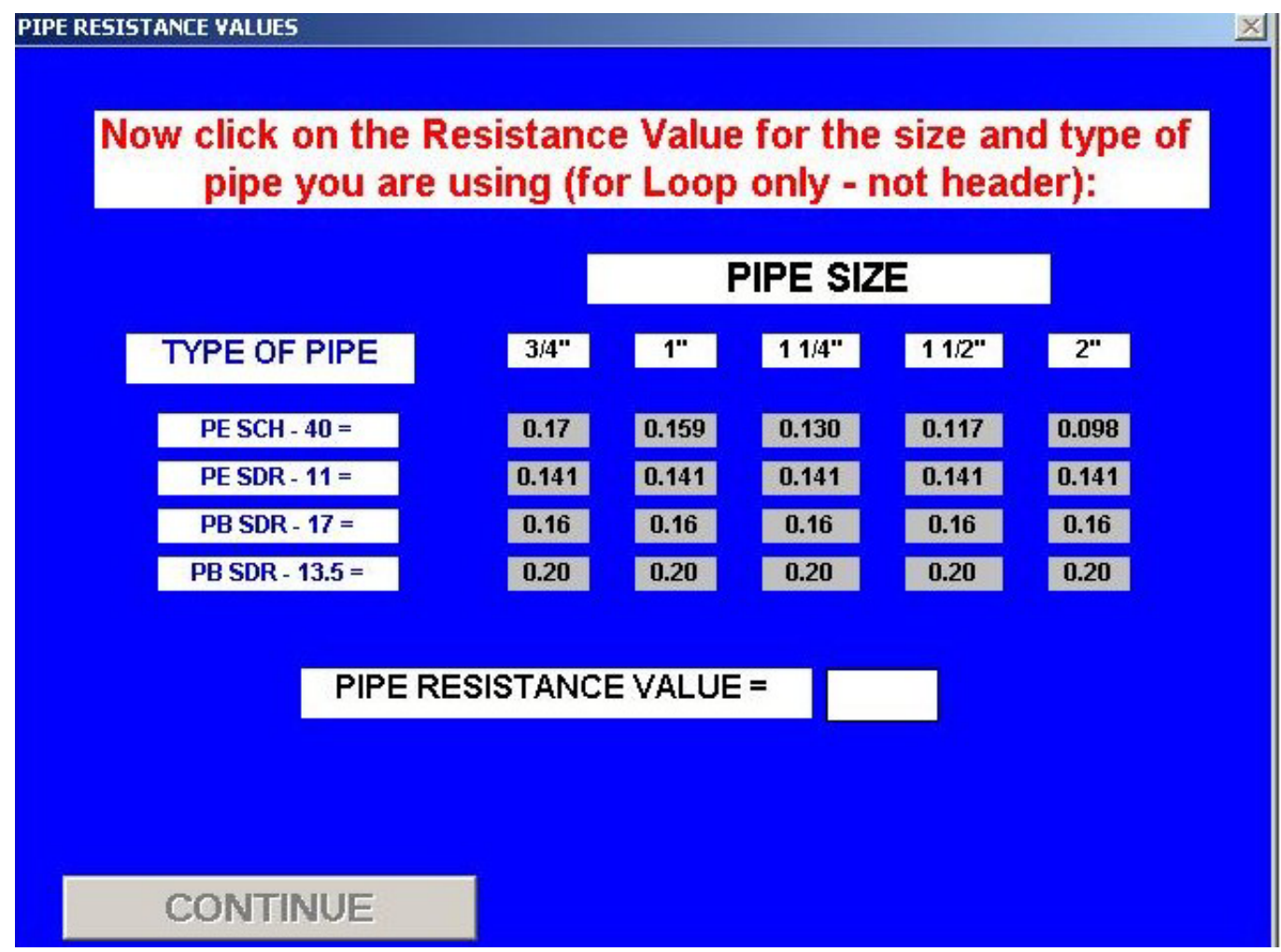

Figure 2-4: GeoCalc Program GUI to calculate head loss [9].

\subsubsection{Commercial Applications}

One type of software program that deals with the design of ground coupled heat pump systems is the "GchpCalc" developed by Steve Kavanaugh and K. Rafferty [1] at the University of Alabama, Huntsville. This program [1] allows the user to change different variables such as undisturbed ground temperature, ground loop pipe thermal resistance, number of boreholes and parallel loops, heat pump manufacturer as shown in the Figure 2-5. It also computes the heating and cooling loads for a user-defined commercial building. 


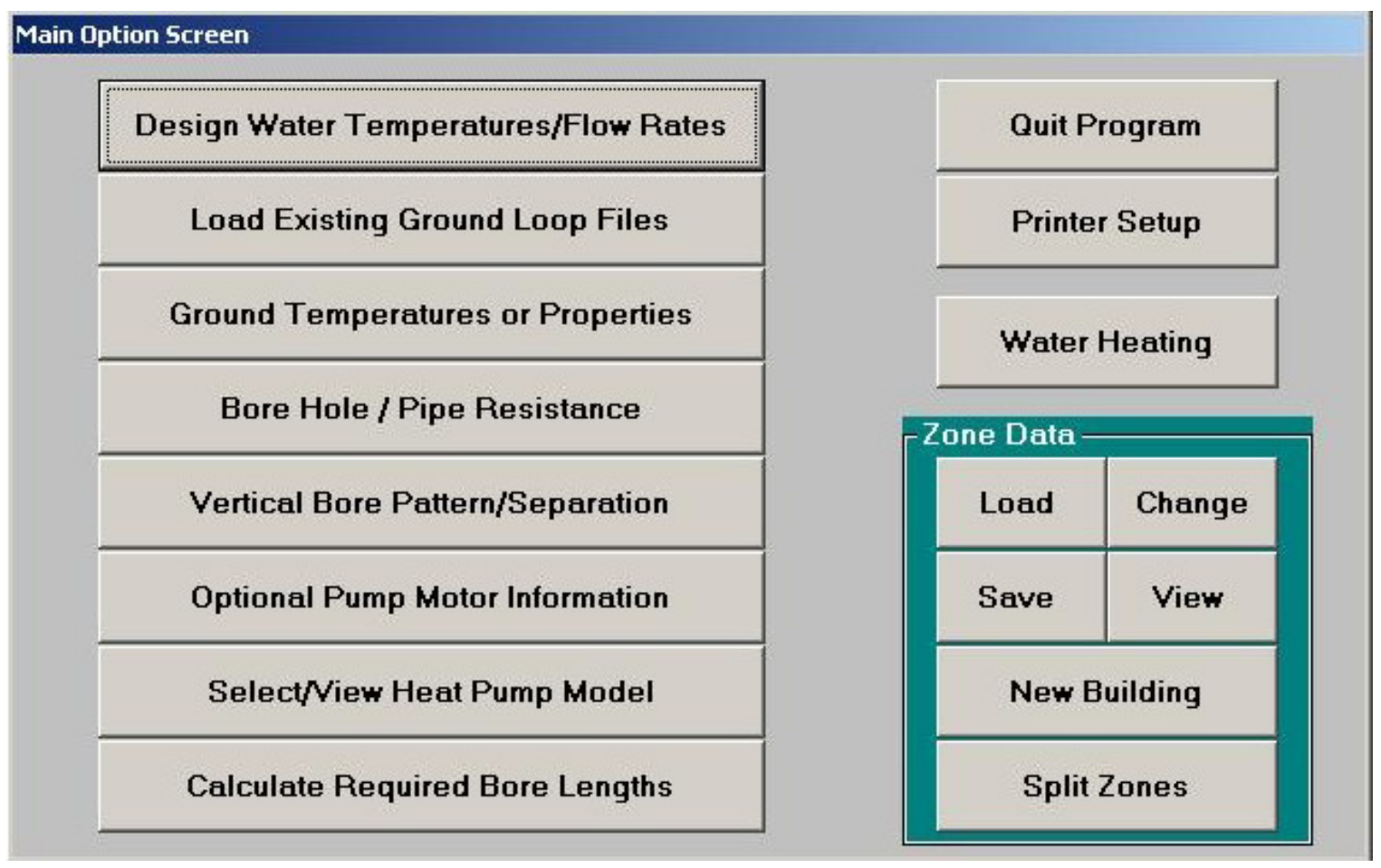

Fig 2-5: Main Screen of the program GCHP Calc [1].

Figure 2-6 above gives a detailed description of the ground properties where in the properties of the ground can be changed based on the location. Similarly, various parameters can be altered in the main screen to get the desired output. This software tool is used to obtain the design loads and bore lengths in heating and cooling, resulting unit outlet water temperatures [1] as shown in the Figure 2-7. 


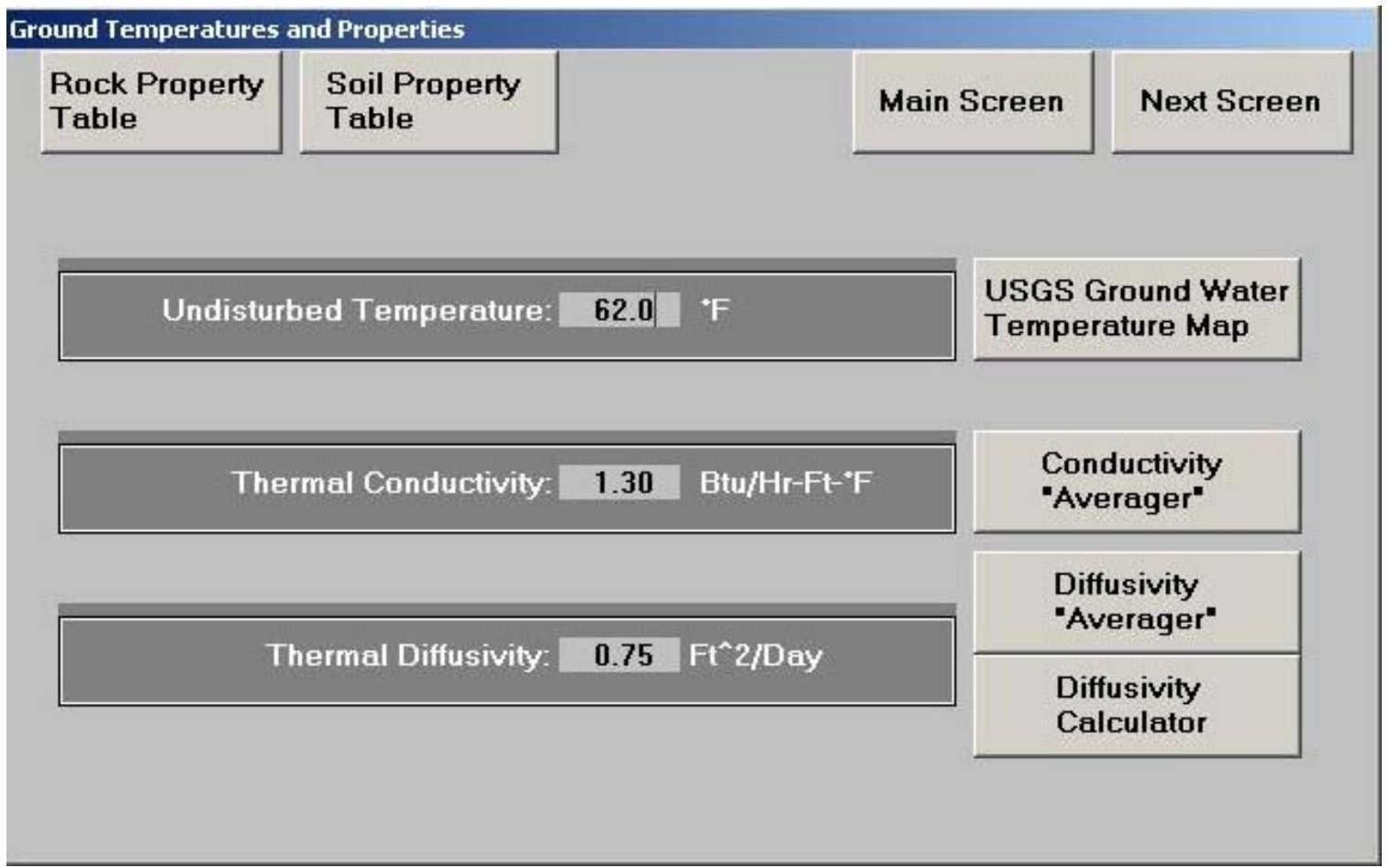

Figure 2-6: User interface to change the ground properties of "GchpCalc" program [1].

\begin{tabular}{|c|c|c|c|c|}
\hline Design Hybrid GCHP & \multicolumn{2}{|c|}{ Save Input to File } & Print Values & Next Screen \\
\hline \multicolumn{5}{|c|}{$\begin{array}{l}\text { Required BORE length with minimal groundwater movement }=7370 \mathrm{ft} \text { ( } 246 \mathrm{ft} / \mathrm{bore} \text { ) } \\
\text { (Design based on COOLING mode - net annual heat rejection to ground) }\end{array}$} \\
\hline \multicolumn{5}{|c|}{$\begin{array}{l}\text { Required BORE lengths with high rates of groundwater movement (or year } 1) \\
\text { Cooling: } L=6060 \mathrm{ft}(202 \mathrm{ft} / \text { bore }) \text {. Heating: } L=4620 \mathrm{ft}(154 \mathrm{ft} / \text { bore })\end{array}$} \\
\hline \multicolumn{5}{|c|}{ Heat Pump Series: Carrier (High Efficiency) } \\
\hline \multicolumn{5}{|c|}{ 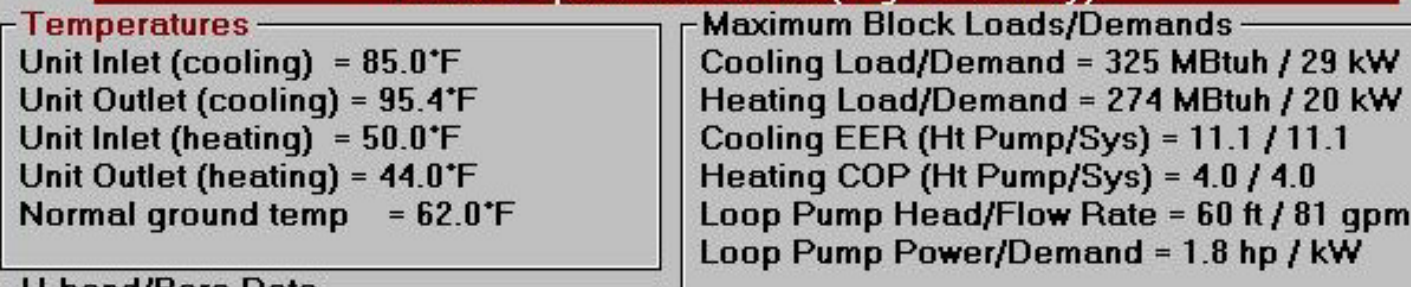 } \\
\hline \multicolumn{2}{|c|}{$\begin{array}{l}\text {-U-bend/Bore Data } \\
\text { U-tube Diameter }=1.00 \text { inch } \\
\text { Separation dist. }=20.0 \mathrm{ft} \\
\text { Grid }=5 \text { wide by } 6 \text { deep } \\
\text { Grout Conductivity }=0.90 \text { Btu } / \mathrm{hr}-\mathrm{ft}-^{*} \mathrm{~F} \\
\text { Bore Diameter }=6.00 \text { inches }\end{array}$} & & $\begin{array}{l}\text { Data- } \\
\text { Conductivity = } \\
\text { I Diffusivity = } 0 \\
\text { Temperature = }\end{array}$ & $\begin{array}{l}\text { tu/hr-ft-`F } \\
\text { /day }\end{array}$ \\
\hline
\end{tabular}

Figure 2-7: Results of the "GchpCalc" program [1]. 


\section{Chapter 3: Problem Statement}

The main objective of this research is to simulate a vertical ground coupled heat pump system by developing a software tool and to

1. Select a GSHP at the residential level for anywhere in the United States.

2. Estimate the seasonal hours of operation of the heat pump and annual energy consumption.

3. Calculate the maximum length of the ground loop.

4. Optimize pipe size and determine the annual pump energy of the circulator.

Optimizing the pipe size is a unique feature in the tool developed by the author and is helpful in estimating the pump energy requirements for variations in the pipe diameter and soil conditions. In northern parts of the United States, it is necessary to run an antifreeze solution in the ground loop since the entering water temperatures fall below the freezing point. The seasonal hours of operation and the corresponding annual energy consumption are obtained using the Bin Method of energy estimation. 


\section{Chapter 4: Model Development}

A number of factors need to be considered in the design of heat pumps systems. This thesis deals with the simulation of a vertical ground coupled heat pump for residential applications. Some of the key features that are involved in the development of GSHPs and to get a better understanding of the subject include:-

\section{Climate}

2. Space Loads

3. Heat Pump elements

4. GSHP elements.

\section{1 $\underline{\text { Climate }}$}

The weather is an important aspect while designing an air-conditioning system in order to provide comfort conditions for the humans to live either in a residential or commercial environment. Outdoor temperature varies significantly over the length of the day and influences the amount of heat transferred or rejected to the environment. The outdoor temperature of a particular location directly affects the performance of an air source heat pump. So in winter, the efficiency of an ASHP especially in the northern regions of the United States will decrease drastically. On the contrary, a GSHP system is more efficient because there is relatively small change in the ground temperature. 
The temperature at which the controlled space needs to be maintained throughout a season is known as the indoor design temperature. It was set to a default value of $70^{\circ} \mathrm{F}$ in winter and around $75^{\circ} \mathrm{F}$ in summer for this simulation to estimate the annual energy consumption. However, these values can be changed depending upon the requirements of the user.

\subsection{Space Loads}

There are three modes of heat transfer namely conduction, convection and radiation that are key to calculating the heat loss and gain in a building. The rate at which the movement of heat takes place between the controlled space and the environment is termed as "Space Load". It is subdivided into heating and cooling loads respectively. These loads of a building represent the heat that must be supplied to or removed from the interior of a building to maintain it at the desired conditions.

A distinction should be made between the design load and the actual load of heating or cooling systems. The design or peak heating load is usually determined with a steadystate analysis using the design conditions for the indoor and the outdoors for the purpose of sizing the heating system. This ensures that the system has the required capacity to perform adequately at the anticipated worst conditions. Design cooling load calculation differs from the heating load in the sense that it turns out to be a transient analysis using 
the design temperatures given in ASHRAE Fundamentals. It is also assumed that an HVAC professional does the load calculations and inputs those values in the tool for optimization purposes.

The heating load of a space is an estimate of the maximum probable heat loss of the space or room to be heated. The two main kinds of heat losses are:

(1) the heat transmitted through the walls, ceiling, floor, glass, or other surfaces and (2) the heat required to warm outdoor air entering the space.

The cooling load on the other hand is the rate at which energy must be removed from a space to maintain the temperature and humidity at the design values. The cooling load will generally differ from the internal heat gain because the radiation from the inside surface of walls and interior objects as well as the solar radiation coming directly into the space through openings does not heat the air within the space directly [7].

This radiant energy is mostly absorbed by floors, interior walls, and furniture, which are then cooled primarily by convection as they attain temperatures higher than that of the room air. Only when the room air receives the energy by convection does this energy become part of the cooling load. The cooling load calculation comprises of estimating the total heat gain in the space and then converting the total heat gain to cooling load. This is done by standard methods like the transfer function method or the CLTD/CLF (Cooling Load temperature difference/ Cooling Load Factor) method recommended by ASHRAE 
(American Society of Heating, Refrigeration and Air Conditioning Engineers) or Radiant Time Series method [7].

The heat gained by the controlled space because of people, lighting, equipment and appliances are categorized as Internal Gains. They are assumed to be negligible for energy estimation.

\subsection{Heat Pump - Elements}

A heat pump is an electrically driven mechanical device that transfers heat energy at one reservoir to another. It can move three times or more heat to or from a building than the amount of electrical input needed to operate it. The primary parts of a heat pump include a compressor, a solenoid valve (also known as the reversing valve), an expansion device and two heat exchangers.

One heat exchanger transfers heat between the heat pump and the controlled space, while the other transmits heat to or from the environment. Usually a refrigerant in the form of gaseous vapor is the medium that supports this heat transfer process shown in Figure 4-1. 


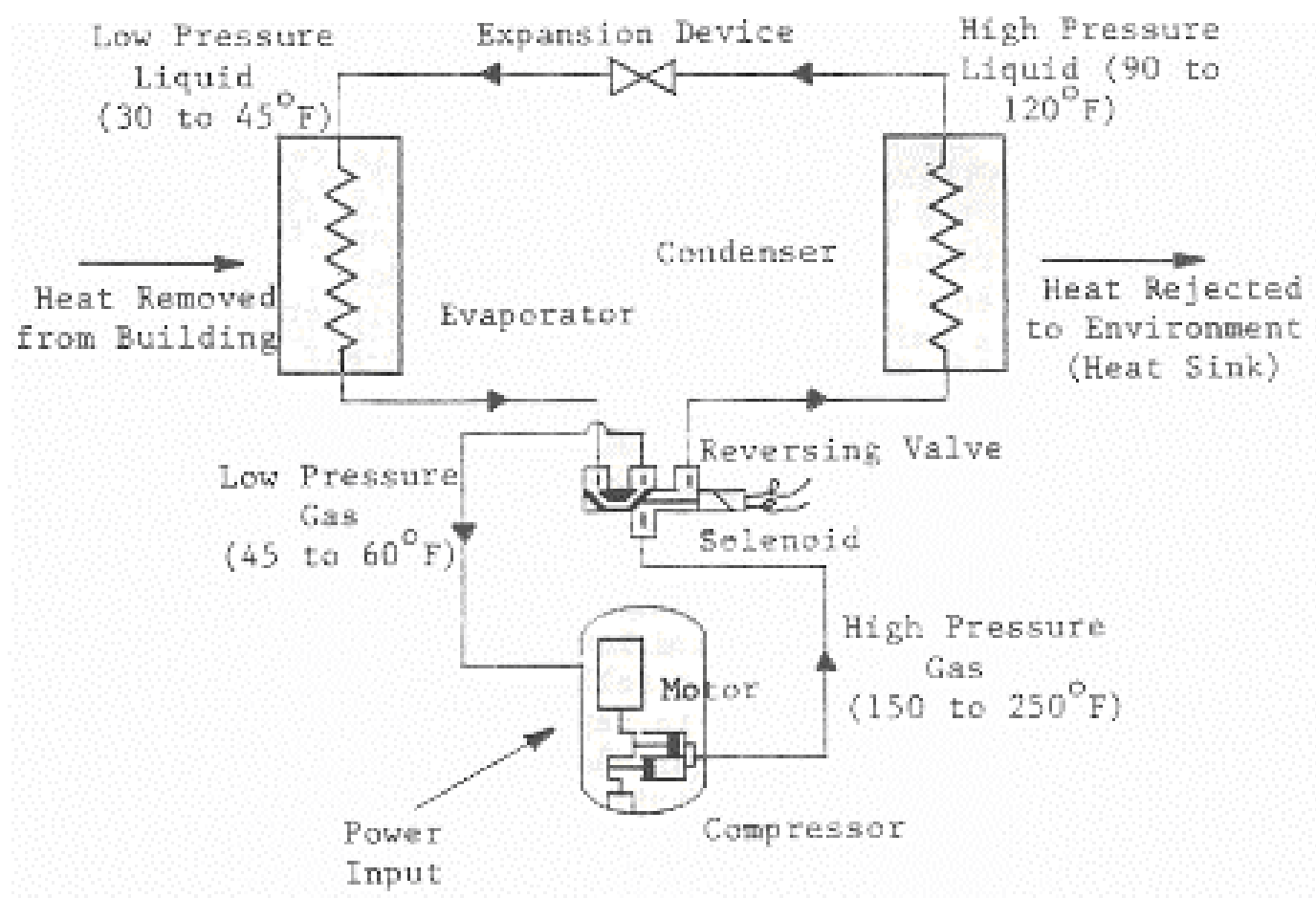

Figure 4-1: Cooling Mode Operation of a basic heat pump [2].

\subsubsection{Operation of Heat Pump}

The action begins with the process of compressing the refrigerant to a high pressure and temperature that moves around ending up either giving heat to or extracting heat from the building. In the cooling mode, the refrigerant fluid coming out of the compressor enters the lower portion of the solenoid valve and is directed to the heat exchanger in contact with the environment. Outside environment is used as a sink to give away heat such that the gas is condensed to a high pressure liquid before entering the expansion device and enabling the heat exchanger in contact with the environment to act as a condenser. This high pressure liquid undergoes a pressure drop along the length of 
the expansion device resulting in a rapid decrease in temperature. The liquid refrigerant entering the indoor heat exchanger extracts heat from the controlled space and evaporates. So the indoor heat exchanger acts as an evaporator in the cooling mode and the cycle continues until a steady state is reached.

Similarly the heating mode operation runs exactly in the opposite direction interchanging the positions of the condenser and evaporator and the solenoid valve is adjusted to account for it. The only difference here is that the outside environment is used as a source of heat. One main drawback in this operation is that the outside air in winter decreases the efficiency of the heat pump and increases the power input to the compressor especially in the northern parts of the United States, when the temperature falls below freezing.

\subsection{Ground Coupled Heat Pump - Design}

Ever since the idea of sizing ground heat exchangers was developed by Ingersoll and Zobel, the earth was considered an ideal source or sink for the development of heat pumps. The ground coupled heat pump is a closed loop heat pump and is a subset of the GSHP. The GCHP utilizes the ground as the heat source/sink enabling it to work more efficiently. Heat is extracted from or rejected to the ground by means of buried pipes, through which a heat transfer fluid circulates usually water or a water/antifreeze solution. These buried pipes are known as ground loop heat exchangers, and are placed in either 
vertical boreholes or horizontal trenches [6]. The parameters that affect the design of GSHP systems are:-

1. Soil

2. Undisturbed ground temperature

3. Thermal resistance of ground

4. Fourier number

5. Bore length calculation

6. Entering water temperature

7. Heat pump capacity

\subsection{1 $\underline{\text { Soil }}$}

Ground plays an important role in the performance of a ground coupled heat pump. So it is necessary to understand the properties of the soil such as conductivity and diffusivity. GCHP operation implies that heat is either drawn from or dissipated to the ground. Therefore the rate at which the soil can disperse heat is called thermal diffusivity of the ground. Thermal conductivity is an intrinsic property of a homogeneous material, which describes the material's ability to conduct heat. This property is independent of material size, shape or orientation. Soil mainly comprises of the most abundant element on our planet that is silicon or the ordinary sand. Based on other elements present in it along with the moisture content, there is a difference in the ground thermal diffusivity 
and conductivity. These values vary with the location and it is imperative that the higher the value, the shorter the length of the ground loop.

Moist, heavy soils are rich in moisture by their name and boast the ability to conduct and diffuse heat rapidly similar to dense rocky soils. On the other hand, dry and arid conditions in the soil present a common problem in installing GCHPs as longer lengths of ground loop is needed to maintain a steady heat absorption or extraction rate. The ground loop is actually inserted in a bigger diameter borehole creating space between the soil and the piping loop. Sufficient care should be taken to fill this gap with grout so that there is direct contact between the rock and the buried ground-coupling pipe.

Grout is a type of loose material such as sand that is used to fill cracks, pouring into joints of masonry and brickwork and so on. Thermal properties of grouting materials are not discussed in this thesis. This enables efficient heat transfer from the ground to the heat pump. Table 4-1 gives the thermal properties of a few soil types in different parts of the world and was used in this research to determine the bore lengths. These values are rounded to ease the calculation procedures followed in the development of the optimization tool. 
Table 4-1: Thermal properties of various soils [2].

\begin{tabular}{|c|c|c|}
\hline Material & $\begin{array}{c}\text { Conductivity }\left(k_{\mathrm{g}}\right) \\
\text { Btu/hr-ft- }{ }^{\circ} \mathbf{F}\end{array}$ & $\begin{array}{c}\text { Diffusivity }\left(\boldsymbol{\alpha}_{\mathrm{g}}\right) \\
\mathrm{ft}^{2} / \mathrm{day}\end{array}$ \\
\hline Dense Rock & 2.0 & 1.2 \\
\hline Rock & 1.6 & 1.0 \\
\hline Wet Clay & 1.4 & 0.75 \\
\hline Wet Sand & 1.2 & 0.7 \\
\hline Damp Clay & 1.0 & 0.5 \\
\hline Damp Sand & 0.8 & 0.4 \\
\hline
\end{tabular}

\subsubsection{Undisturbed Ground Temperature (UGT)}

Apart from the thermal properties of the ground, the earth temperature or the undisturbed ground temperature is a major factor in the design of GCHPs. They should be considered to ensure proper operation of the heat pump unit. Similar to the properties of the ground, its temperature also varies from place to place. Table 4-2 gives the approximate ground water temperatures in the United States according to the national ground water association (NGWA). Further details are available in the ASHRAE handbook of Applications, 1999. 
Table 4-2: Approximate Ground Water Temperatures in the U.S.A [2]

\begin{tabular}{|c|c|}
\hline Location & Undisturbed Ground Temperature $\left({ }^{\circ} \mathbf{F}\right)$ \\
\hline Birmingham, AL & 65 \\
\hline Charleston, WV & 57 \\
\hline Miami, FL & 78 \\
\hline
\end{tabular}

\subsubsection{Thermal Resistance of Ground}

The thermal resistance of the ground is an important factor in calculating the bore lengths. Factors influencing the ground thermal resistance include Fourier number, outside pipe diameter, ground conductivity and the G-factor (G). Ground piping loops are interconnected either in parallel or series combinations using U-bends that allows laminar flow through the length of the circuit. These loops are made from a special alloy of plastic also known as Polyethylene (PE) or Polybutylene (PB) pipes. The outside diameter of these pipes is the same, but on the inside, it varies depending on the pressure required by the application. The pipe size in the ground loop usually starts from three quarters of an inch and increases by a quarter of an inch up to two inches based on the heat pump requirements. Table 4-3 gives the variation of outside diameter with respect to the pipe size. 
Table 4-3: Pipe size and outside diameter in inches [2].

\begin{tabular}{|c|c|}
\hline Pipe Size & Outside Diameter \\
\hline $3 / 4 "$ & 1.05 \\
\hline $1 "$ & 1.315 \\
\hline $1-1 / 4 "$ & 1.66 \\
\hline $1-1 / 2 "$ & 1.90 \\
\hline $2 "$ & 2.375 \\
\hline
\end{tabular}

\subsubsection{Fourier Number}

Fourier number is used in heat transfer in general and unsteady state heat transfer calculations in particular. It is a dimensionless number and is directly proportional to the thermal diffusivity of the ground, time of operation of the heat pump and inversely proportional to the square of the buried pipe diameter. The solution to calculate the Fourier number was developed by Carslaw and Jaeger and is governed by the equation 4$1[2]:-$

$$
F=\frac{4 \alpha t}{\mathrm{~d}^{*} \mathrm{~d}}
$$

where

$$
\begin{aligned}
& \alpha=\text { ground diffusivity. } \\
& d=\text { outside pipe diameter. } \\
& t=\text { time of operation. }
\end{aligned}
$$


The above method can be modified to calculate equivalent thermal resistance for different heat pulses. A heat pulse is the duration of time in days that is used to measure the amount of heat transfer between any two mediums. In this application for example, the author chose to calculate the Fourier number based on two heat pulses, a ten year (3650day) pulse and a seasonal pulse (180-days). The Fourier number is obtained from a seasonal heat pulse of 180 days or half a year, because the building design heating and cooling loads are calculated on a yearly basis. Therefore two times are defined as:

$$
\begin{aligned}
& \mathrm{t}_{10}=3650 \text { days. } \\
& \mathrm{t}_{1}=3650+180=3830 \text { days } .
\end{aligned}
$$

Fourier numbers corresponding to the two heat pulses are computed as follows:-

$$
\begin{aligned}
& F_{10}=4 \alpha \mathrm{t}_{10} / \mathrm{d}^{2} \\
& \mathrm{~F}_{1}=4 \alpha \mathrm{t}_{1} / \mathrm{d}^{2}
\end{aligned}
$$

The difference of these Fourier numbers based on the heat pulses gives the actual Fourier number $\left(\mathrm{F}_{\mathrm{a}}\right)$ i.e., $F_{a}=F_{1} \sim F_{10}$. The development of a software tool involves many assumptions to be taken. G-Factor is also a dimensionless number that is dependent of Fourier number and used to obtain the thermal resistance of the ground. In this thesis, a linear correlation was formulated to get 
an equation between the actual Fourier number and the G-factor that follows the graph developed by Kavanaugh and Rafferty and is available in the ASHRAE applications handbook [4]. The equation 4-2 is used to calculate the G-factor and is approximated to:-

$$
\mathrm{G}=0.0758 * \ln \left(\mathrm{F}_{\mathrm{a}}\right)+0.1009
$$

The $G$ values obtained using the equation 4-2 are very close to the values required from the graph shown in ASHRAE handbook [4] with an error of about two percent. The graph used to get the equation for G-Factor is shown in the Figure 4-2.

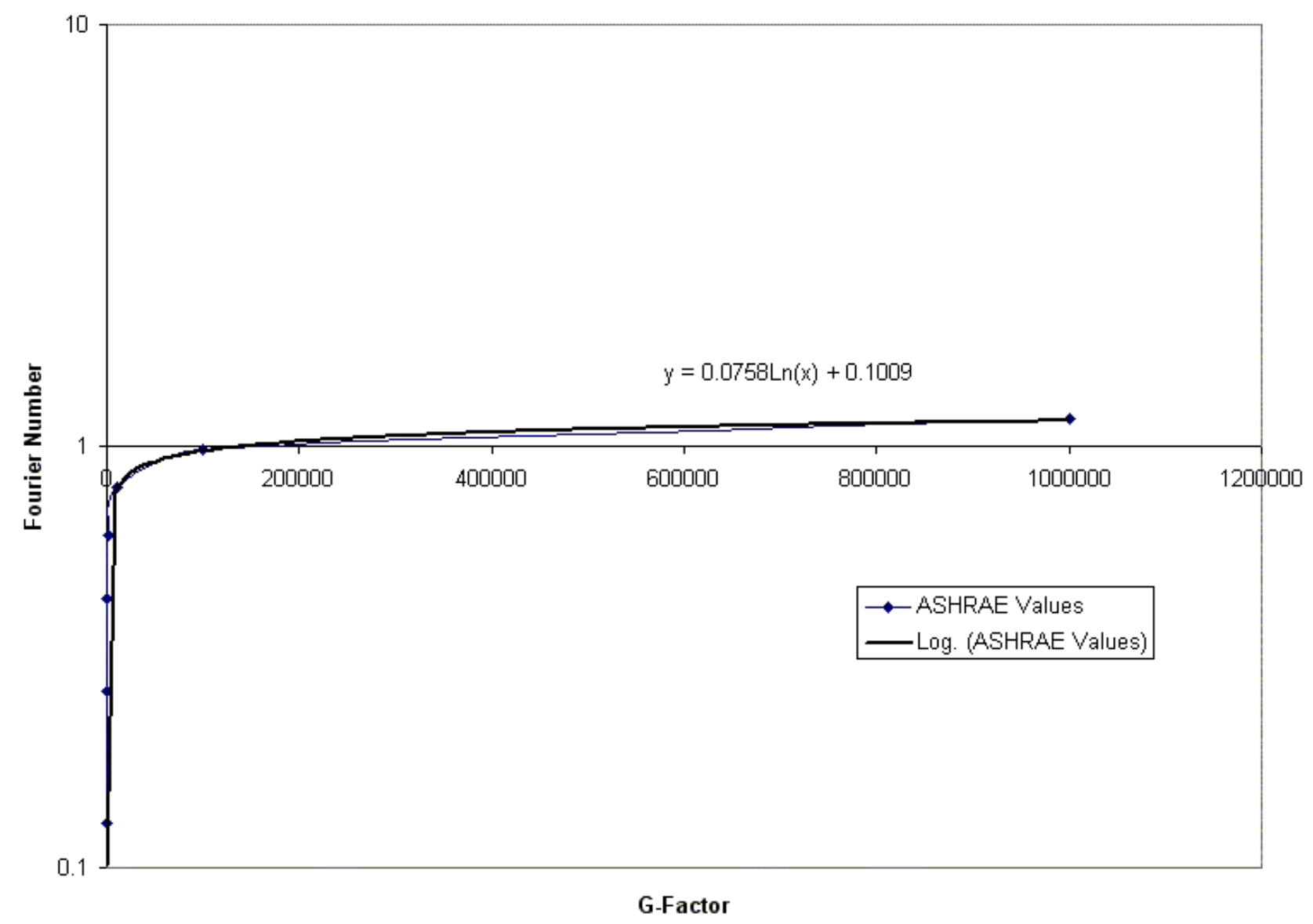

Figure 4-2: Correlation between Fourier number and G-Factor. 
Now that the G-factor is calculated, finally it is necessary to find out the equivalent thermal resistance of the ground. It is obtained from the following equation 4-3 [2]:-

$$
\mathrm{R}_{\mathrm{g}}=\mathrm{G} / \mathrm{k}_{\mathrm{g}}
$$

where

$$
\begin{aligned}
& \mathrm{R}_{\mathrm{g}}=\text { equivalent ground thermal resistance. } \\
& \mathrm{k}_{\mathrm{g}}=\text { ground thermal conductivity. }
\end{aligned}
$$

\subsubsection{Bore Length Calculation}

The method for sizing of residential ground heat exchangers explained by Ingersoll and Zobel was extended and simplified by Kavanaugh [2] that is used in the software tool for obtaining the required bore lengths for heating and cooling. Equivalent thermal resistance of the ground is calculated as a function of time corresponding to the time span over which a particular heat pulse occurs. The resulting equation for cooling takes the form [2]

$$
\mathrm{L}_{\mathrm{c}}=\frac{(C C+3.412 * P-W H) *\left(R_{p}+R F^{*} R_{g}\right) * F_{s c}}{\left(t_{a}-t_{g}-t_{p}\right)}
$$

and the corresponding equation for heating would be [2] 


$$
\mathrm{L}_{\mathrm{h}}=\frac{(H C-3.412 * P+W H) *\left(R_{p}+R F * R_{g}\right) * F_{s c}}{\left(t_{g}-t_{a}-t_{p}\right)}
$$

where

$\mathrm{L}_{\mathrm{c}}=$ Total bore length required for cooling in $\mathrm{ft}$.

$\mathrm{CC}=$ Cooling capacity of the heat pump in Btu/hr.

$\mathrm{HC}=$ Heating capacity of the heat pump in Btu/hr.

$\mathrm{P}=$ Power input to the heat pump (compressor and fan) in watts.

$\mathrm{WH}=$ Water heating capacity of the desuperheater.

$\mathrm{R}_{\mathrm{p}}=$ Thermal resistance of pipe in $\mathrm{hr}-\mathrm{ft}^{\circ} \mathrm{F} / \mathrm{Btu}$.

$\mathrm{R}_{\mathrm{g}}=$ Equivalent thermal resistance of ground .

$\mathrm{RF}=$ fraction of time the heat pump is operational during design period.

$t_{a}=$ average fluid temperature in and out of the heat pump.

$$
=\frac{\text { Entering Water Temp. }(\text { EWT })+\text { Leaving Water Temp.(LWT) }}{2}
$$

$\mathrm{t}_{\mathrm{g}}=$ Undisturbed ground temperature.

$t_{p}=$ temperature penalty resulting from shallow bores.

$\mathrm{F}_{\mathrm{sc}}=$ Thermal short-circuiting factor in U-bends.

$=1.05$ for one U-bend per parallel circuit.

$=1.02$ for two U-bends per parallel circuit.

$=1.01$ for three U-bends per parallel circuit. 
The temperature penalty is assumed to be zero because this thesis does not study the effect of shallow bores. RF factor is found out from the bin method of energy estimation. Table 4-4 provides the minimum bore length per cooling ton for residential U-bend GCHP systems in the Tennessee Valley Authority service area and beyond. These values hold good for simulation purposes in most parts of the United States and for soils with a ground thermal conductivity of $\mathrm{k}_{\mathrm{g}}=1.2 \mathrm{Btu} / \mathrm{hr}-\mathrm{ft}-{ }^{\circ} \mathrm{F}$.

Table 4-4: Recommended Lengths of Bore in feet Per Ton of cooling for GCHPs [30].

\begin{tabular}{|c|c|c|c|c|c|c|c|}
\hline Coil Type & \multicolumn{7}{|c|}{ Ground Temperature ( $\left.{ }^{\circ} \mathrm{F}\right)$} \\
Vertical & 44 to 47 & 48 to 51 & 52 to 55 & 56 to 59 & 60 to 63 & 64 to 67 & 68 to 70 \\
U-tube & ${ }^{\circ} \mathrm{F}$ & ${ }^{\circ} \mathrm{F}$ & ${ }^{\circ} \mathrm{F}$ & ${ }^{\circ} \mathrm{F}$ & ${ }^{\circ} \mathrm{F}$ & ${ }^{\circ} \mathrm{F}$ & ${ }^{\circ} \mathrm{F}$ \\
\hline $3 / 4 "$ & 180 & 170 & 155 & 170 & 180 & 200 & 230 \\
\hline $1 "$ & 170 & 160 & 150 & 160 & 170 & 190 & 215 \\
\hline $1-1 / 4 ”$ & 160 & 150 & 145 & 150 & 160 & 175 & 200 \\
\hline
\end{tabular}

For other conditions with varying thermal conductivities of the ground, the corrected bore length is obtained by multiplying with a correction factor given in Table 4-5 with the values given in Table 4-4.

L/Ton $($ Corrected $)=L /$ Ton $\left(\right.$ Table 4.44-1)*CF $\left(k_{g}\right)$ 
Table4-5: Correction factors for different values of $\mathrm{k}_{\mathrm{g}}$ [30].

\begin{tabular}{|c|c|c|c|c|c|c|c|}
\hline $\mathrm{k}_{\mathrm{g}}\left(\mathrm{Btu} / \mathrm{hr}-\mathrm{ft} .{ }^{\circ} \mathrm{F}\right)$ & 0.8 & 1.0 & 1.2 & 1.4 & 1.6 & 1.8 & 2.0 \\
\hline Vertical Loop (CF) & 1.23 & 1.10 & 1.0 & 0.93 & 0.87 & 0.83 & 0.79 \\
\hline
\end{tabular}

\subsubsection{Efficiency of a Heat Pump}

In general, efficiency is defined as the useful work or energy output divided by the energy input to that work. But in the case of heat pumps, the definition of efficiency is somewhat different and varies for both heating and cooling. For cooling, the efficiency of a heat pump is expressed as the Energy Efficiency Ratio (EER). For heating, it is expressed as the Coefficient of Performance (COP). The rating of a heat pump is usually defined in tons and

One ton $=12000 \mathrm{Btu} / \mathrm{hr}(\mathrm{BTUH})$.

As defined in the equations for calculating the bore lengths in heating and cooling modes, $\mathrm{CC}$ and $\mathrm{HC}$ are the heating and cooling capacities of the heat pump. According to the manufacturer's equipment, these capacities may vary slightly by a couple of hundred BTUH. For this application, it is assumed that these capacities are the same. The power input in kilowatts (KW) to the heat pump can be calculated based on its EER and COP values. 
For cooling,

$$
\mathrm{P}=\frac{\mathrm{CC}}{\mathrm{EER} * 1000 \text { watts } / \mathrm{KW}} .
$$

Similarly for heating,

$$
\mathrm{P}=\frac{H C}{C O P^{*} 3413 \mathrm{BTUH} / \mathrm{KW}} .
$$

\subsubsection{Entering Water Temperature (EWT)}

Unlike the ASHPs, the ground coupled heat pump capacity is dependent of the entering water temperatures. The selection of the entering water temperature is a critical component in this design. A value close to the undisturbed ground temperature will result in a higher system efficiency increasing the required bore length and first cost. On the other hand, assuming a value far away from the UGT will reduce the system performance. According to ASHRAE, selecting the EWT to be 20 to $30^{\circ} \mathrm{F}$ higher than $\mathrm{t}_{\mathrm{g}}$ in cooling and 10 to $20^{\circ} \mathrm{F}$ lower than $\mathrm{t}_{\mathrm{g}}$ in heating is a good compromise between first cost and efficiency [4].

These values are assumed to be $22^{\circ} \mathrm{F}$ higher in cooling and $14^{\circ} \mathrm{F}$ lower in heating for simulation purposes in estimating the bore lengths. In the bin method, capacity of the heat pump varies with the EWT. According to a report [18] given by the US Department of Energy, the entering water temperature is assumed to be a linear interpolation between 
two points in a heating cycle and again for the cooling cycle. During peak load conditions, these values are set $22^{\circ} \mathrm{F}$ higher than $\mathrm{t}_{\mathrm{g}}$ and $14^{\circ} \mathrm{F}$ lower than $\mathrm{t}_{\mathrm{g}}$ in cooling and heating respectively as mentioned above. The entering water temperatures obtained were used in the bin method for getting the appropriate heat pump capacity from the manufacturer data. This linear interpolation for finding the EWT follows the equations given by [18]:-

Cooling:-

$\mathrm{EWT}_{\text {cooling }}=\mathrm{t}_{\mathrm{g}}+\left[\left(\right.\right.$ peak load EWT- $\left.\left.\mathrm{t}_{\mathrm{g}}\right) *\left(\mathrm{t}_{\text {bin }}-\mathrm{t}_{\text {bal }}\right) /\left(\mathrm{t}_{\text {max_bin }}-\mathrm{t}_{\text {bal }}\right)\right]$

Heating:-

$\mathrm{EWT}_{\text {heating }}=$ peak load EWT $+\left[\left(\mathrm{t}_{\mathrm{g}}-\right.\right.$ peak load EWT $\left.) *\left(\mathrm{t}_{\text {bin }}-\mathrm{t}_{\text {min__bin }}\right) /\left(\mathrm{t}_{\text {bal }}-\mathrm{t}_{\text {min_bin }}\right)\right]$

where $t_{\max \_ \text {bin }}=$ maximum outdoor bin temperature in cooling at the selected location.

$\mathrm{t}_{\text {min_bin }}=$ minimum outdoor bin temperature in heating at the selected location.

$\mathrm{t}_{\mathrm{bin}}=$ outdoor bin temperature.

peak load EWT $=$ value of entering water temperatures assumed in the calculation of bore lengths.

$t_{b a l}=$ balance point temperature at which no heating or cooling is required. 


\subsubsection{Heat Pump Capacities}

The capacity of a ground coupled heat pump is directly proportional to the entering water temperature. It varies with the residence requirements and also according to the manufacturer specifications. For simulation purposes in computer modeling, it is good to have the user enter custom heat pump data as that makes a program more effective. In this thesis, the ground loop heat pump data [20] was taken as a basis to obtain an equation to perform the calculations quickly and to increase the efficiency of the program. The data for a three ton heat pump unit in tabulated in the Table 4-6.

Table 4-6: Capacity and efficiency of a Three Ton GCHP system vs. EWT [20].

\begin{tabular}{|l|c|c|c|c|c|c|c|c|}
\hline EWT (F) & 25 & 30 & 40 & 50 & 60 & 70 & 85 & 100 \\
\hline Cooling Capacity (Btu/hr). & & & & 45720 & 44140 & 42560 & 40180 & 37180 \\
\hline EER & & & & 25.99 & 22.34 & 19.41 & 15.96 & 13.3 \\
\hline Heating Capacity (Btu/hr). & 26290 & 28700 & 33520 & 39100 & 44010 & & & \\
\hline COP & 3.33 & 3.58 & 4.05 & 4.58 & 5 & & & \\
\hline
\end{tabular}




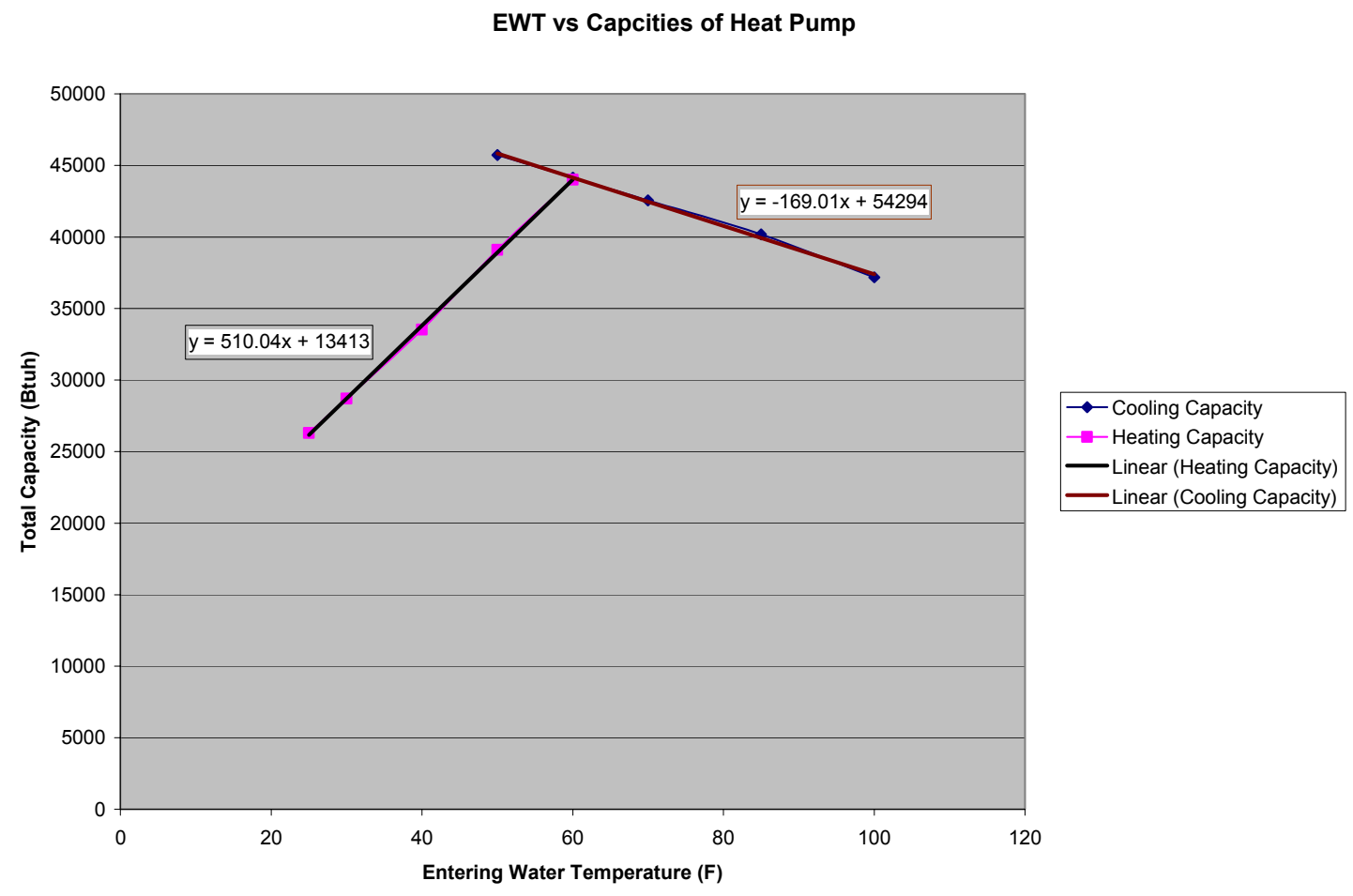

Figure 4-3 Capacities of a 3-ton heat pump unit [20].

A linear interpolation exists between the EWT and the capacity, efficiency of the heat pump. So the equations for the capacities and efficiencies in heating and cooling corresponding to the entering water temperature values are developed using Microsoft Excel are shown in Figure 4-3 and Figure 4-4 respectively. The equations for the heating and cooling capacity of a three ton GCHP [20] from the graph indicate.

$$
\begin{aligned}
& \mathrm{HC}_{3 \text { ton }}=510.04 * \mathrm{EWT}+13413 \\
& \mathrm{CC}_{3 \text { ton }}=-169.01 * \mathrm{EWT}+54294
\end{aligned}
$$




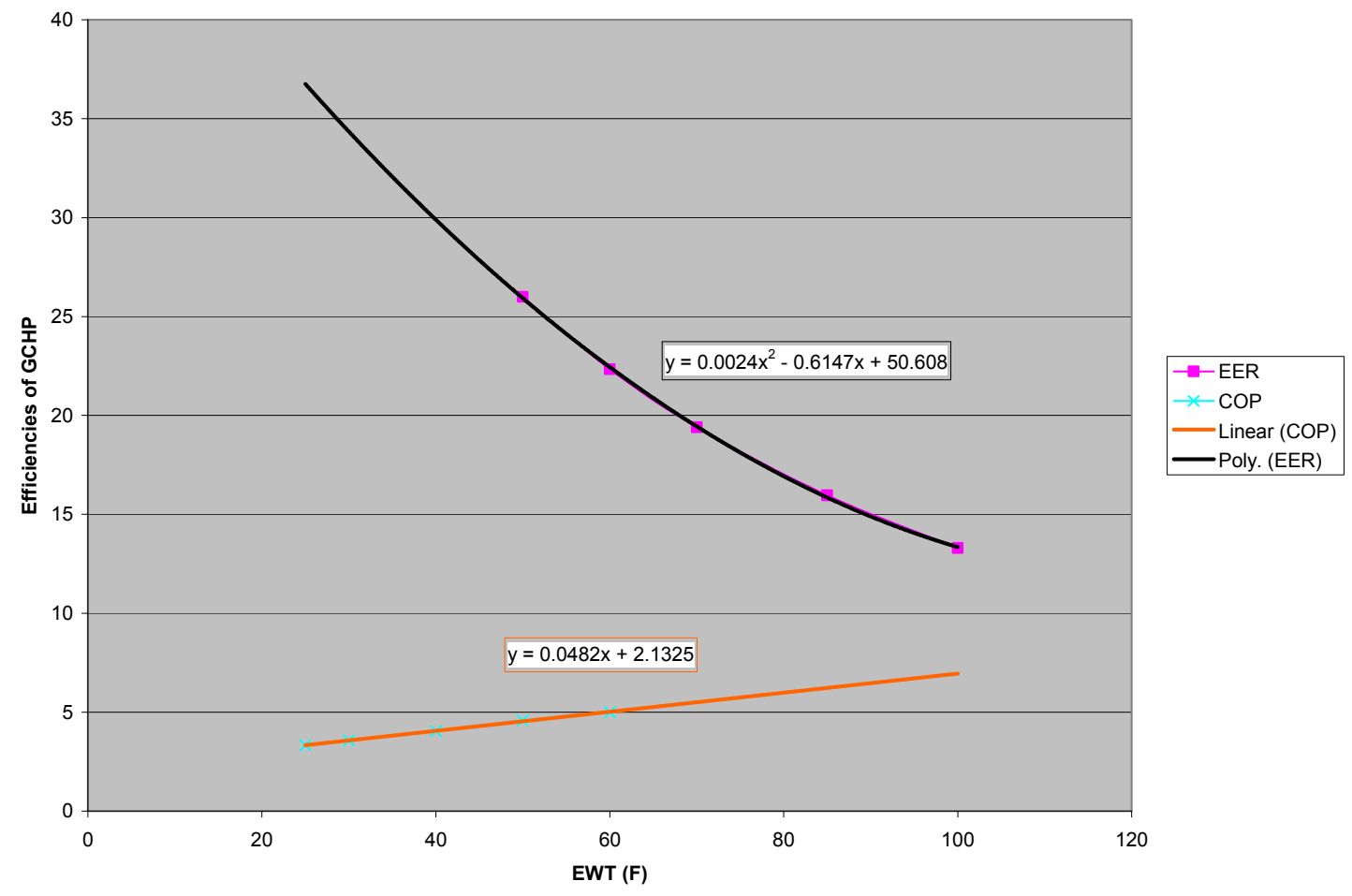

Figure 4-4 Efficiencies of a 3 ton heat pump unit [20].

$$
\begin{aligned}
& \mathrm{EER}_{3 \text { ton }}=0.002 *(\mathrm{EWT})^{2}-0.6147 * \mathrm{EWT}+50.608 \\
& \mathrm{COP}_{3 \text { ton }}=0.0482 * \mathrm{EWT}+2.1325
\end{aligned}
$$

Similar equations were developed for two and four ton heat pump units from FHP Manufacturing Company's Data [20] and used in the program developed in this thesis for simulation purposes. 


\subsubsection{Energy Estimation}

The process of energy estimation is necessary to calculate the operational time of the heat pump during the entire heating or cooling season. Operational times are used in obtaining the bore lengths for ground loop installation. Procedures of energy estimation vary with the nature of the problem. For example, in case of residential applications a detailed methodology may not be required for design purposes. Energy calculations play an important role leading to an economic analysis and helps in predicting the exact electric usage. There are various methods like Degree-Day method, Simplified Bin method and the Modified Bin method for performing such calculations.

The modified bin method is the most complex of all and performs energy balance calculations on an hourly basis for some period of time, typically a year. Also it should be noted that it is applied to commercial or institutional buildings where the internal gains become a major part of the cooling load. Degree-Day method is also known as the single measure method as the total energy usage depends on the annual heating or cooling degree days. It does not give a precise measure of the energy consumption and cannot predict the time of operation for the entire season. Optimization of the software tool is done using the Simplified Bin method because it permits the use of off-design calculations and predicts the hours of operation needed and the power input to run the unit for various outdoor temperatures. 


\subsubsection{Simplified Bin Method}

The simplified bin method consists of performing an instantaneous energy calculation at many outdoor temperatures and multiplying the results with the number of hours of occurrence of each bin. A bin usually involves a temperature variation in the form of $5^{\circ} \mathrm{F}$. For example, a calculation is performed for $57^{\circ} \mathrm{F}$ outdoor temperature that represents for all the occurrences of $55-59^{\circ} \mathrm{F}$. The bin method requires a load profile for the residence, i.e. the heating or cooling required to maintain the controlled space at the design indoor temperatures. A balance point temperature is assumed that is defined as the temperature at which neither heating nor cooling is required. In this application, the balance point is set to $60^{\circ} \mathrm{F}$. Weather data for the hours of occurrence of temperature bins for a few locations are embedded into a text file and have been obtained from Engineering Weather Data, Facility Design and Planning manual. Figure 4-5 shows a schematic of the bin calculation procedure followed in the energy estimation.

In the heating mode, the internal and solar gains are assumed to be minimal and the energy consumption is calculated for different values of outdoor temperatures $t_{0}$ and multiplied by the number of hours of the temperature interval (bin). Heat Loss or the Building Load is defined as the rate at which a building is losing heat and is measured in $\mathrm{Btu} / \mathrm{hr}$. The design or peak heating load is used to calculate the heat loss per degree, which is also known as the heat loss coefficient. It is the ratio of the design load to the design temperature difference between the outdoor and the indoor temperatures. 
For example, if the design heating load for a residence in Pittsburgh, PA is assumed to be 45000Btu/hr and the heat loss coefficient has to be calculated, then the design outdoor temperature for the $99.6 \%$ dry bulb temperature is obtained from the Climatic data in ASHRAE 1997 Fundamentals handbook [20]. The design outdoor temperature for the above example would be $2^{\circ} \mathrm{F}$. Dry-Bulb temperature is the temperature of outside air measured using a thermometer and the $99.6 \%$ value says that only $0.4 \%$ of the time does the city of Pittsburgh, PA experience a temperature below $2^{\circ} \mathrm{F}$. Usually the indoor conditions are set to $70^{\circ} \mathrm{F}$ and so the heat loss coefficient is calculated by the ratio of the design heating load to the design temperature difference shown below:-

Heat Loss Coefficient $=\frac{45000}{(70-2)}=661.76 \mathrm{Btu} / \mathrm{hr}-{ }^{\circ} \mathrm{F}$.

As seen in Figure 4-5, column A indicates the outdoor bin temperature and column B has the heat loss coefficient values for a given design heating load. Column $\mathrm{C}$ is the temperature difference between the outdoor and balance point temperatures. Therefore the product of heat loss coefficient and the value in column $\mathrm{C}$ gives the heat loss of the residence at that particular bin given in column $\mathrm{D}$. Then the heating capacity of the ground coupled heat pump is obtained for the corresponding values of EWT. Operational time of the heat pump is calculated by dividing the heat loss by the heating capacity. 


\begin{tabular}{|c|c|c|c|c|c|c|c|c|c|c|c|}
\hline A & $B$ & C & D & $E$ & $F$ & G & $\mathrm{H}$ & 1 & J & K & $L$ \\
\hline Bins Dutdoor Temp & Heat Loss Coefficient & Temp. Diff & Heat LossBildg. Load & Internal Gains & Net Heat Loss & EWT & GSHP Cap. & $\%$ Pump Oper. Time & Bin Hours & Seasonal Input & Pump Run \\
\hline F & Btuthr. ${ }^{\circ} \mathrm{F}$ & $\Delta T$ & & Btuthr. & & ${ }^{*} \mathrm{~F}$ & Btuthr. & $\times 100 \%$ & hrs. & Btu & hrs. \\
\hline & & & & & & & & & & & \\
\hline & & & & & & & & & & & \\
\hline & & & & & & & & & & & \\
\hline & & & & & & & & & & & \\
\hline & & & & & & & & & & & \\
\hline & & & & & & & & & & & \\
\hline & & & & & & & & & & & \\
\hline & & & & & & & & & & & \\
\hline & & & & & & & & & & & \\
\hline & & & & & & & & & & & \\
\hline & & & & & & & & & & & \\
\hline & & & & & & & & & & & \\
\hline
\end{tabular}

Figure 4-5: Bin method calculation procedure.

Similarly, the COP of the heat pump also varies with EWT and so the seasonal input and the hours of compressor operation are found out. 
In the cooling mode, the process of assessing the annual energy consumption varies slightly when compared to heating. The design temperature difference in summer is relatively small to that in winter and so the conduction gains constitute only a part of the total cooling load. This means that solar gains dominate in summer. Conduction gains include the heat gain from the roof, floor, walls, etc. Solar energy in the form of radiation does not become part of the cooling load immediately, but instead is taken up by the windows, furniture etc. and heat energy is given to the surroundings in the form of convection. It is a delayed process and this thesis presents a modified cooling bin method where it becomes necessary to take the amount of sunshine that is available in a particular location.

Table 4-7 gives the mean percentage of sunshine available in selected locations. The extreme northern and the southern regions of the United States have the most heating and cooling requirements respectively. Minimum and maximum UGT is around $44^{\circ} \mathrm{F}$ and $80^{\circ} \mathrm{F}$ respectively in the US and the regions under these conditions experience ninety percent of the sunshine in summer and that value follows a sinusoidal curve as the places in between these, experience somewhat less sunshine. It is assumed that the extreme regions of US have approximately ninety percent of sunshine in summer and that there is a two percent decrease in the sun's radiation up to the center of the country for every one degree Fahrenheit change in the undisturbed ground temperature. So those in the middle of these limits with an UGT of $62^{\circ} \mathrm{F}$ experience about $54 \%$ of the annual sunshine 
percentage. And since this value follows a sine curve, the sun's radiation increases from the center to the south in a linear fashion.

Table 4-7: Mean percentages of sunshine hours in USA

\begin{tabular}{|c|c|c|c|c|c|}
\hline Location & $\begin{array}{c}\text { Birmingham, } \\
\text { AL. }\end{array}$ & $\begin{array}{c}\text { Phoenix, } \\
\text { AZ. }\end{array}$ & $\begin{array}{c}\text { Los Angels, } \\
\text { CA. }\end{array}$ & $\begin{array}{c}\text { Washington, } \\
\text { DC. }\end{array}$ & $\begin{array}{c}\text { Tampa, } \\
\text { FL. }\end{array}$ \\
\hline January & 43 & 76 & 70 & 46 & 63 \\
\hline February & 49 & 79 & 69 & 53 & 67 \\
\hline March & 56 & 83 & 70 & 56 & 71 \\
\hline April & 63 & 88 & 67 & 57 & 74 \\
\hline May & 66 & 93 & 68 & 61 & 75 \\
\hline June & 67 & 94 & 69 & 64 & 66 \\
\hline July & 62 & 84 & 80 & 64 & 61 \\
\hline August & 65 & 84 & 81 & 62 & 64 \\
\hline September & 66 & 89 & 80 & 62 & 64 \\
\hline October & 67 & 88 & 76 & 61 & 67 \\
\hline November & 58 & 84 & 79 & 54 & 67 \\
\hline December & 44 & 77 & 72 & 47 & 61 \\
\hline Annual & 59 & 85 & 73 & 58 & 68 \\
\hline
\end{tabular}

The design or peak cooling load is the one that occurs at the design temperature difference and does not take into account the actual solar gains at each outdoor temperature. This thesis provides a modified bin cooling method that takes the actual sunshine available in summer at a particular location in calculating the heat gain and thus the energy estimation. Therefore the product of the annual percent of sunshine and the percent of that experienced in summer gives the exact percent of solar radiation available in summer for cooling purposes. Now the actual heat gain coefficient is the theoretical value multiplied by the actual percent of solar radiation available. So this way the operational times are obtained and used to calculate the bore lengths in heating and cooling. 


\subsubsection{Optimization}

Development of a software tool that can minimize the energy consumption in the ground loop for varying pipe sizes by estimating the time of heat pump operation during a design period was considered the primary objective of this thesis. The Figure 4-7 shows the typical flow diagram of how the design tool optimizes the pump energy for various pipe sizes.

Input to the program include variables such as location, type of soil, design cooling and loads, undisturbed ground temperature and the desired indoor conditions as per user requirements. The ground and water source heat pump manual is a design guide in the development of this optimal design tool [2]. Section 5.4 of Chapter Five discusses how to install the Java plug-in and run the software tool.

Optimization of the GSHP starts with calculating the operating times from the bin method. A text file is read before creating the user interface that consists of bin hours for the entire year and also has the details of the mean dry bulb outdoor design temperatures for summer and winter respectively. The text file is typed in a certain format and it is recommended that the user follow the specifications accordingly. Additional locations can be added to this file to run the simulation program. 


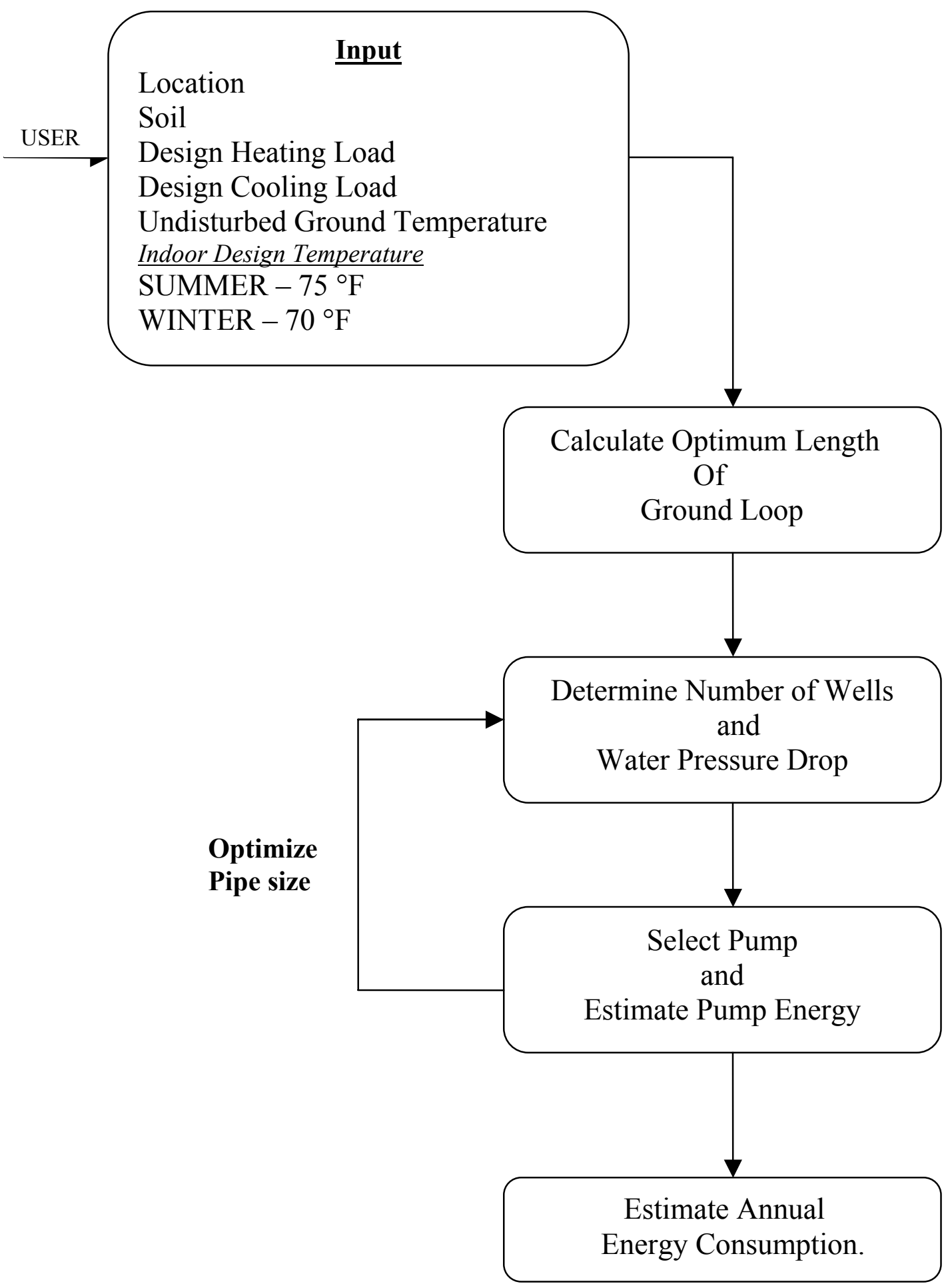

Figure 4-7: Flow diagram of the optimization tool. 
As seen from the flow chart, the heat pump capacity is determined based on the design heating and cooling load specified by the user. Once the capacity of the GCHP is determined, bore lengths are calculated from the equations for the heat pump capacities and efficiencies. Then the recommended piping arrangement as a function of the heat pump capacity given in Table 4-8 is used to account for various combinations of the ground loop.

Table 4-8: Recommended GCHP piping arrangement and pumps [30].

\begin{tabular}{|c|c|c|c|c|c|}
\hline & \multicolumn{5}{|c|}{ Nominal Heat Pump Capacity (Tons) } \\
\hline & 2 & 3 & 4 & 5 & 6 \\
\hline & \multicolumn{5}{|c|}{ Required Ground Loop Flow Rate In GPM } \\
\hline & $5-6$ & $7-9$ & $10-12$ & $12-15$ & $15-18$ \\
\hline Coil Type & \multicolumn{5}{|c|}{ Number of Parallel Loops } \\
\hline Slinky (10 pitch) & $3-4$ & $4-6$ & $6-9$ & $8-10$ & $8-10$ \\
\hline 6-Pipe & $3-4$ & $4-6$ & $6-9$ & $8-10$ & $8-10$ \\
\hline 4-Pipe & $2-3$ & $4-6$ & $5-8$ & $6-9$ & $6-10$ \\
\hline 2-Pipe & $2-4$ & $3-5$ & $4-6$ & $5-8$ & $6-10$ \\
\hline Vert.-3/4" PE & $2-3$ & $3-5$ & $4-6$ & $5-8$ & 6-10 \\
\hline Vert.-1"PE & $2-3$ & $2-4$ & $3-5$ & $4-6$ & $4-6$ \\
\hline Vert.-1-1/4"PE & $1-2$ & $1-2$ & $2-3$ & $2-3$ & $2-4$ \\
\hline Trench Ft. & \multicolumn{5}{|c|}{ Header Diameter HDPE, DR 11 Pipe } \\
\hline Less $100^{\prime}$ & $1 \frac{1 / 4}{10}$ & $11 / 4^{\prime \prime}$ & $11 / 4^{\prime \prime}$ & $11 / 2 "$ & $11 / 2 n$ \\
\hline \multirow[t]{3}{*}{$100-200^{\prime}$} & $1 \frac{1 / 4}{"}$ & $1 \frac{1 / 4^{\prime \prime}}{}$ & $1 \frac{112 "}{1}$ & $1 \frac{1 / 2 "}{\prime \prime}$ & $11^{1 / 2 "}-2^{\prime \prime}$ \\
\hline & \multicolumn{5}{|c|}{ Number \& Size Of Pumps Required } \\
\hline & $1-1 / 12 \mathrm{hp}$ & $1-1 / 6 \mathrm{hp}$ & $\begin{array}{l}1-1 / 6 \text { hp (1/" lidss. }) \\
2-1 / 12 \text { hp (1/"hdrs, })\end{array}$ & $2-1 / 6 h p$ & $2-1 / 6 h p$ \\
\hline
\end{tabular}

Then the pump energy is determined for that combination of the ground loop and is continued until all the combinations are examined. The ground loop with the least amount of circulator pump energy is highlighted as the optimal solution in the "Results" 
graphical user interface. Annual energy consumption is obtained from the bin method of energy estimation.

\subsubsection{Pump Energy}

Pump energy plays an important role in the design of a heat pump. In ground coupled systems for residential applications typically the circulator pump is the smallest energy user. However, this can be a major factor in increasing the installation and operational costs if proper care is not taken to select the right pump and ground loop piping. It is necessary to know the factors that are responsible and can affect the amount of energy required to run the ground loop. The ground-coupled heat pumps consist of a water-to-air or water-to-water heat pump, a circulator pump, a buried pipe grid and an interconnecting header [2].

A piping system design procedure has to be followed so that the buried ground loop works effectively. In order to achieve this, a separation distance of 15 to $20 \mathrm{ft}$. is employed between loops either in parallel or series to get the ideal heat extraction or rejection rate. Ends of each loop are joined with U-bends by means of thermal fusion so that there is no obstruction to the flow. This is to avoid turbulence in the flow. Ground loop consists of an indoor pipe often called the hose, header pipe that runs the total flow to the ground loop and returns it to the ground side heat exchanger, and the pipe run including the fittings. 
These pipes are usually made of high density polyethylene (SDR 11 and SDR 9), polybutylene (SDR 13.5) and schedule 40 (which is either PVC or polyethylene). Schedule 40 pipe is used to calculate the head losses in the ground loop. SDR stands for standard dimension ratio and is defined as the ratio of the outside pipe diameter to its wall thickness. The software tool is flexible enough to include additional pipe types and other variables as an extension of this thesis. There is a pipe thermal resistance associated with each of the pipe types, because the composition of the pipe varies from material to material. Equivalent pipe thermal resistances for various pipe types corresponding to different pipe diameters are given in Table 4-9.

Table 4-9: Equivalent pipe thermal resistance and outside diameters [4].

\begin{tabular}{|c|c|c|c|c|}
\hline Diameter & SDR 9 & SDR 11 & Sch 40 & SDR 13.5 \\
\hline 3/4" & 0.093 & 0.075 & 0.10 & - \\
\hline $1 "$ & 0.093 & 0.075 & 0.10 & 0.98 \\
\hline $1-1 / 4 "$ & - & - & - & 0.98 \\
\hline $1-1 / 2 "$ & 0.093 & 0.075 & 0.10 & - \\
\hline
\end{tabular}

The hose run is limited to $10 \mathrm{ft}$. and the header supply and return lengths are contained to $80 \mathrm{ft}$. to allow for simplicity in the head loss calculation procedure. Head loss across the longest section of the ground loop at the desired flow rate based on the number of fittings included and length of the pipe run in the closed loop. These calculations are fitted into the program after tabulating those values manually for different types of circuits. First the 
equivalent lengths of these pipe fittings are important in obtaining the total head loss in the longest circuit.

Table 4-10 gives the equivalent lengths of fittings as a function of pipe diameter. Usually a system curve is plotted for the head loss in feet of water against the total flow rate in gallons per minute (gpm) and the pump that shows up on the curve is selected to determine the pump energy. It is difficult for the user to select the pump and enter its energy rating as part of the optimization sub-routine. So by observing the graphs for circulator pumps [27], it was deduced that the efficiency of these pumps lie in the range of $20 \%, 24 \%$ and $28 \%$ for two, three and four ton heat pump units respectively.

Table 4-10: Equivalent length of pipe for fittings and values in feet [2].

\begin{tabular}{|c|c|c|c|c|}
\hline Fitting & $3 / 4 "$ & 1" & $1-1 / 4 "$ & $1-1 / 2 "$ \\
\hline $90^{\circ}$ Elbow & 2.2 & 2.7 & 3.5 & 4.0 \\
\hline Tee (Straight) & 1.4 & 1.8 & 2.3 & 2.7 \\
\hline Tee(Branch & 4.3 & 5.4 & 6.9 & 8.1 \\
\hline U-Bend & 3.6 & 4.5 & 5.8 & 6.7 \\
\hline Reducer & 0.4 & 0.4 & 0.5 & 0.6 \\
\hline 3-Way Valve & 9 & 16 & 22 & 30 \\
\hline
\end{tabular}

The efficiency of a circulator pump is defined as the ratio of the water horsepower to the brake horsepower. It can be represented in the form of an equation as:- 


$$
\eta_{\text {pump }}=\frac{\text { waterhorsepower }(\text { WHP })}{\text { brakehorsepower }(B H P)}
$$

Water horsepower is calculated from the head loss obtained from the piping loop and is given as:-

$$
\mathrm{WHP}=\frac{\text { headloss }(\text { ft. }) * \text { flowrate }(\text { gpm. })}{3960}
$$

and

$$
\mathrm{BHP}=\mathrm{WHP} / \eta_{\text {pump }}
$$

Thus the circulator pump energy is equal to the product of BHP converted to kilowatts and the operational time of the heat pump in hours, which is obtained from the bin method. 


\section{Chapter 5: Programming - Java}

\section{1: $\underline{\text { Origin }}$}

Historical accounts of the computer typically begin with the evolution of calculator that is basically a search for a device that could perform the four basic arithmetic functions of addition, subtraction, division and multiplication ${ }^{[12]}$. A computer is a device, which collects data and gives a readable output by performing a series of calculations on the data after converting it into machine language. The computers have traveled a long way from punch cards, vacuum tubes, and transistors to the silicon chips of this era, which do trillions of calculations in a fraction of a second. The art of developing computer programs in order to speed up a process with a few lines or pages of code and obtaining the result from some keyboard input or just a few clicks of a mouse is called programming.

The basic parts of a computer include the central processing unit (CPU), input devices such as keyboard, output devices like the monitor and the storage devices that include the floppy and zip drives, hard disk and the CD-RW drives. These storage devices are usually part of the central processing unit or can be external to it. The CPU consists of the silicon chip, random access memory (RAM) and the input and output ports to have some accessories. The RAM is a kind of cache memory that reads data according to the 
computers configuration. It can access data quickly and write to other storage devices mentioned above.

A number of programming languages have evolved that can be used to write computer programs, since the invention of computers. There are two basic types of programming languages namely, Low Level and High Level languages. The Low Level languages can be further divided into Machine and Assembly languages. The High level languages such as FORTRAN, C, C++, Java, Oracle, etc. are much more efficient and easy to follow. The Machine languages on the other hand mostly consist of numbers and are difficult for humans to understand. Low level languages are directly understood by the computers, so no translation is needed. Each type of CPU has its own machine language and assembly language. So a program written in assembly language for one type of CPU won't run on

another ${ }^{[13]}$. Usually a lot of compilers are available free of charge for the high level languages. These compilers convert computer programs into machine language that accept input data and provide the result as output.

\section{2: Object Oriented Programming (OOP)}

The first and the foremost thing is that Java is a high level language based on the concept of object oriented programming unlike FORTRAN and C. The concept of object oriented language is related to the objects found in the real world that exhibit their state and behavior. For example, dogs have state (name, color and breed) and behavior 
(barking, fetching and wagging tail) [14]. The state of an object is also known as its "Attribute", which is defined as a property or characteristic of that particular object.

A class is a template expressed as a piece of program code for a collection of objects with common properties. An instance of a class is a technical term for an existing object of that class and any class that cannot be instantiated is known as an abstract class. The name of a particular java source file should be the same as the class name defined in it. A subclass is one that inherits the properties of the parent class [15].

The main features of Java that makes it unique are because it is:

- Simple

- Object Oriented

- Portable

- Secure

- Interpreted

- Distributed

- Garbage Collection and

- High Performance [16].

Java is simple because it does not consist of pointers that can initiate memory leaks and cause a program to crash, which is a possibility in $\mathrm{C}++$ and $\mathrm{C}$. A program that does not 
follow the concept of OOP has its solution usually expressed only in terms of numbers and characters known as "data structures". Every High level language comprises of the basic data structures that are used to define variables like integer, float, character and Boolean respectively.

Java contains a suite of reusable class libraries called "Packages" and a collection development tools including a compiler, an interpreter, debugger, html converter, etc. as part of the Java Development Kit (JDK) making it object oriented. The Java programming language supports interfaces used to define a protocol of behavior that can be implemented by any class anywhere in the class hierarchy ${ }^{[14]}$. Classes in a package are allowed to access other classes within the same package. The other aspects are also important in the sense that Java supports various protocols. Some of them include file transfer protocol (FTP), hypertext transfer protocol (HTTP) and remote method invocation (RMI).

The author opted to program his software tool in Java because it is portable and can run on a computer working on any type of operating system. In order to run java source code, one needs to have Java2 standard edition (J2SE) available free of charge at http://www.java.sun.com.

The documentation for the J2SE software is found on the WWW at, http://www.java.sun.com/docs. 
Once the J2SE software is installed, it is recommended that the Path and Classpath variables are set in the computer for proper execution of the program. The detailed instructions for doing this can be found by clicking on the link below, http://java.sun.com/docs/books/tutorial/getStarted/cupojava/index.html.

\section{3: How Java Works}

A typical execution process of a Java program inside a computer is represented in the form a schematic diagram shown in Figure 5-1. Once the path variables are set, the compilation of java source code will result in the creation of a ".class" file stored in the same directory as the source file. This class file consists of byte code that is understood by the Java interpreter and is also known as Java Object code. The execution of a program initiates the Java interpreter, which checks byte code of the ".class" file ensuring its content. In this fashion, the program does not directly act on the computer making it safe and secure to execute. The Java interpreter is also referred to as the Java Virtual Machine (JVM) that runs as a standardized hypothetical computer ${ }^{[15]}$. 


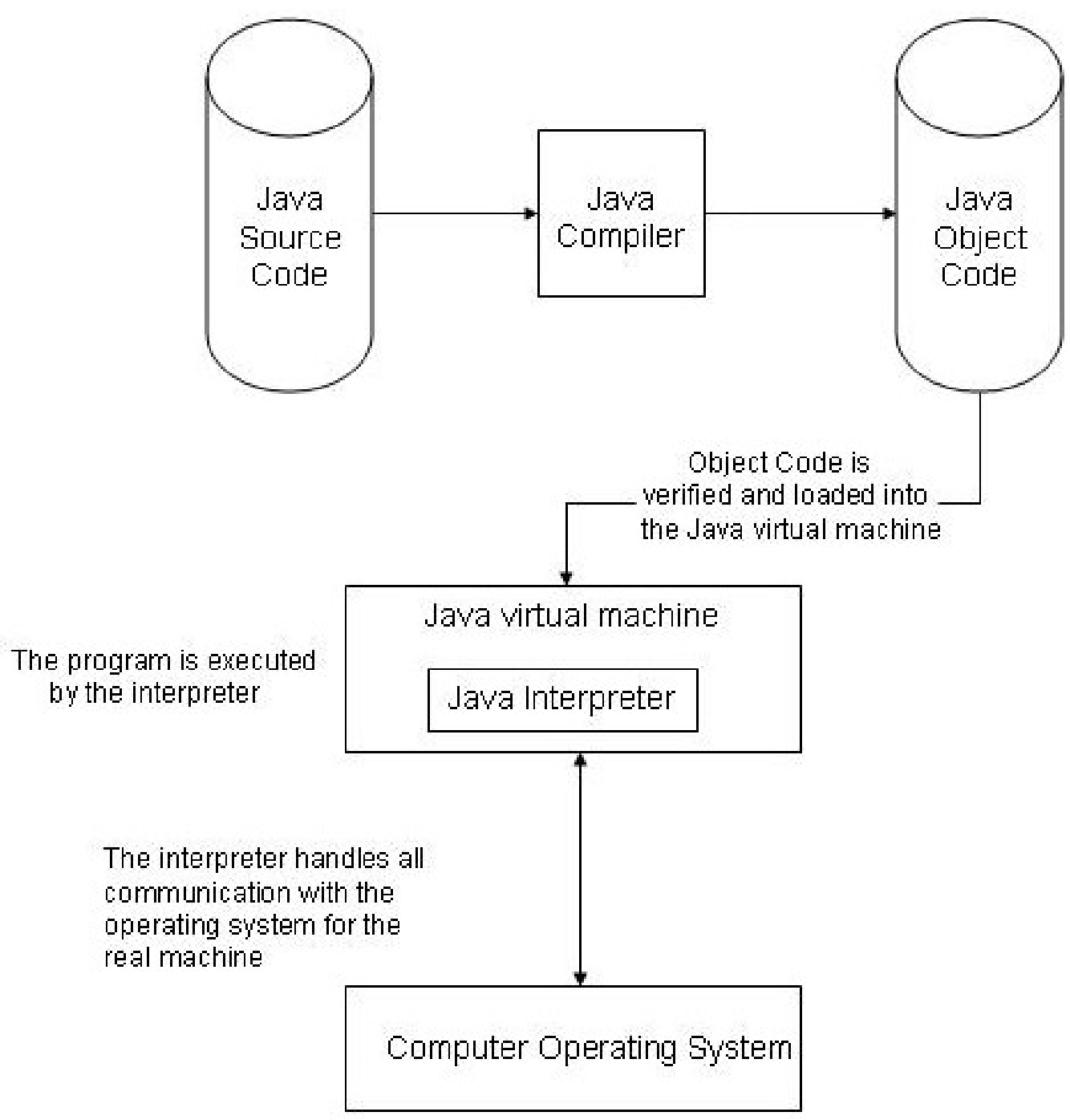

Figure 5-1: Standard Execution of a Java Program inside a computer [15].

Java enables the users to embed simple computer programs on the World Wide Web (WWW) or the Internet allowing them to be accessible anywhere. Those types of programs are referred to as "Java Applets" and ordinary standalone programs are called "Java Applications". Java Applications can be categorized into "Console Applications" and "Windowed Applications". The former support only character output in either a command prompt or Java console. On the other hand, Windowed Applications can create 
and handle multiple windows, which are also known as "Graphical User Interfaces" (GUI). Java has a huge library of built in classes that are part of the package "Abstract Windowing Toolkit" (AWT). These classes can be used to develop custom GUIs that can display characters and numbers, images and even play animations depending on the program requirement.

\section{4: $\underline{\text { Running the software }}$}

Java has a special feature that enables developers to create special programs known as "Applets" that are accessible throughout the world. So it is imperative that every computer has the Java plug-in installed to run the program. The software tool is available at http://cemrweb.cemr.wvu.edu/ kadivi/HeatPumpSim/MainPageApplet.html. Any computer that does not have Java plug-in will ask the permission of the user to install it in order to run the program successfully. Figure 5-2 shows the screen capture of the pop-up message and instructions on installing the plug-in. 


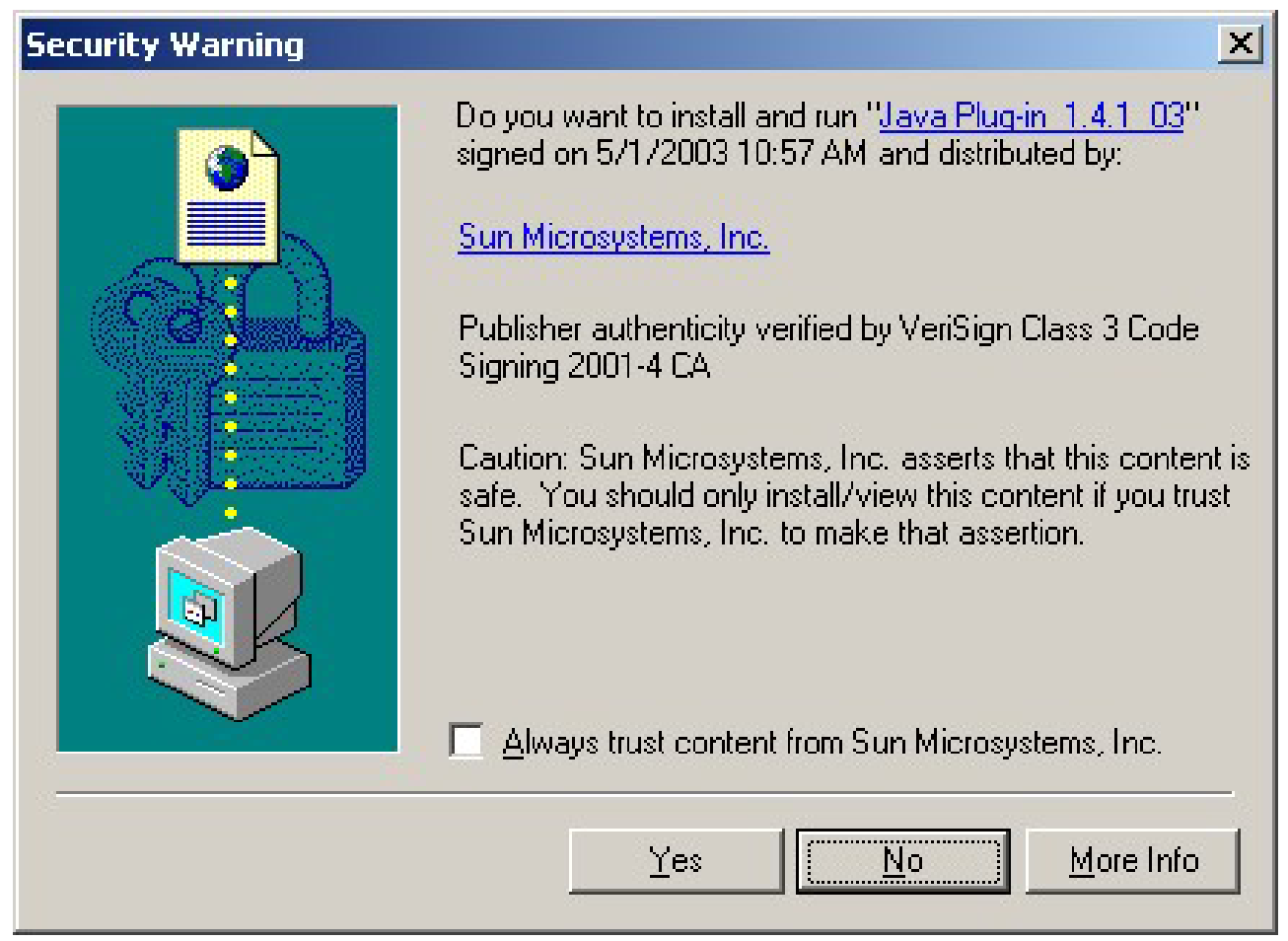

Figure 5-2: Instructions for installing Java plug-in 


\section{Chapter 6: Results}

The ground and water source heat pumps (GWSHP) manual [2] was used as a guide in doing this thesis. It provides the results of building analysis done for a residence in Tuscaloosa, Alabama. The design heating and cooling loads were assumed as 40000 and $36000 \mathrm{Btu} / \mathrm{hr}$. with a house area of 1800 sq.ft. This was used as a basis and used to determine the operational hours of the ground coupled heat pump, ground loop piping required and to optimize the pump energy. Figure 6-1 shows the input screen where the user has the option to enter the values of design heating and cooling loads, undisturbed ground temperature and the indoor design temperatures. Also a schematic diagram of the ground loop circuit was prepared using Microsoft Paint and is useful in understanding the calculations easily. The input to the expert system was:-

$\begin{array}{lll}\text { Location } & : & \text { Birmingham } \\ \text { State } & : & \text { Alabama } \\ \text { Soil type } & : & \text { Wet Sand } \\ \text { Design heating load } & : & 40,000 \mathrm{Btu} / \mathrm{hr} . \\ \text { Design cooling load } & : & 36,000 \mathrm{Btu} / \mathrm{hr} . \\ \text { Undisturbed ground temperature } & : & 65^{\circ} \mathrm{F} \\ \text { Indoor Temperature } & & \\ \text { Winter } & : & 70^{\circ} \mathrm{F} \\ \text { Summer } & : & 75^{\circ} \mathrm{F}\end{array}$




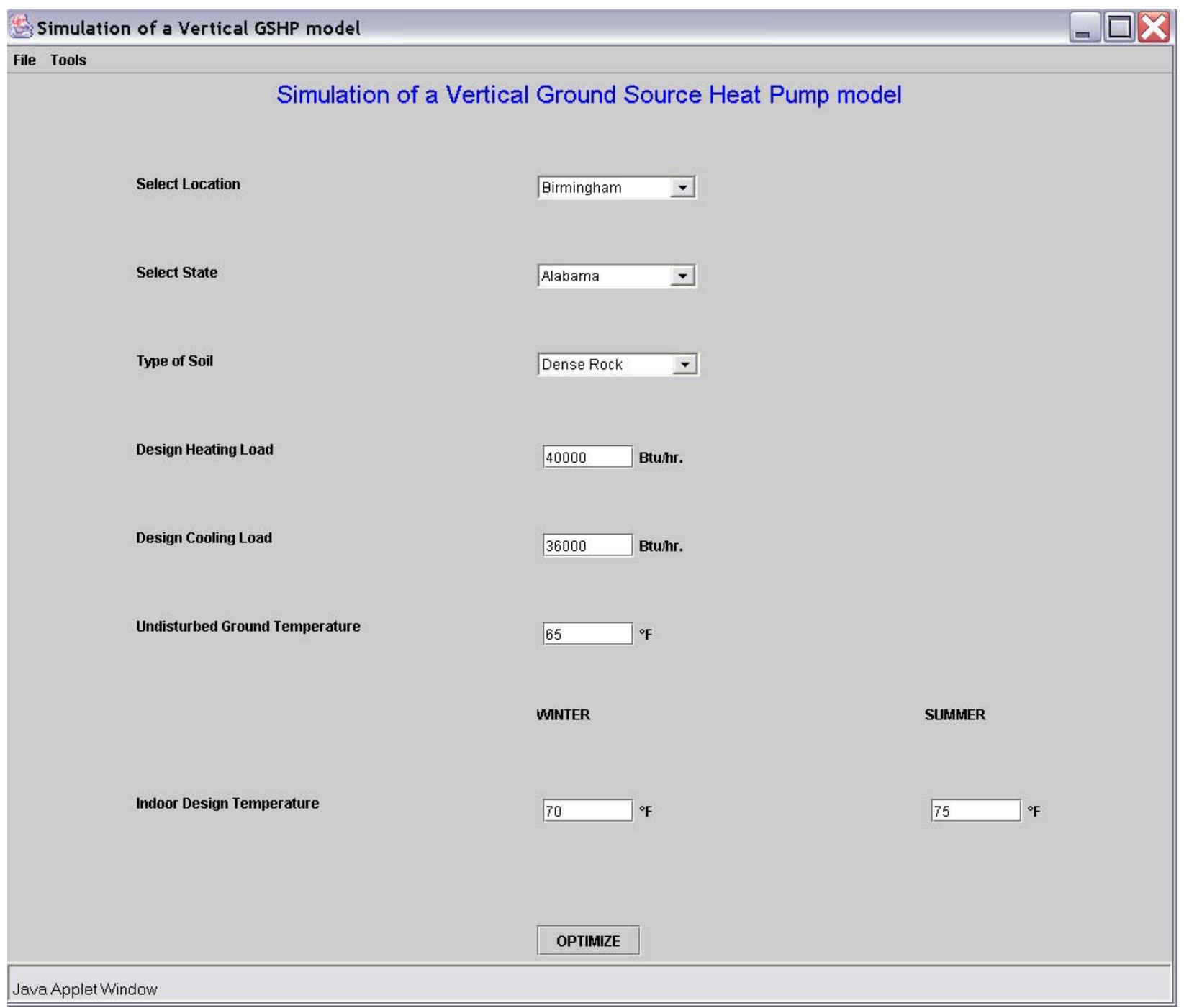

Figure 6-1: Main page showing the user input

The "OPTIMIZE" button should be pressed to run the simulation. This tool has been taken care of to control accidental erroneous input problems. Once the simulation starts and based on the design loads, the program would select the right ground coupled heat pump unit and calculates the hours of compressor operation in heating and cooling using the bin method. Then the results are displayed in the form of a results page shown in Figure 6-2. 


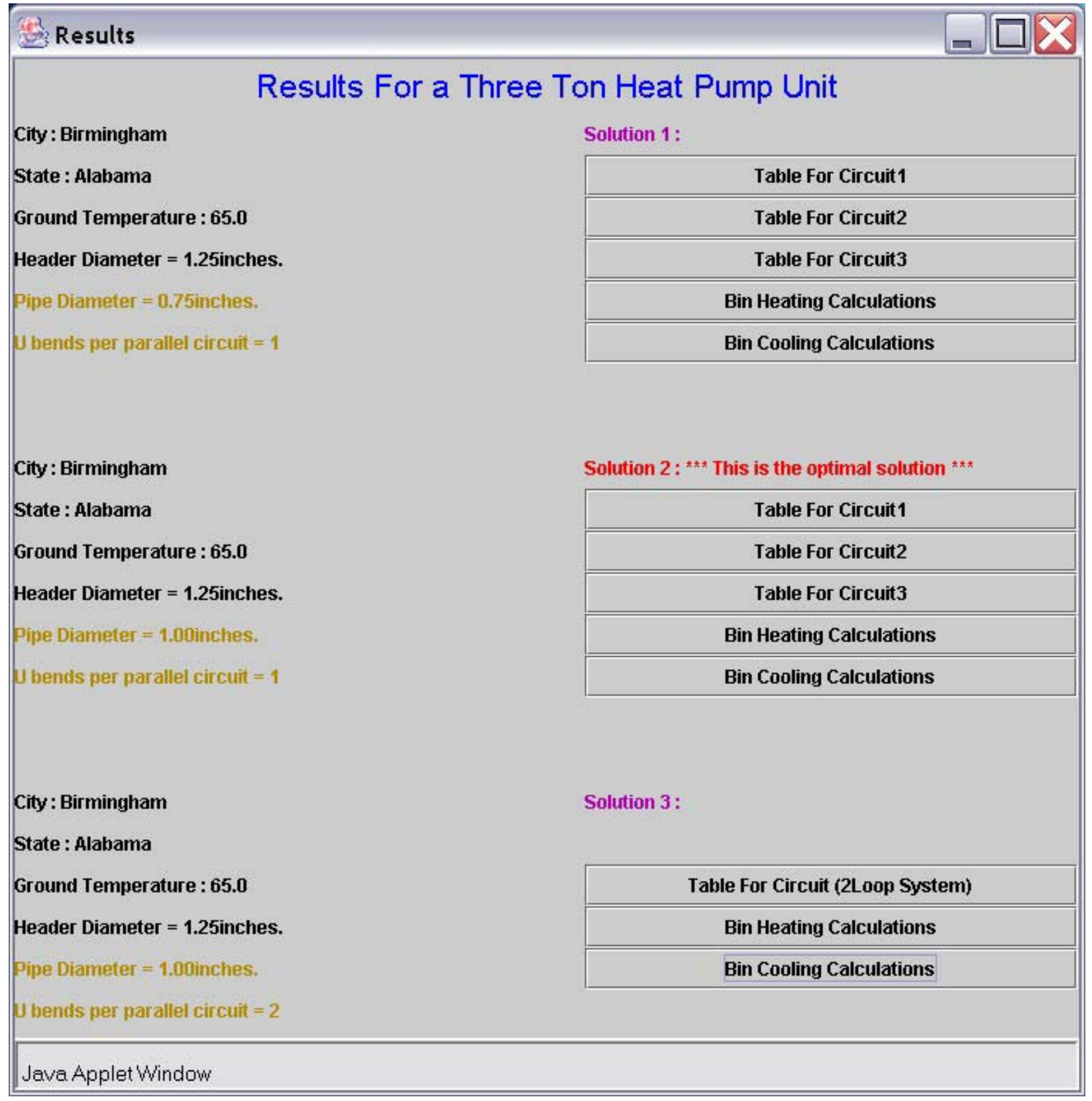

\section{Figure 6-2: Graphical user interface of results page}

These calculations for various pipe sizes is performed using the Table 4-8 and another couple of computations are carried out with series loops to exactly find out the difference in energy consumption in KWh. The labels highlighted in Figure 6-2 indicate the parameters being changed to compute the circulator pump energy and the solution in red is the optimal solution. 
Rectangular boxes below the solution labels are buttons that navigate to the bin calculations and the head loss calculations for each circuit with all the fittings included. One assumption was made to limit the header size to $80 \mathrm{ft}$.

Head loss calculation for the "Solution 1" is shown in Figure 6-3. It consists of a tabbed pane with labels in bright green color. The three tabs account for the details of ground loop head loss, circuit diagram of the ground loop and the specifications including the flow rate, bore lengths recommended, user input details and operational times. For every ton of GCHP capacity, there is a need to have a flow rate of three gallons per minute. Diagram Tab includes the schematic of the ground loop and the sections of the loop are marked in color with a number corresponding to it. The Figure 6-4 shows the ground loop arrangement and similarly the numerical values are shown in Figure 6-5. 


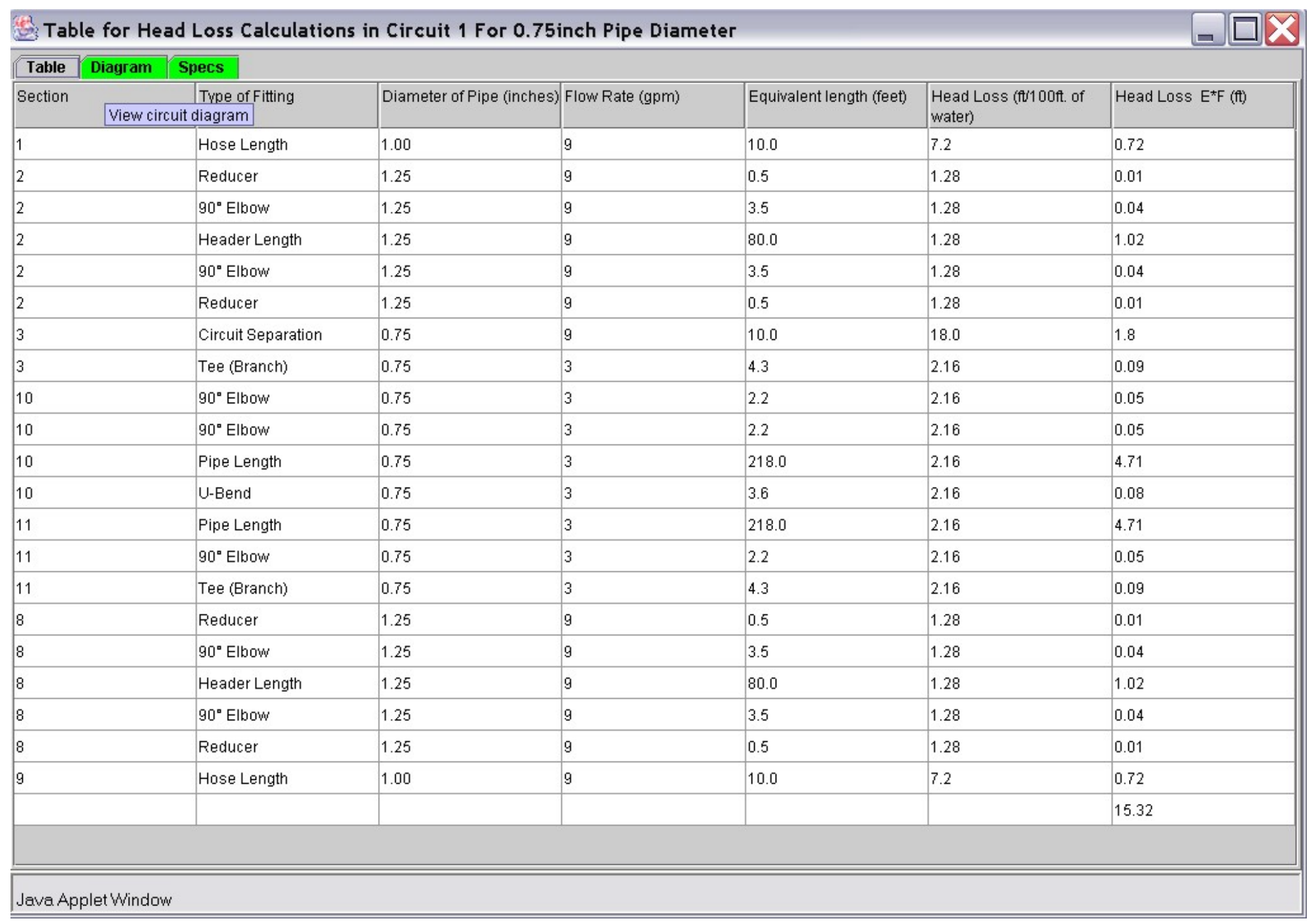

Figure 6-3: Head loss calculation in the piping loop 


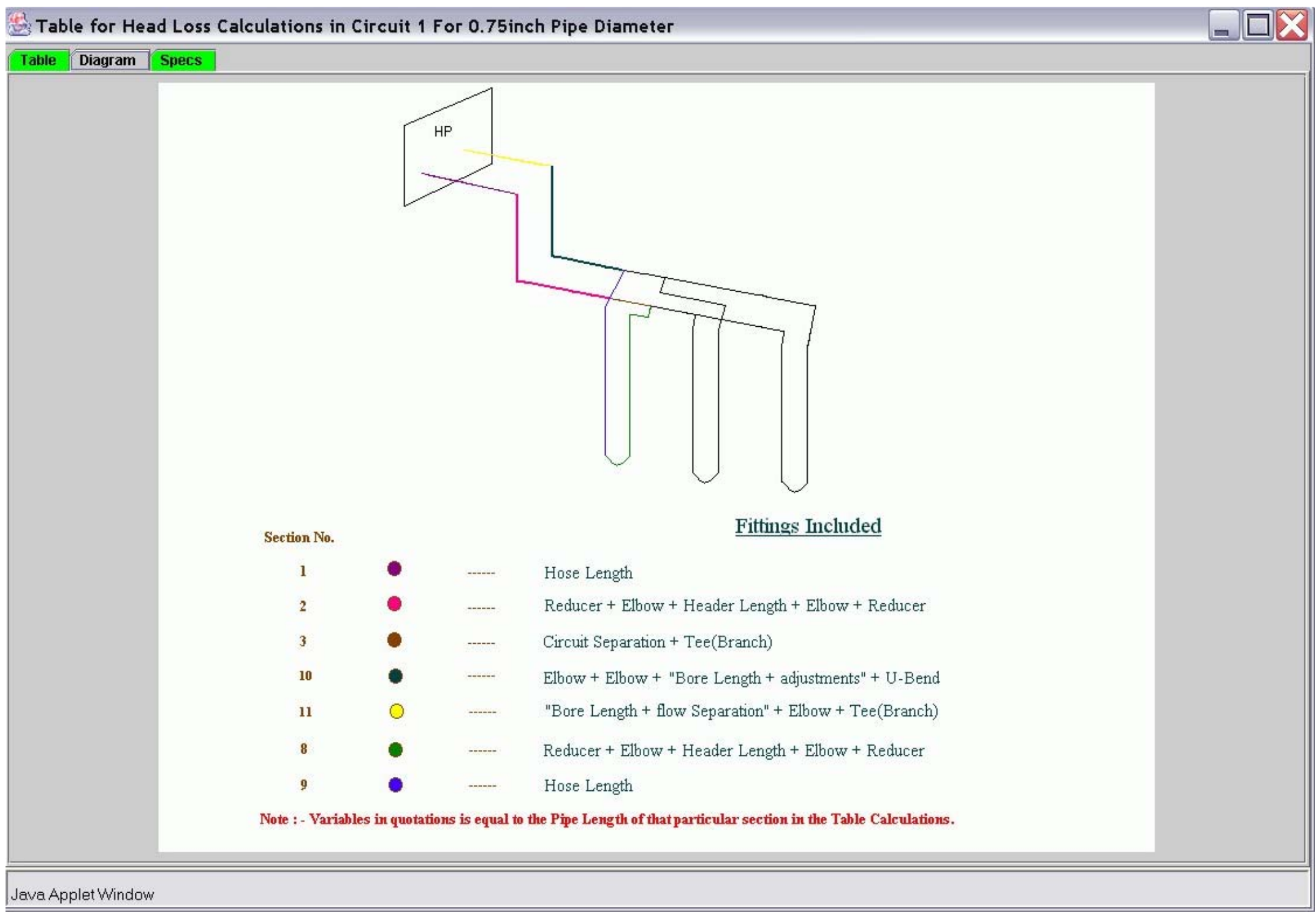

Figure 6-4: Screen Capture of the ground loop arrangement 
Figure 6-5 gives the results in the form of a summary and also mentions about the ground properties depending on the Fourier number. It also separates the results and is self explanatory. Bin methods for calculating the annual energy consumption are provided in Figures 6-6 and 6-7 respectively. The last columns in both these figures represent the operational times of the GCHP throughout the season. So it is implied that the circulator should run to extract from or dissipate heat energy to the ground loop as long as the heat pump operates. Therefore, the power input to the circulator pump in $\mathrm{KW}$ required to operate the ground loop multiplied by the hours of compressor operation yields the circulator pump energy. The pump energy consumption is estimated on a yearly basis and is represented according to the loop arrangement and buried pipe diameter as follows:-

P1 - parallel loop with 3/4" diameter pipe and one U-bend per parallel circuits.

P2 - parallel loop with 1" diameter pipe and one U-bend per parallel circuits.

P3 - combination of series and parallel loop with 1" diameter and two U-bends per parallel circuit.

S1 - series loop with $3 / 4 "$ diameter pipe.

S2 - series loop with 1" diameter pipe.

The variation in the circulator pump energy in the form a histogram is shown in Figure 6-8. 


\begin{tabular}{|c|c|c|c|c|c|c|c|}
\hline Tab & le for Head Loss & s Calculations ir & & & & & $\square \square \ll$ \\
\hline Table & Diagram Specs & & & & & & \\
\hline User Inpt & it :--.- & & HeatPump Details :--- & & & & \\
\hline Location & & $=$ Birmingham & System Capacity & $=3$ ton & & & \\
\hline State & & $=$ Alabama & Pipe Diameter & $=1.00 \mathrm{incl}$ & & & \\
\hline Soil & & $=$ Wet Sand & Circuit Flow Rate & $=3.0 \mathrm{gpm}$ & & & \\
\hline Heating L & oad & $=40000.0 \mathrm{Btuhr}$ & Total Flow Rate & $=9 \mathrm{gpm}$ & & & \\
\hline Cooling $L$ & oad & $=36000.0 \mathrm{Btuhr}$ & Hours of Cooling Required & $=1201$ & & & \\
\hline Undisturt & bed Ground Temp & $=65.0^{\circ} \mathrm{F}$ & Hours of Heating Required & $=884$ & & & \\
\hline Winter In & door Design Temp & $=70.0^{\circ} \mathrm{F}$ & Pump running time (Cooling Season) & $=22 \%$ & & & \\
\hline & & & Pump running time (Heating Season) & $=25 \%$ & & & \\
\hline Piping Lo & Iop Results (Circuit 1) : & $:--$ & Energy Optimization :---- & & & & \\
\hline Actual Fo & urier Number & $=41970.25$ & Parallel Loop Combination :- & & & & \\
\hline Thermal & Resistance of ground & $=0.76$ & Head Loss in Circuit 1 & & $=$ & $7.17 \mathrm{ft} . /(100 \mathrm{ft}$ of water $)$ & \\
\hline Bore Len & gth for Cooling & $=624 \mathrm{ft}$. & Head Loss in Circuit 2 & & $=$ & $7.77 \mathrm{ft} . /(100 \mathrm{ft}$. of water) & \\
\hline Bore Len & gth for Heating & $=526 \mathrm{ft}$. & Head Loss in Circuit 3 & & $=$ & $7.99 \mathrm{ft.} /(100 \mathrm{ft}$. of water $)$ & \\
\hline Correcte & d Bore Length & $=624 \mathrm{ft}$. & Energy required to run water pump (So & Iution 1) & $=$ & 269.74 Kwh. (yearly) & \\
\hline Bore Len & gth Per Ton & $=208 \mathrm{ft}$. & Energy required to run water pump (So & (ution 2) & $=$ & 118.31 Kwh. (yearly) & \\
\hline & & & Energy required to run water pump (Sc & Iution 3) & $=$ & 204.77 Kwh. (vearly) & \\
\hline & & & Series Loop Combination :- & & & & \\
\hline & & & Energy required to run water pump ( 0 . & 5in.pipe dia) & $=$ & 3984.14 Kwh. (yearly) & \\
\hline & & & Energy required to run water pump (1. & Din.pipe dia) & $=$ & 1150.06 Kwh. (yearly) & \\
\hline
\end{tabular}

Figure 6-5: User interface showing the specifications 


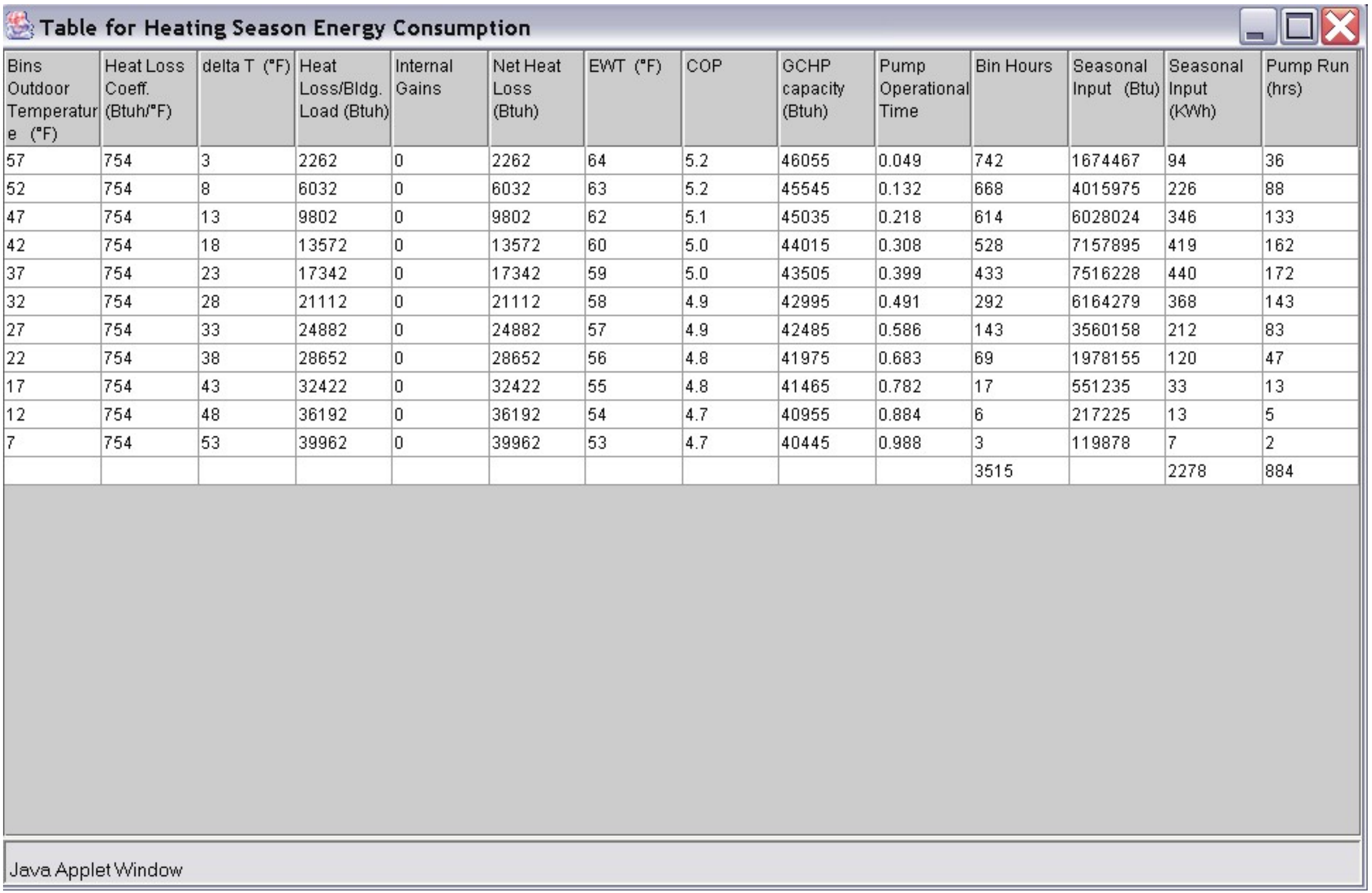

Figure 6-6: Bin method for heating season 


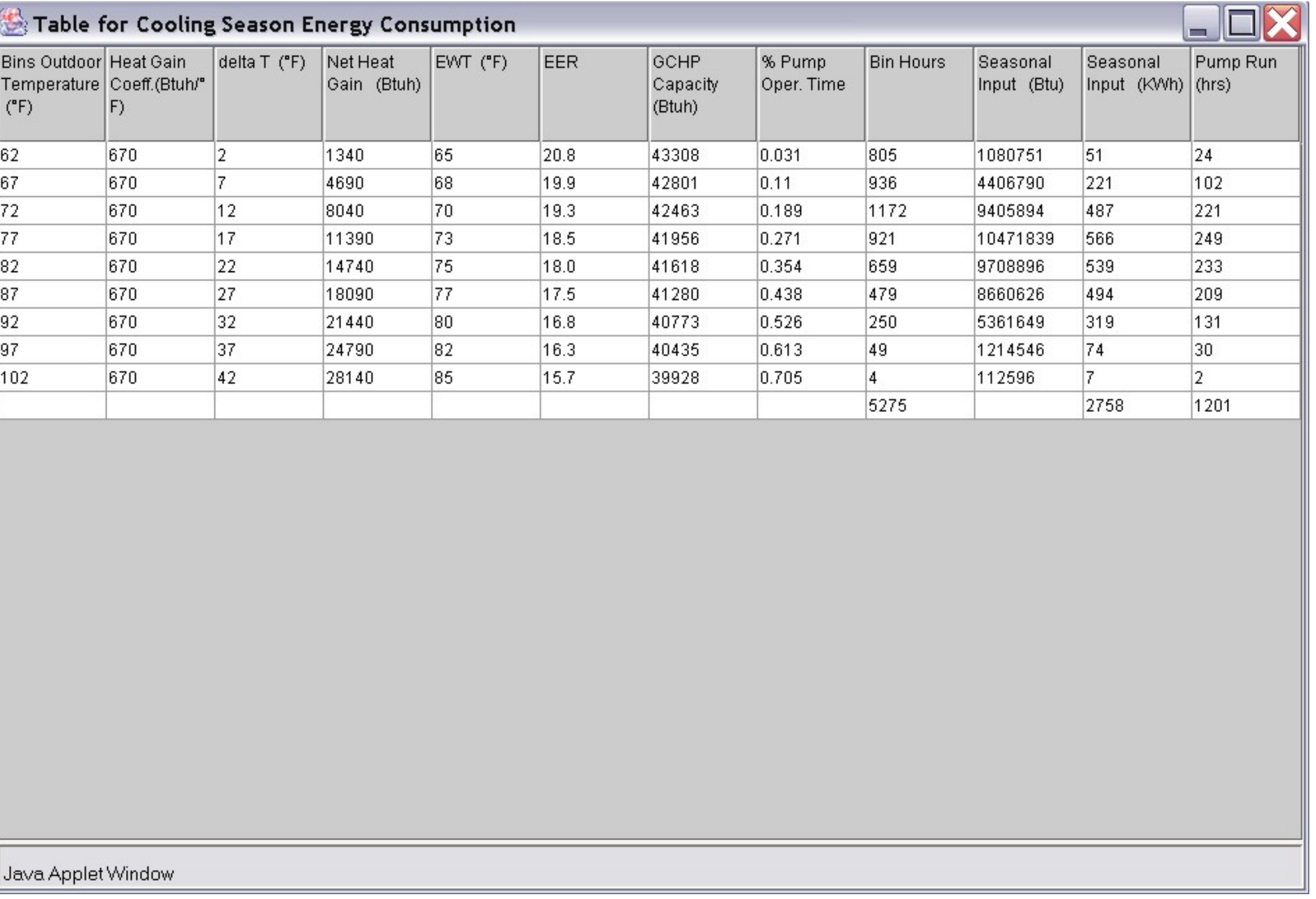

Figure 6-7: Bin method for cooling season 


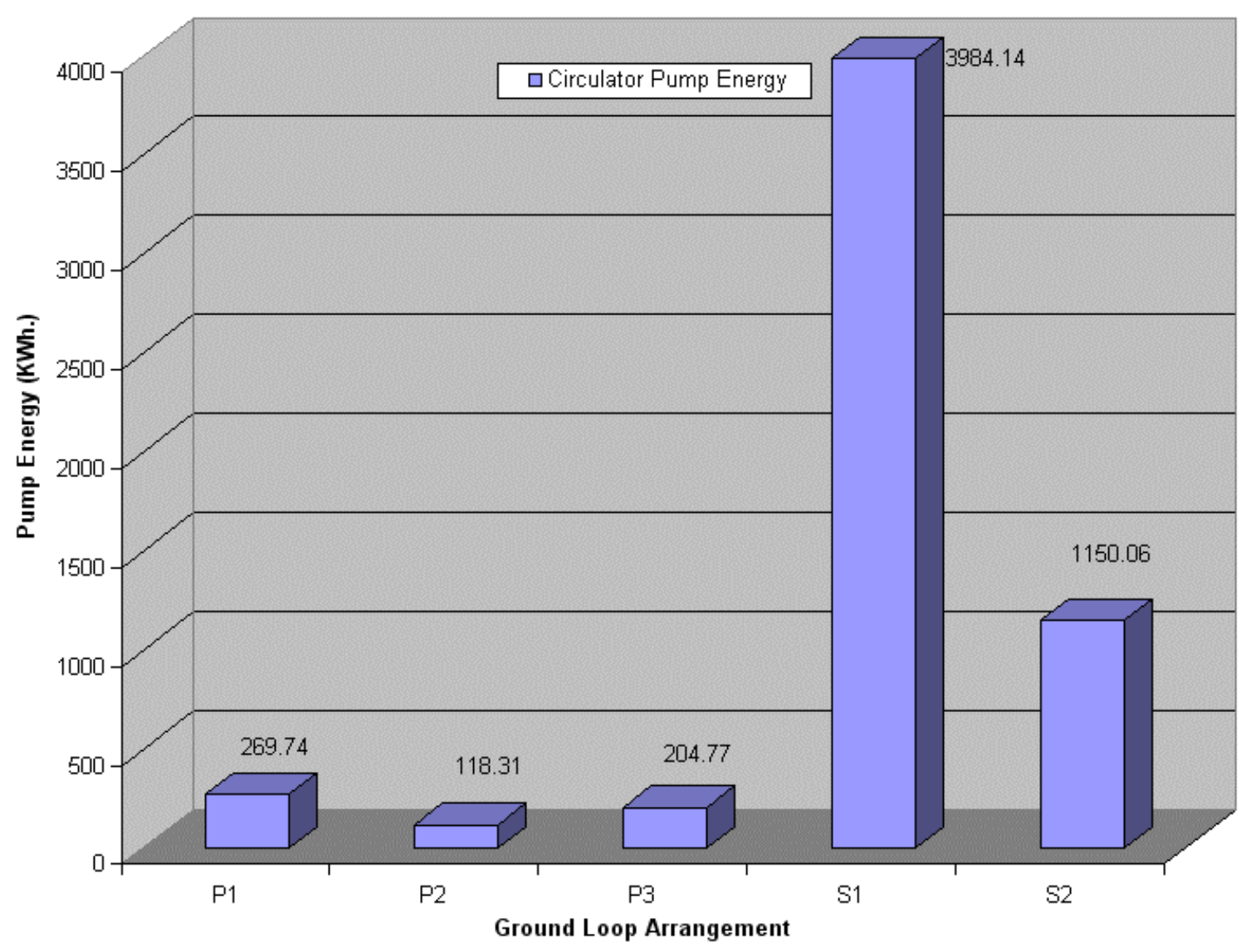

Figure 6-8: Variation of pump energy with pipe size and loop arrangement

\section{1: Verification}

Verification is the process of determining that the system actually works and fulfills the requirements for which it was intended. The validation of the tool should be verified to check that it performs a given task well and is usable by all means. Results obtained from the software tool are verified with the economic analysis of a residence provided in the ground and water source heat pumps manual. As shown in Figures 6-6 and 6-7, the hours of compressor operation for heating and cooling are found to be 884 and $1201 \mathrm{hrs}$. It may be argued that the locations are 
different, so how is there a scope for comparison? The solution is that these places experience the same undisturbed ground temperature and are just a few miles apart besides being in the same state with only a few hours of difference in heating and cooling. The operational times for Tuscaloosa, AL are 800 and $100 \mathrm{hrs}$ for heating and cooling respectively. Bore length required for the ground loop obtained from the software tool is found out to be $208 \mathrm{ft} /$ ton of cooling and those compared to the values given in Table 4-4 turned out to be $200 \mathrm{ft}$. /ton of cooling. These values are tabulated and arranged in the Table 6-1.

Table 6-1: Comparison of results

\begin{tabular}{|c|c|c|}
\hline Parameter estimated & This Research & GWSHP manual \\
\hline Pump run (winter) in hours & 884 & 800 \\
\hline Pump run (summer) in hours & 1201 & 1100 \\
\hline Length of Bore /Ton. (feet) & 208 & 200 \\
\hline
\end{tabular}




\section{Chapter 7: Conclusions and Future Work}

\section{1: $\underline{\text { Conclusions }}$}

The pump run and the bore length values obtained from this research using the Java program are higher than the GWSHP manual in heating and cooling. Results obtained are within $12 \%$ of the desired range. This is because the internal solar gains were not taken into account that could have provided passive heating in winter thereby decreasing the input energy and the hours of operation. On the other hand, multiple measure methods such as hour-by-hour method that deal with the hourly variations of solar and cooling loads were not considered in summer.

Java turned out to be a useful tool and is user-friendly with features that make programs to run on the internet. This thesis provides an algorithm to estimate the annual energy consumption for the cooling season using the simplified bin method, which takes the cloudiness and sunshine factor into account. 


\section{2: Future Work}

The scope of this tool can be extended so as to predict the exact requirements of residences in building technology using HVAC principles and some of them include:-

- To enhance the accuracy of the software tool by performing a dynamic analysis for cooling.

- To include various other parameters such as pipe types, antifreeze solutions etc. for enhancing the scope of this tool.

- To perform a cost analysis and thereby give an economic comparison based on other alternative fuels. 


\section{References}

[1] Steve Kavanaugh, Rafferty, "Designing Vertical Ground-Coupled Heat Pumps with GchpCalc 4.0”. [On-line].

Available: http://www.geokiss.com

Available: http://www.geokiss.com/software/Ver40_Instructions.PDF

[2] Kavanaugh, S.P., "Ground and Water Source Heat Pumps", International Ground Source Heat Pump Association (IGSHPA). Stillwater, OK, 1992

[3] Joe Hoggle, “GHP Piping Design”. [On-line].

Available: http://www.geokiss.com/gsoftware.htm

[4] American Society of Heating, Refrigerating and Air-Conditioning Engineers (ASHRAE) Handbook, “1999 HVAC Applications”, I-P Edition, pp. 31.1-31.26, 1999.

[5] Hannifan M.J, Joseph King, "Geothermal Heat Pump Options Manual”, Heckman Bindery Inc., pp. 14-80, 1987. 
[6] Yavuzturk, Dissertation "Modeling of Vertical Ground Loop Heat

Exchangers for GSHP systems", Ph.D. Dissertation, Oklahoma State University, 1999. [On-line]. Available:

http://www.mae.okstate.edu/Faculty/spitler/pdfs/Yavuzturk thesis.pdf

[7] McQuiston F.C, Parker J.D, Spitler J.D, "Heating, Ventilating and AirConditioning", $5^{\text {th }}$ Edition, New York: John Wiley \& Sons, Inc., pp. 89-135, pp. 191-361, 1998.

[8] Elite Software, "ECA (Earth Coupled Pipe Loop Sizing) program". [On-line]. Available: http://www.elitesoft.com/web/hvacr/ecaw.html

[9] Thermal-Works Software, "GeoCalc program". [On-line] Available: http://www.iserv.net/ thermwks

[10] Geothermal Bore Technologies, Inc., "Ground Loop Design”. [On-line] Available: http://www.geoclip.com

[11] IGSHPA, “GLHEPRO program”. [On-line]. Unavailable: http://www.igshpa.okstate.edu/Publications/catalog/1998/software.html

[12] DotCalm Computing, "History of Computing". [On-line] Available: http://www.dotcalmcomputing.com/history.htm 
[13] Jupitermedia Corporation, “Assembly Language”. [On-line]

Available: http://networking.webopedia.com/TERM/A/assembly language.html

[14] Sun Microsystems, "The Java Tutorial”. [On-line]

Available : http://java.sun.com/docs/books/tutorial

[15] Ivor Horton, “Beginning Java 2”, Wrox Press Limited, pp. 1-31, pp. 159-267, 2000.

[16] European Interactive Directories, “Key Java Features”. [On-line] Available: http://www.euroyellowpages.com/exhibitn/javafeat.html

[17] Bingul Hasan, Thesis "Computer modeling of Earth coupled heat pumps", Master's Thesis, West Virginia University, 1990.

[18] U.S. Department of Energy, "GSHP applied to federal facilities", $2^{\text {nd }}$ Edition. [On-line]. Available: http://www.pnl.gov/fta/gshp/gshp.htm

[19] FHP manufacturing company, "GS Series - 60 hertz. Water Source Heat Pumps Data Sheets". [On-line]. Available: http://www.fhp-mfg.com/ftp/pub/gsip60.pdf

[20] ASHRAE Handbook, “1997 Fundamentals”, I-P Edition, pp. 26.1-27.14, pp. 30.130.30, pp. 33.1-33.6, 1997.

[21] ASHRAE Handbook, “1976 Systems”, pp. 43.1-43.18, 1976. 
[22] Peter J. Lunde, "Solar Thermal Engineering", New York: John Wiley \& Sons, Inc., pp. 87-89, 1979.

[23] McQuiston F.C. and Parker J.D., "Principles of HVAC", ASHRAE Inc., pp. 4.14.22, pp. 8.1-8.20, 2001.

[24] Ambrose E.R., "Heat Pumps and Electric Heating”, New York: John Wiley \& Sons, Inc., 1979.

[25] Air Force Manual 88-29, "Facility Design and Planning - Engineering Weather Data”, 1978.

[26] McQuiston F.C. and Spitler P.E., "Load Calculation Manual", $2^{\text {nd }}$ Edition, ASHRAE Inc., pp. 3.1-8.8, 1988.

[27] Bell \& Gossett Hydronic Specialties Centrifugal Pumps, "Series 1522 pumps", Thermoflo Equipment Co., Inc.

[28] Collie M.J., "Heat Pump Technology for Saving Energy”, Noyes Data Corp., 1979.

[29] Steven W. Carlson, P.E., "Monitored Desuperheater Performance in Residential Ground-Source Heat Pumps". [On-line]. Available: www.cdhenergy.com

[30] GSHP Design, "Residential Design Recommendations", [On-line] Available: http://www.geokiss.com/res-design/GSHPDesignRec2.pdf 


\section{Appendix B}

The source code can be seen in this section based on chronological order and the first letter with which the program class name starts. The author chose to put it that way only to make it simple for the user to look at the code the easy way.

\section{Source code for BoreLengthCalculation.java}

import java.awt.*;

import java.lang.*;

import java.lang.Math.*;

public class BoreLengthCalculation \{

$/ *$ The Cooling capacity of the heat pump is $=$ hpCapacity.

Power Input to the heat pump is = wattage.

The Water heating capacity of the Desuperheater is assumed to be $10 \%$ of heating capacity.

Based on ground water temperature in Morgantown, WV, U.S.A

enteringWaterTemp (Undisturbed ground Temperature $+/-(20 / 12)^{\circ} \mathrm{F}$ )

leavingWaterTemp (Undisturbed ground Temperature $\left.+/-(8)^{\circ} \mathrm{F}\right)^{*} /$

static String soil, diameter, pipeType, noOfParallelCircuits, tableNo;

String[] soilStr = \{"Dense Rock", "Rock", "Wet Clay", "Wet Sand", "Damp Clay", "Damp Sand"\};

static int boreLength, coolingLength, heatingLength, boreLengthPerTon;

static double actualFourierNo, thermalResistanceOfGround;

double pipeThermalResistance, pipeDiameter, conductivity, diffusivity;

double term1 Numerator, term2Numerator, termDenominator, shortCircuitFactor;

double tenYrFourierNo, seasonalFourierNo, time_tenYrs $=3650.0$, time_halfSeason $=180.0$;

double[ $]$ conductivityArray $=\{2.0,1.6,1.4,1.2, \overline{1.0}, 0.8\}$;

double[] diffusivityArray $=\{1.2,1.0,0.75,0.7,0.5,0.4\}$;

boolean flag = false;

HeatPumpValues hpvt $=$ new HeatPumpValues();

PumpEnergyFor2LoopSystem pe2ls = null;

PumpEnergyFor3LoopSystem pe31s = null;

PumpEnergyFor4LoopSystem pe4ls = null;

SelectAppropriateHeatPumpSystem sahps = new SelectAppropriateHeatPumpSystem();

//constructor

public BoreLengthCalculation(String temp1, String temp2, String temp3, String soil)\{

this.diameter $=$ temp 1

this.pipeType $=$ temp2;

this.noOfParallelCircuits = temp3;

this.soil = soil; 


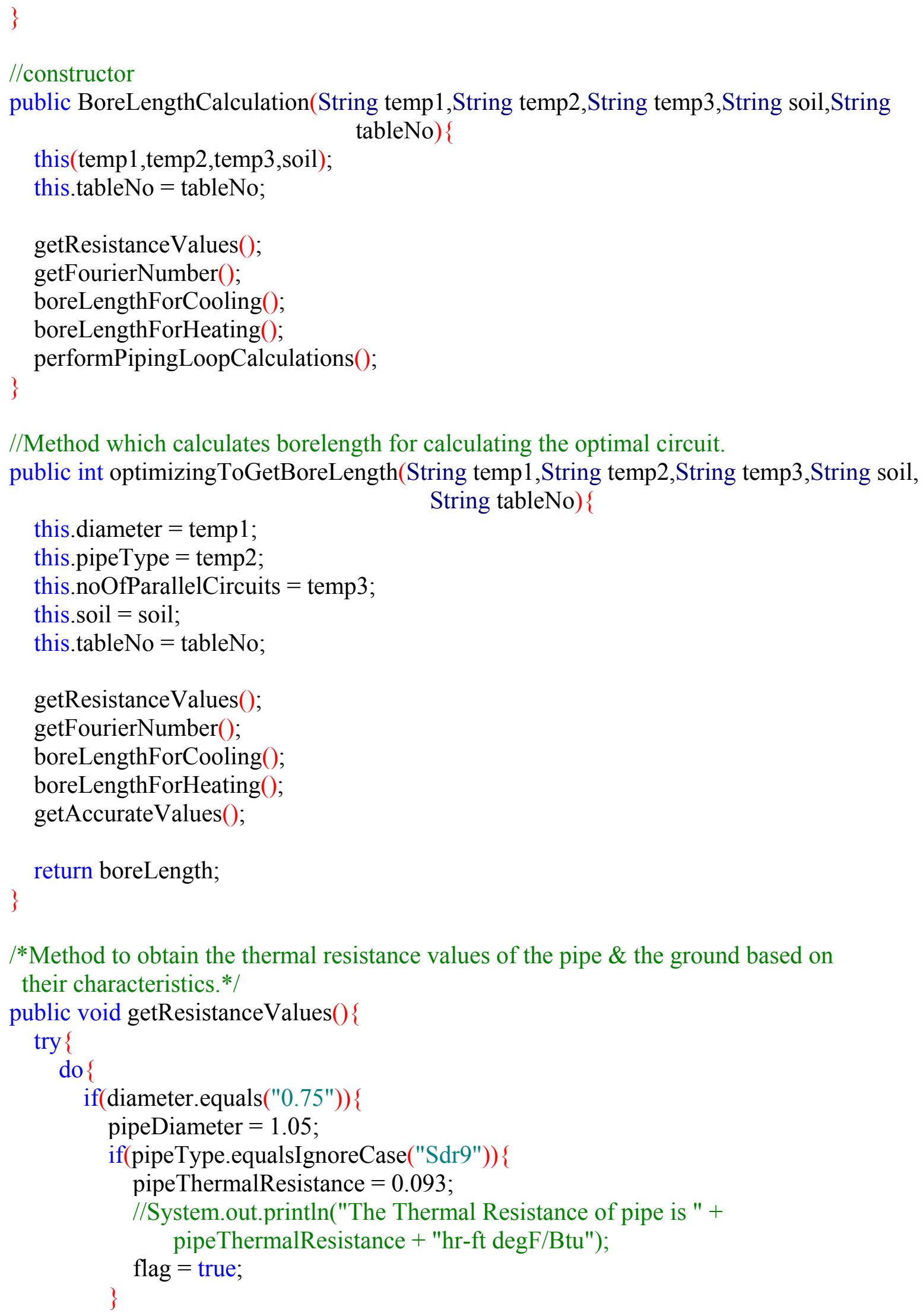

//Method which calculates borelength for calculating the optimal circuit. public int optimizingToGetBoreLength(String temp1,String temp2,String temp3,String soil,

this.diameter $=$ temp 1 ; String tableNo) \{ 


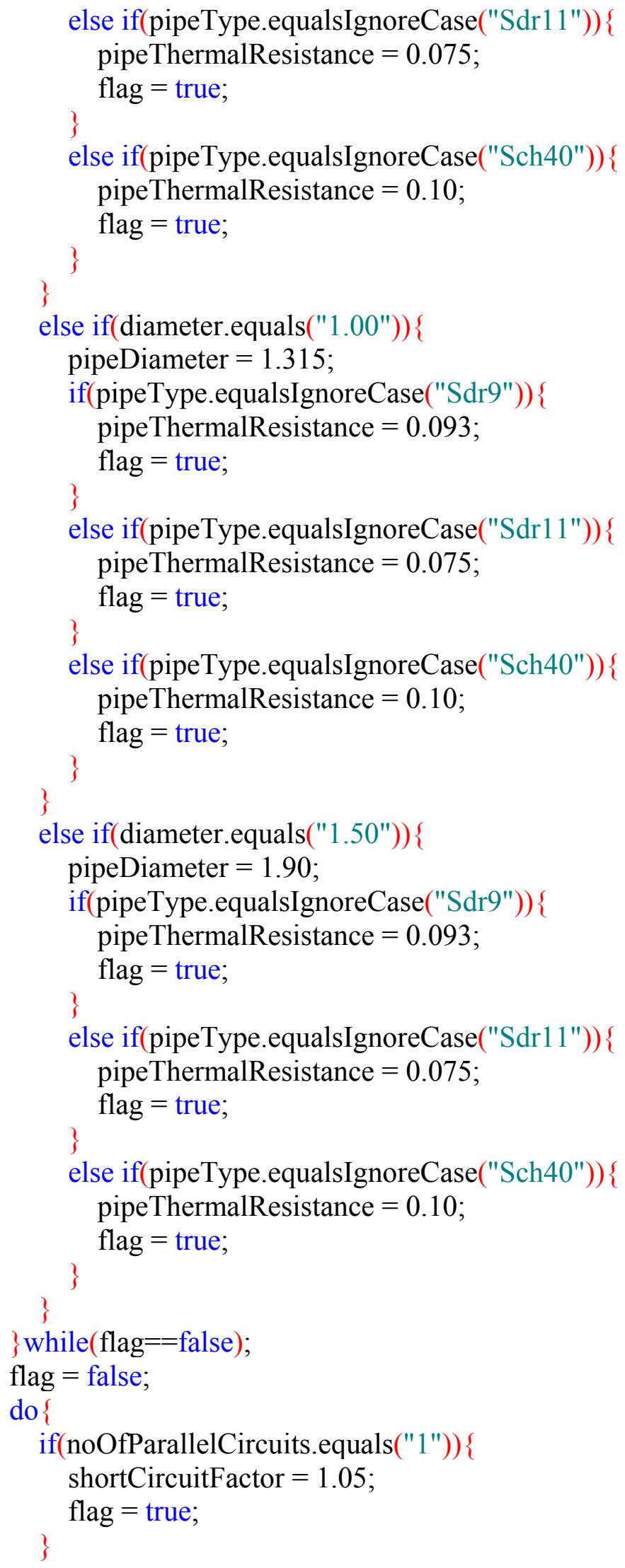




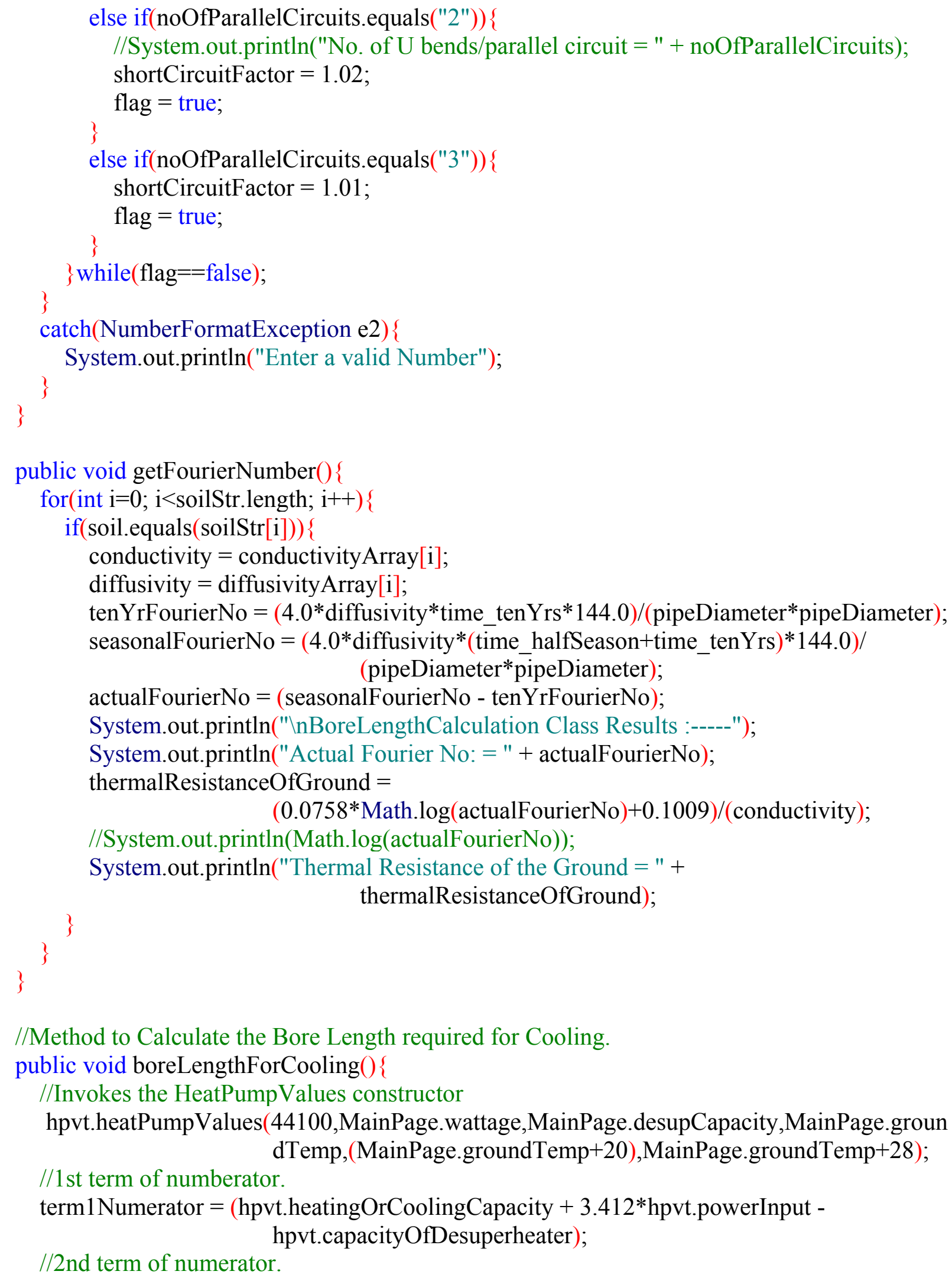

//Method to Calculate the Bore Length required for Cooling. public void boreLengthForCooling () \{

//Invokes the HeatPumpValues constructor

hpvt.heatPumpValues(44100,MainPage.wattage,MainPage.desupCapacity,MainPage.groun dTemp,(MainPage.groundTemp+20),MainPage.groundTemp+28);

$/ / 1$ st term of numberator.

term1 Numerator $=($ hpvt.heatingOrCoolingCapacity $+3.412 *$ hpvt.powerInput hpvt.capacityOfDesuperheater);

//2nd term of numerator. 


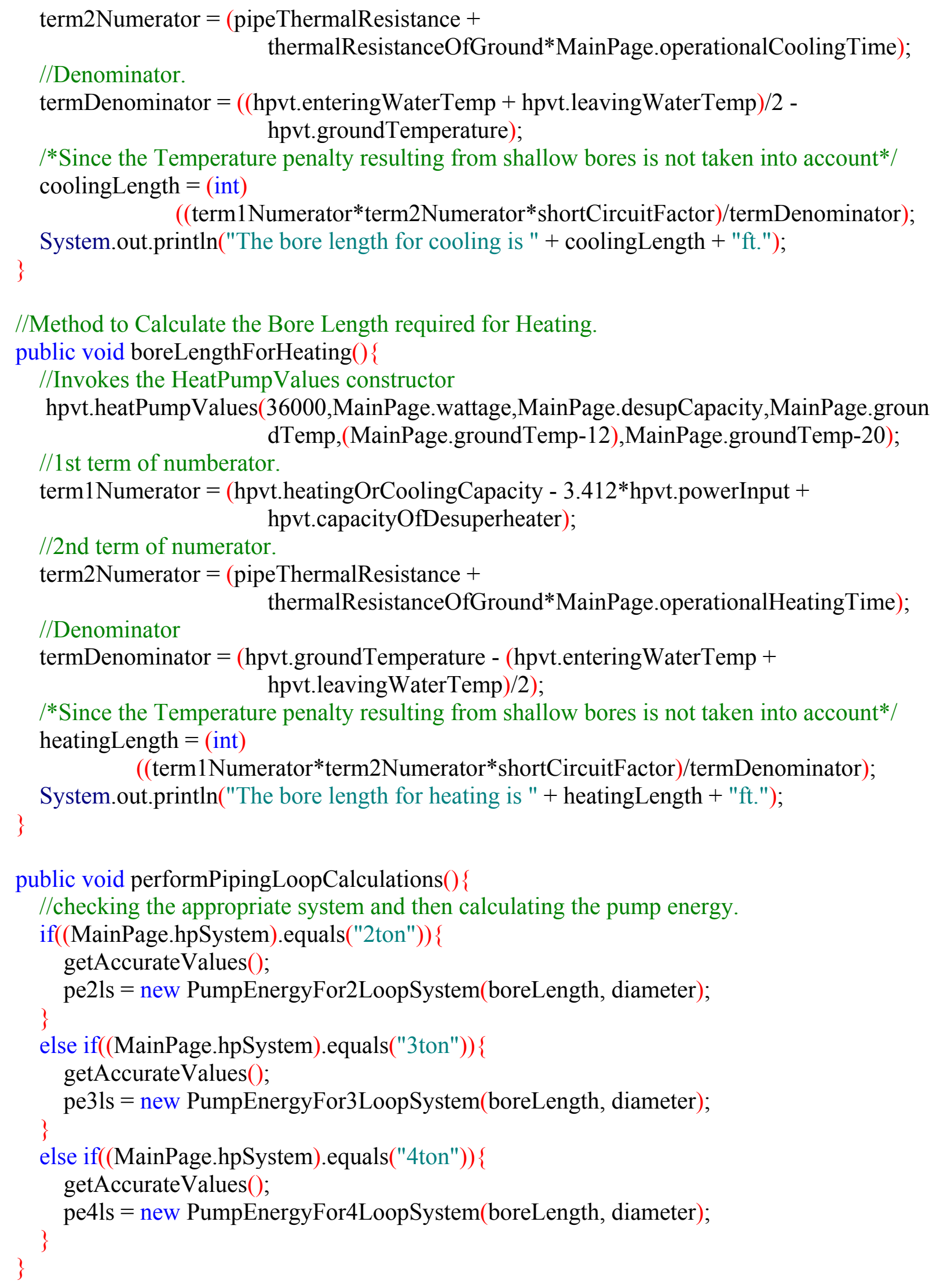


public void getAccurateValues() \{

//checking the appropriate system and then calculating the pump energy.

if((MainPage.hpSystem).equals("2ton")) \{

//calculate approximate bore length value

if(heatingLength $>$ coolingLength $)\{$

boreLength $=$ heatingLength;

\}

else \{

boreLength $=$ coolingLength;

\}

boreLength $=($ boreLength-boreLength $\% 2)$;

\}

boreLengthPerTon $=$ boreLength $/ 2$;

else if((MainPage.hpSystem).equals("3ton")) \{

//calculate approximate bore length value

if(heatingLength $>$ coolingLength $)\{$

boreLength = heatingLength;

\}

else \{

boreLength $=$ coolingLength;

\}

if(tableNo.equals("1.00t1_u2") || tableNo.equals("Solution 3 : ")) \{

boreLength $=($ boreLength-boreLength $\% 4)$;

boreLengthPerTon $=$ boreLength $/ 4$;

\}

else \{

boreLength $=($ boreLength-boreLength $\% 3)$;

boreLengthPerTon $=$ boreLength $/ 3$;

\}

else if((MainPage.hpSystem).equals("4ton")) \{

//calculate approximate bore length value

if(heatingLength $>$ coolingLength $)\{$

boreLength $=$ heatingLength;

\}

else \{

\}

boreLength = coolingLength;

if(tableNo.equals("1.50t1_u3") || tableNo.equals("Solution 3 : ")) \{

boreLength $=($ boreLength-boreLength $\% 6)$;

boreLengthPerTon $=$ boreLength $/ 6$;

\}

else \{

boreLength $=($ boreLength-boreLength $\% 4)$;

boreLengthPerTon $=$ boreLength $/ 4$; 


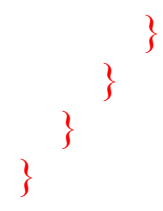




\section{Appendix H}

\section{Source code for HeatPumpValues.java}

public class HeatPumpValues \{

double heatingOrCoolingCapacity, powerInput, capacityOfDesuperheater, groundTemperature, enteringWaterTemp, leavingWaterTemp,

conductivity, diffusivity;

//Constructor with no arguments.

HeatPumpValues ()\{

\}

$/ *$ Constructor with six arguments to take the values of Cooling Capacity, Power

Input, Capacity of Desuperheater, Ground Temperature and Entering \& Leaving

Water Temperatures.*/

public void heatPumpValues(double hocc, double pi, double whc, double gt, double ewt, double lwt) \{

heatingOrCoolingCapacity $=$ hocc;

powerInput $=\mathrm{pi}$;

capacityOfDesuperheater $=$ whc;

groundTemperature $=\mathrm{gt}$;

enteringWaterTemp $=$ ewt;

leavingWaterTemp = lwt; 


\section{Appendix M}

Source code for MainPage.java

import java.io.*;

import java.util.*;

import javax.swing.*;

import javax.swing.table.*;

import javax.swing.border.*;

import java.lang.*;

import java.awt.*;

import java.awt.event.*;

import java.text.*;

public class MainPage extends JFrame implements ActionListener \{

JButton optimize;

JPanel northPanel, centerPanel, southPanel;

JPanel centerPanel1, centerPanel2, centerPanel3;

JPanel grid1, grid2, grid3;

JLabel title;

JTextField dhl, dcl, gt, widt, sidt, wot, sot;

JMenuBar mbar;

JMenu fileMenu, toolsMenu;

JMenuItem quitItem, addItem;

static Hashtable ht, ct, misc;

static Vector hv, cv, ov;

static Choice soilType, cityNames;

protected static String info, hpSystem;

protected static Choice stateChoice $=$ new Choice () ;

protected static String[] diaOfPipe $=\{" 0.75 ", " 1.00 "$, "1.50" $\}$;

protected static String[] typeOfPipe $=\{"$ Sdr9","Sdr11","Sch40" $\}$;

protected static String[] uBends = \{"1","2","3"\};

protected static String[] states $=$

\{"Alabama","Alaska","Arizona","Arkansas","California","Colorado",

"Connecticut","Delaware","District of Columbia","Florida",

"Georgia","Hawaii","Idaho","Illinois","Indiana","Iowa",

"Kansas","Kentucky","Louisiana","Maine","Maryland","Massachusetts",

"Michigan","Minnesota","Mississippi","Missouri","Montana",

"Nebraska","Nevada","New Hampshire","New Jersey","New Mexico",

"New York","North Carolina","North Dakota","Ohio","Oklahoma",

"Oregon","Pennsylvania","South Carolina","South Dakota",

"Tennessee","Texas","Utah","Vermont","Virginia","Washington",

"West Virginia","Wisconsin","Wyoming"\}; 


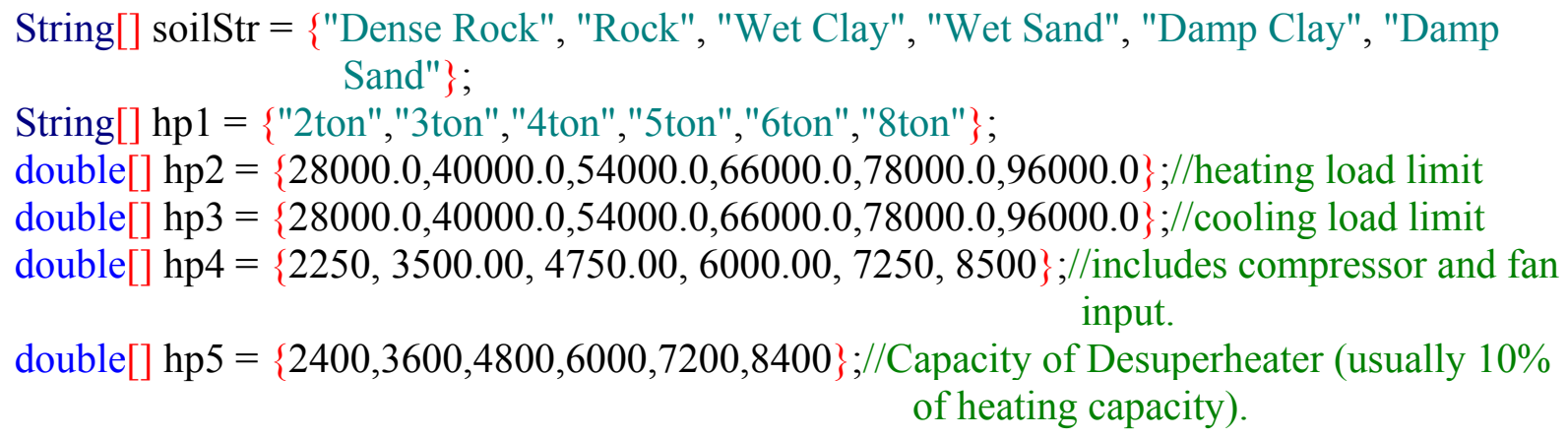

\section{//User input variables}

protected static double heatingLoad,coolingLoad,groundTemp,summerInTemp,winterInTemp; protected static double hpCapacity,wattage, desupCapacity;

protected static int heatLossPerDegree, heatGainPerDegree;

protected static double operationalHeatingTime, operationalCoolingTime;

protected static String soil, tmpCity, tmpState, tmpStr="", check="";

double tmp2, fc;

int tmp1, count $=0$, error $=0$;

static int sodt, wodt, sunshine;

static double summerSunshinePercent;

ResultsFor2TonSystem rf2ts = null;

ResultsFor3TonSystem rf3ts = null;

ResultsFor4TonSystem rf4ts = null;

HeatingEnergyCalculations hec $=$ null;

CoolingEnergyCalculations clc = null;

SelectAppropriateHeatPumpSystem sahps = new SelectAppropriateHeatPumpSystem();

//Constructor

public MainPage(Hashtable ht1, Hashtable ct1, Hashtable other, Vector v1, Vector v2, Vector v3, Choice cityNames 1) throws IOException \{

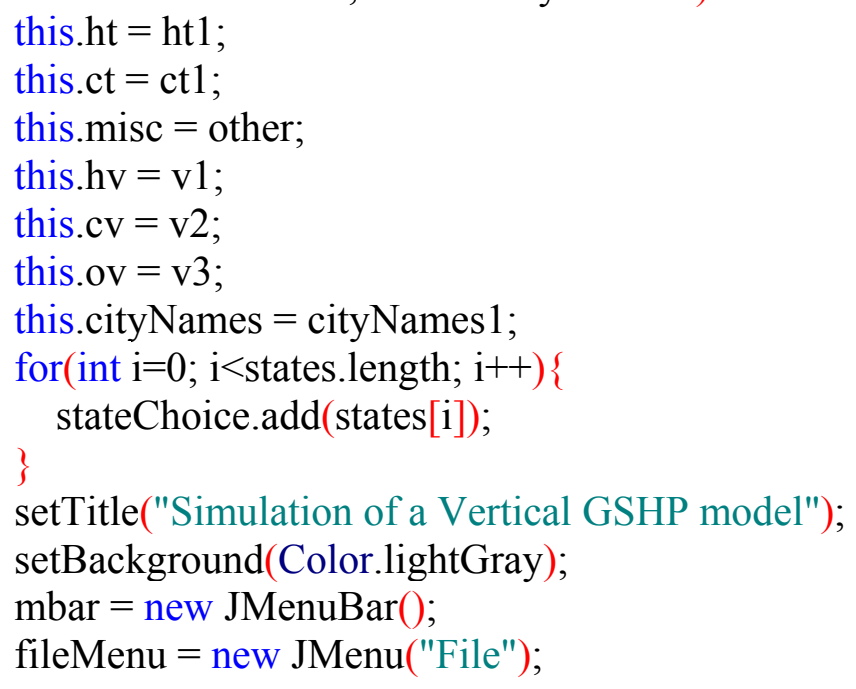




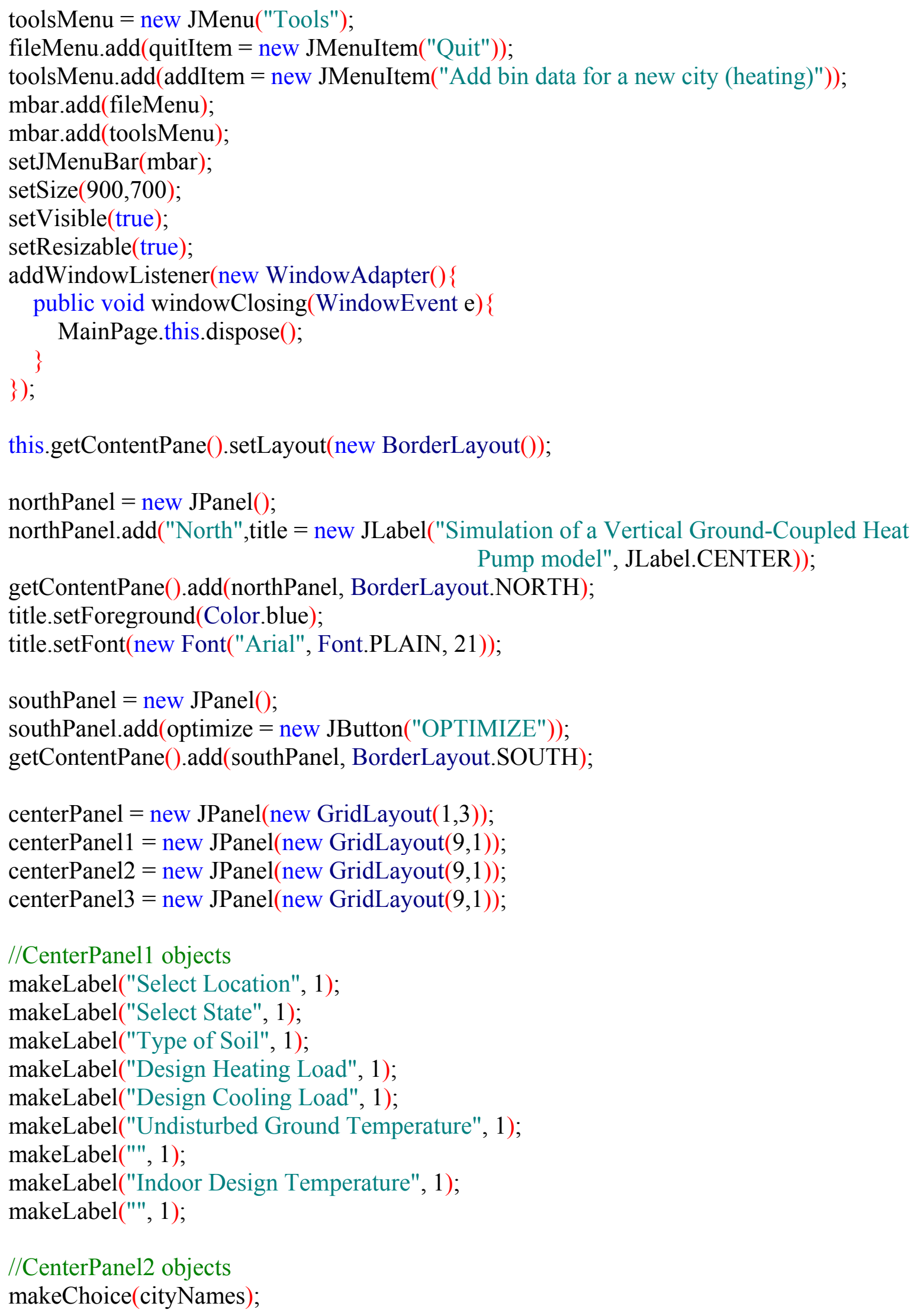




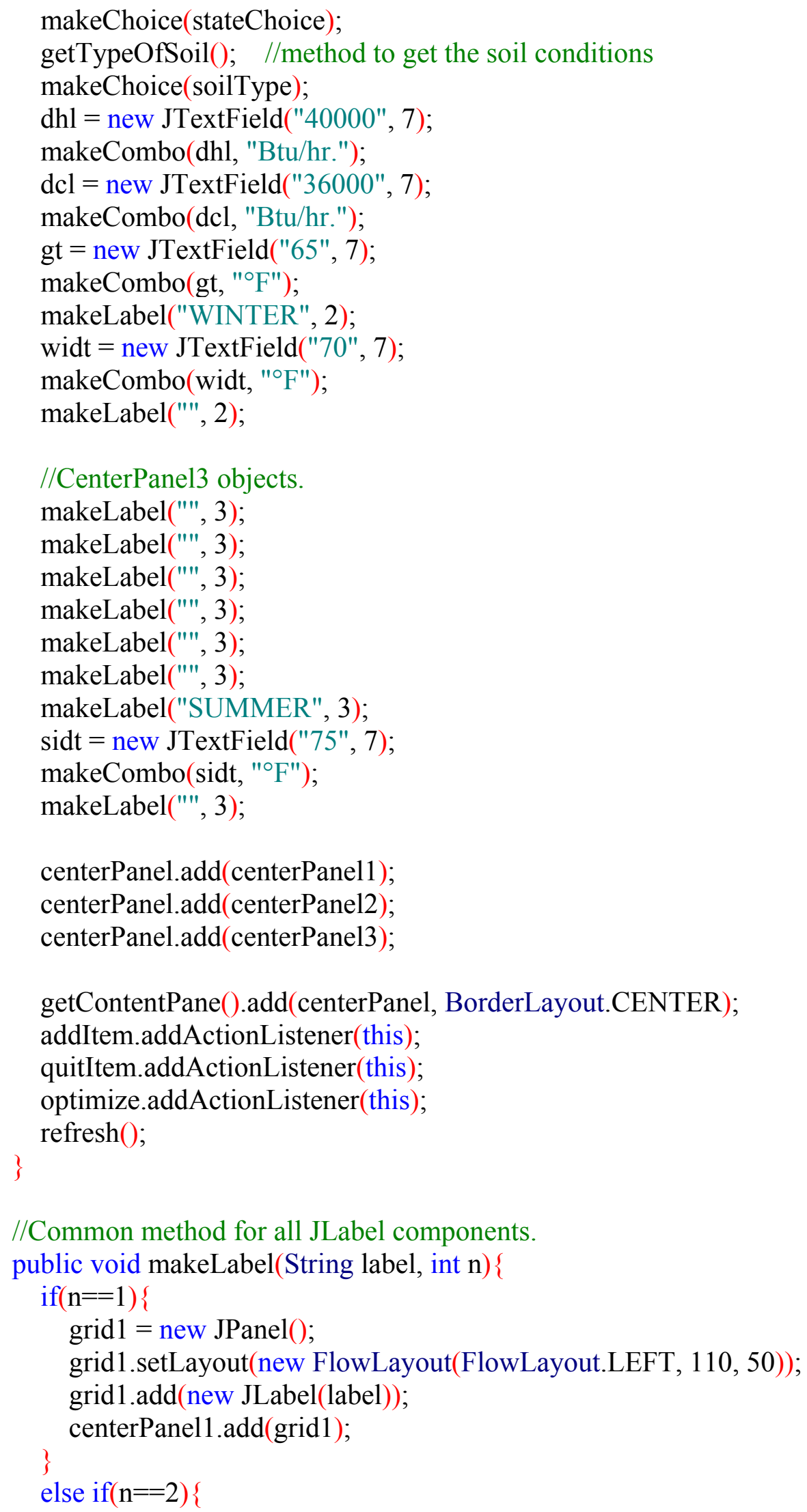




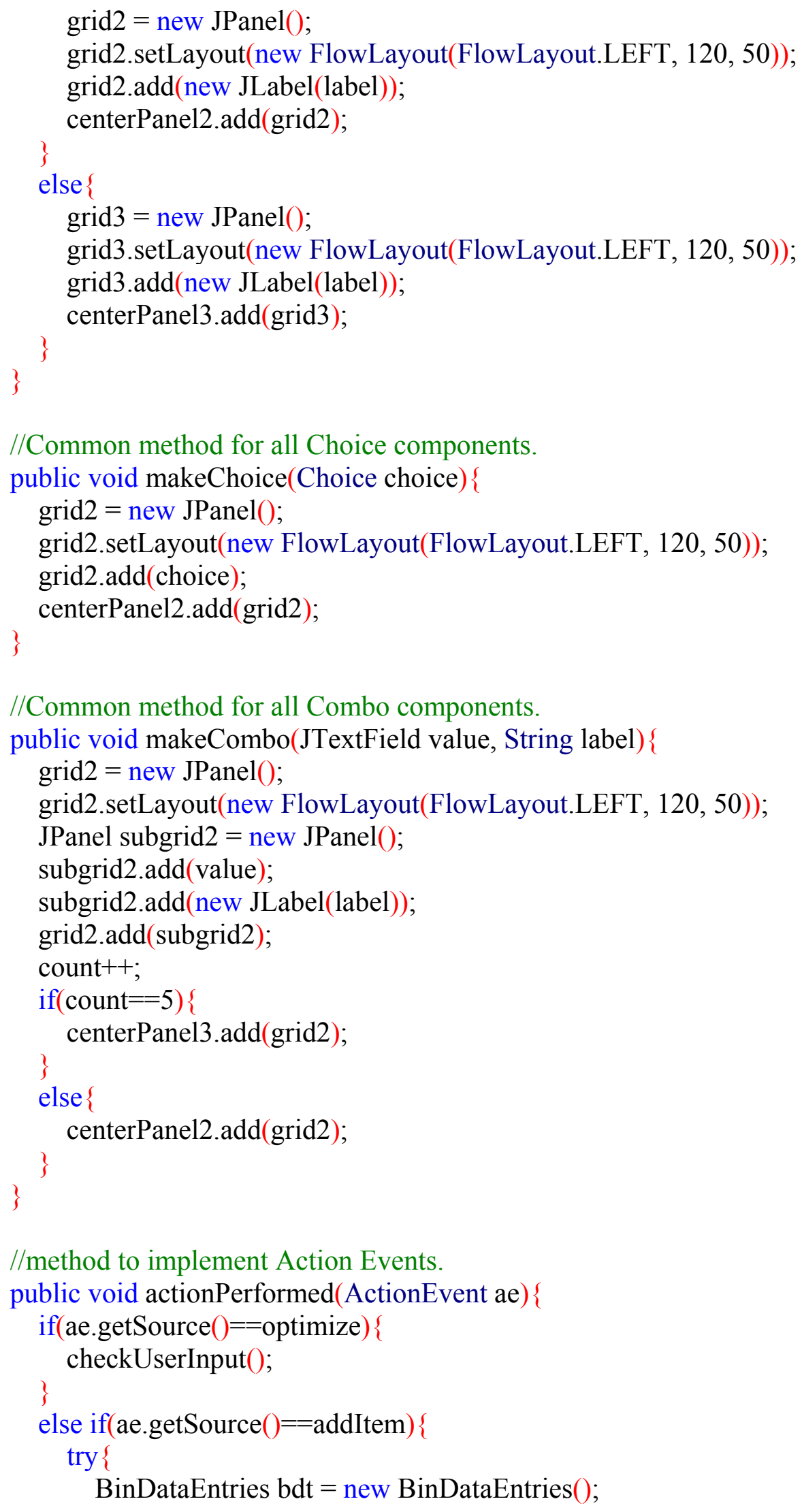




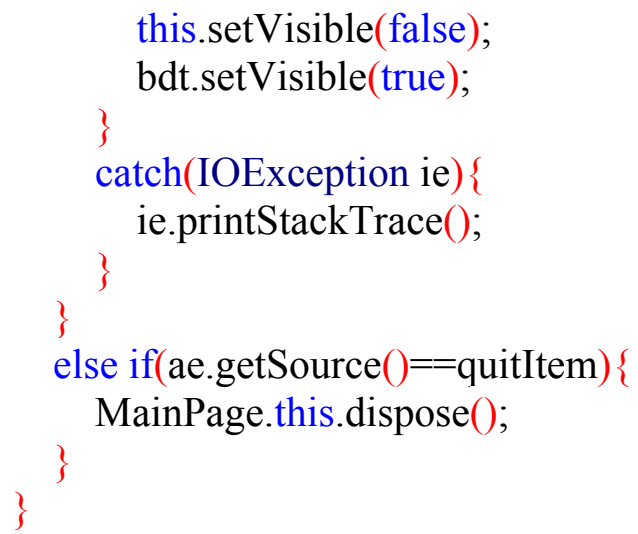

//method to repaint the GUI to display all items without any errors. public void refresh ()\{

$/ /$ method to get the textfield values and find the heat loss per degree fahrenheit public void checkUserInput() throws NumberFormatException \{

//Correct User Input until the user enters the right values.

if $(($ dhl.getText ()$)$.length ()$!=0.0 \& \&($ del.getText ()$)$.length ()$!=0.0 \& \&$ $($ gt.getText ()$)$. length ()$!=0.0 \& \&($ widt.getText ()$)$. length ()$!=0.0)\{$ try

if(Double.valueOf(dhl.getText()).doubleValue ()$<54000 \& \&$

Double.valueOf $(\operatorname{dcl}$.getText ()$)$.doubleValue ()$<54000)\{$

heatingLoad $=$ Double.valueOf(dhl.getText()).doubleValue(); coolingLoad $=$ Double.valueOf(dcl.getText()).doubleValue(); soil $=($ soilType.getSelectedItem ()$) \cdot \operatorname{trim}()$; groundTemp = Double.valueOf(gt.getText()).doubleValue(); winterInTemp = Double.valueOf(widt.getText()).doubleValue(); summerInTemp = Double.valueOf(sidt.getText()).doubleValue();

//calculation of heat loss $/{ }^{\circ} \mathrm{F}$ and retrieving the bin hours for a particular city. tmpCity $=($ cityNames.getSelectedItem ()$) \cdot \operatorname{trim}()$; tmpState $=$ stateChoice.getSelectedItem () ; //System.out.println("City Selected $=$ " + tmpCity.trim()); //System.out.println("State Selected $="+\operatorname{tmpState} \cdot \operatorname{trim}())$; tmpStr = (tmpCity.trim ()$+" @ "+\operatorname{tmpState} \cdot \operatorname{trim}())$;

//Check if the Hashtable contains the combination of city \& state. if(ht.containsKey $(\mathrm{tmpStr}))\{$ hv $=($ Vector $)$ ht.get $(\operatorname{tmpStr})$ $\mathrm{cv}=($ Vector $)$ ct.get $(\mathrm{tmpStr})$; ov $=($ Vector $)$ misc.get $($ tmpStr $)$; 
System.out.println("Heating Vector Elements = " + hv.size());

System.out.println("Cooling Vector Elements = " + cv.size());

sodt $=(($ Integer $)$ ov.elementAt $(0))$.intValue () ;

wodt $=(($ Integer $)$ ov.elementAt $(1)) \cdot$ intValue () ;

sunshine $=(($ Integer $)$ ov.elementAt $(2))$.intValue () ;

System.out.println("wodt = " + wodt);

System.out.println("sodt = " + sodt);

System.out.println("sunshine = " + sunshine);

double temp1 = (heatingLoad/(winterInTemp-(double) wodt $)$ );

if(MainPage.groundTemp $>44.0 \& \&$ MainPage.groundTemp $<62.0)\{$

summerSunshinePercent $=0.9$ - $(($ MainPage groundTemp-44 $) * 0.02)$;

\}

else if(MainPage.groundTemp $>62.0 \& \&$ MainPage.groundTemp $<80.0)\{$

summerSunshinePercent $=0.54+(($ MainPage .groundTemp-62 $) * 0.02)$; \}

else if(MainPage.groundTemp $=44.0 \|$ MainPage. groundTemp $==80.0)\{$

summerSunshinePercent $=0.9$;

\}

else \{

summerSunshinePercent $=0.54$;

\}

double temp $2=$

(coolingLoad*((double)sunshine)*summerSunshinePercent $) /\left(100.0^{*}\right.$

(sodt-summerInTemp));

heatLossPerDegree $=$ (int) temp1;

heatGainPerDegree $=$ (int) temp2;

System.out.println("MainPage Class Results :-----");

System.out.println("Heat Loss per degree $=$ "+heatLossPerDegree);

System.out.println("Heat Gain per degree = "+heatGainPerDegree);

//selects the appropriate heat pump system.

check $=$ sahps.check(heatingLoad, coolingLoad);

System.out.println("Check = "+ check);

for $($ int $\mathrm{i}=0 ; \mathrm{i}<\mathrm{hp} 1$.length $; \mathrm{i}++)$ \{

if(check.equals $(\mathrm{hp} 1[\mathrm{i}]))\{$

hpSystem = check;

hpCapacity $=\mathrm{hp} 2[\mathrm{i}]$;

wattage $=\mathrm{hp} 4[\mathrm{i}]$;

desupCapacity $=\mathrm{hp} 5[\mathrm{i}]$;

break;

\}

if(hpSystem.equals("2ton")) \{

this.setVisible(false);

$\mathrm{fc}=24000.0$;

operationalTime();

rf2ts = new ResultsFor2TonSystem(); 


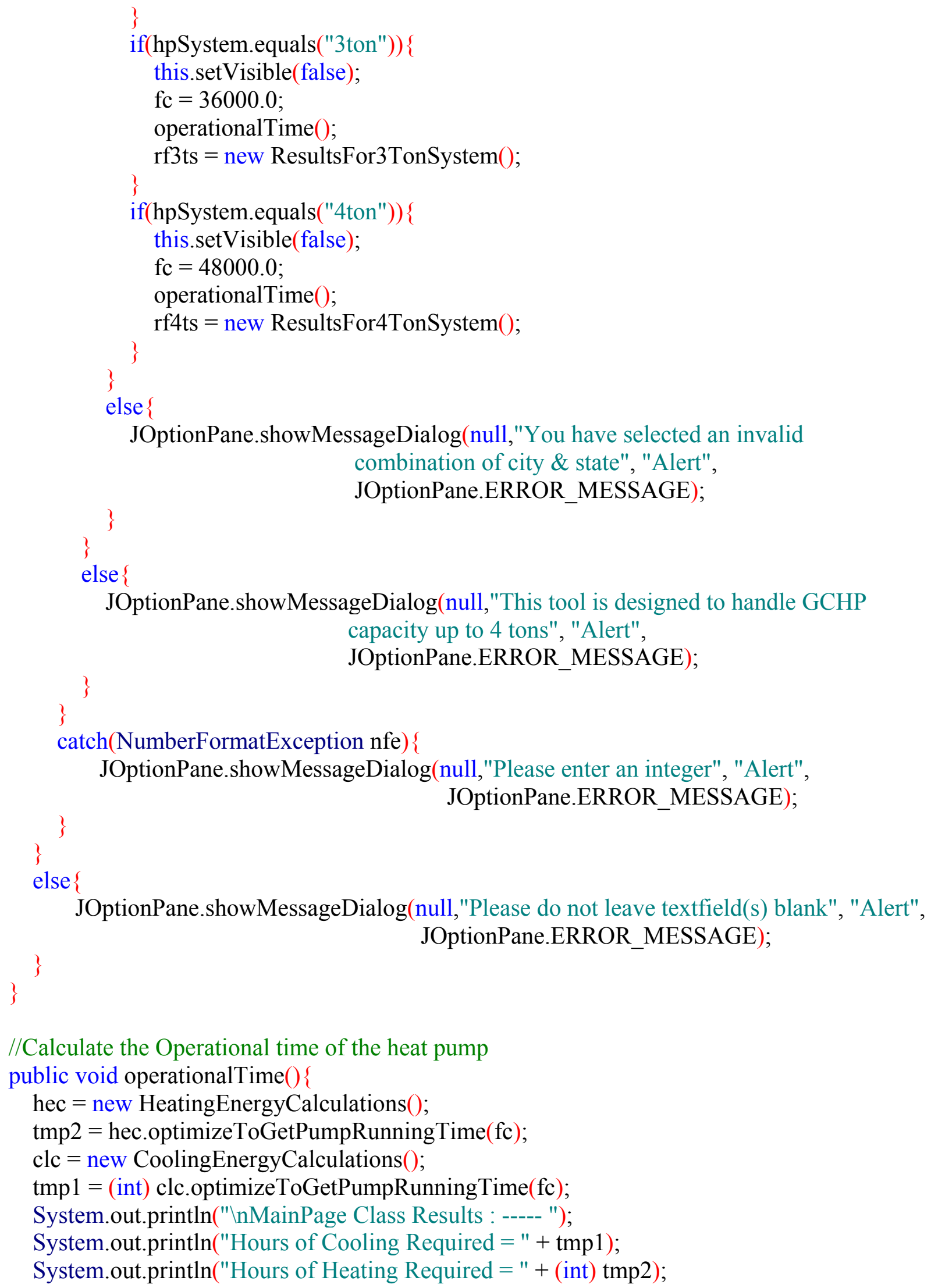

JOptionPane.showMessageDialog(null,"You have selected an invalid combination of city \& state", "Alert", JOptionPane.ERROR_MESSAGE);

JOptionPane.showMessageDialog(null,"This tool is designed to handle GCHP capacity up to 4 tons", "Alert", JOptionPane.ERROR_MESSAGE); 
operationalHeatingTime $=$ HeatingEnergyCalculations.oht; \} operationalCoolingTime $=$ CoolingEnergyCalculations.oct;

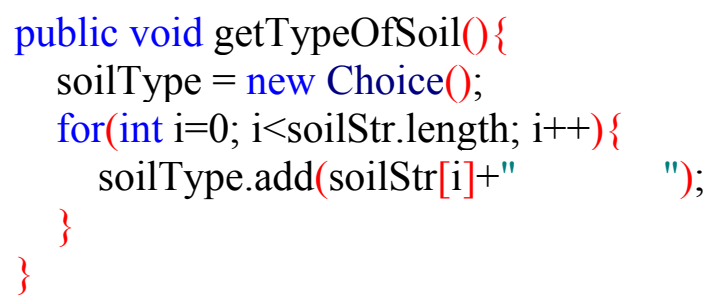

